\title{
Effects of emotion-oriented care in homes for the elderly
}

Citation for published version (APA):

Schrijnemaekers, V. J. J. (2002). Effects of emotion-oriented care in homes for the elderly. [Doctoral Thesis, Maastricht University]. Universiteit Maastricht. https://doi.org/10.26481/dis.20020531vs

Document status and date:

Published: 01/01/2002

DOI:

10.26481/dis.20020531vs

Document Version:

Publisher's PDF, also known as Version of record

\section{Please check the document version of this publication:}

- A submitted manuscript is the version of the article upon submission and before peer-review. There can be important differences between the submitted version and the official published version of record.

People interested in the research are advised to contact the author for the final version of the publication, or visit the DOI to the publisher's website.

- The final author version and the galley proof are versions of the publication after peer review.

- The final published version features the final layout of the paper including the volume, issue and page numbers.

Link to publication

\footnotetext{
General rights rights.

- You may freely distribute the URL identifying the publication in the public portal. please follow below link for the End User Agreement:

www.umlib.nl/taverne-license

Take down policy

If you believe that this document breaches copyright please contact us at:

repository@maastrichtuniversity.nl

providing details and we will investigate your claim.
}

Copyright and moral rights for the publications made accessible in the public portal are retained by the authors and/or other copyright owners and it is a condition of accessing publications that users recognise and abide by the legal requirements associated with these

- Users may download and print one copy of any publication from the public portal for the purpose of private study or research.

- You may not further distribute the material or use it for any profit-making activity or commercial gain

If the publication is distributed under the terms of Article $25 \mathrm{fa}$ of the Dutch Copyright Act, indicated by the "Taverne" license above, 
Effects of Emotion-oriented Care in Homes for the Elderly 
ISBN: 90-9015793-X

Lay-out: Cobie Martens, Epidemiologie, Universiteit Maastricht Cover: Guus van Rooy

Production: Datawyse | Universitaire Pers Maastricht

\section{(1) 2002, V.J.J. Schrijnemaekers}

All rights reserved. No part of this thesis may be reproduced or transmitted in any form or by any means, electronic or mechanical, including photocopying, recording or any information storage or retrieval system, without permission in writing from the author, or, when appropriate, from the publishers of the publications. 


\title{
Effects of Emotion-oriented Care in Homes for the Elderly
}

\author{
PROEFSCHRIFT \\ ter verkrijging van de graad van doctor aan \\ de Universiteit Maastricht. \\ op gezag van de Rector Magnificus, \\ Prof. dr. A.C. Nieuwenhuijzen Kruseman, \\ volgens het besluit van het College van Decanen, \\ in het openbaar te verdedigen \\ op vrijdag 31 mei 2002 om 14.00 uur \\ door
}

Veronica Josephina Johanna Schrijnemaekers 


\section{Promotores}

Prof. dr. ir. P.A. van den Brandt

Prof. dr. C.M.A. Frederiks (Katholieke Universiteit Nijmegen)

\section{Co-promotor}

Dr. E. van Rossum

\section{Beoordelingscommissie}

Prof. dr. H. Huyer Abu-Saad (voorzitter)

Prof. dr. J. van Eijck

Dr. A. Kerkstra (NIVEL)

Prof. dr. C. Spreeuwenberg

Prof. dr. G.A.M. Widdershoven

The main study of this thesis, the randomised controlled trial on the effectiveness of emotionoriented care, was funded by the National Centre for Nursing and Care (LCVV), the Province of Limburg and the VSB-fund. The additional qualitative study was funded by the Netherlands organisation for health, research and development.

The study presented in this thesis was performed at the department of Epidemiology of Maastricht University, the Netherlands. The department participates in the Netherlands School of Primary Care Research (CaRe), which is acknowledged by the Royal Netherlands Academy of Art and Scienes (KNAW). 


\section{CONTENTS}

$\begin{array}{llr}1 & \text { Introduction } & 7\end{array}$

2 The effectiveness of validation: a review of the literature 15

3 Design of a study to test the effects of emotion-oriented care 29

4 Effects of emotion-oriented care on elderly people with cognitive impairment and behavioral problems

5 Effects of emotion-oriented care on work-related outcomes in professional caregivers in homes for the elderly

6 Compliance in a randomized contolled trial:

the implementation of emotion-oriented care in psycho-geriatric care

7 Discussion

Summary

Samenvatting

Appendices

1 Vragenlijst bewoner

2 Vragenlijst verzorgende

Dankwoord 
Introduction 


\section{BACKGROUND}

Dementia is one of the most important causes of disability in the elderly. With the ageing of the population, its prevalence increases exponentially in the most advanced ages (Ott et al.. 1995). In the Netherlands, for example, prevalence rates range from $2.1 \%$ in the 70 to 74 age group to $32 \%$ in the 85 to 90 age group (Ott et al., 1995). The overall European prevalences are more or less the same (Hofman et al., 1991; Lobo et al., 2000).

The diagnostic criteria for dementia are cognitive impairment (including memory impairment) and at least one of the following: aphasia, apraxia, agnosia or a disturbance in executive functioning (e.g. plan, initiate, sequence of activities). In addition, the cognitive deficits must be sufficiently severe to cause impairment in occupational or social functioning and must represent a decline from a previous level of functioning (American Psychiatric Association, 1995).

Many elderly persons with dementia display behavioral disturbances like (verbal) aggression, restlessness or nonsocial behavior. It is estimated that as many as 50 to $90 \%$ of these elderly have behavioral problems during the course of their illness (Allen Burge et al., 1999; Davis et al., 1997; Lyketsos et al., 2000; Swearer et al., 1988; Teri et al., 1989; Teri et al., 1988; Teri et al., 1992). Because cognitive impairment and especially the accompanying behavioral problems critically impact on the patient and also cause distress, concern and frustration for their caregivers (Burgio et al., 1988; Everitt et al., 1991; Teri, 1997), they deserve special attention in psycho-geriatric care.

\section{TREATMENT OPTIONS}

As little is known about the etiology and ways to treat dementia, no effective prevention and cure is yet available (Boller and Forbes, 1998; Frederiks, 2001; Gezondheidsraad, 2002; Selkoe, 2001). Consequently, treatment often addresses symptom management. Main options for symptom management are pharmacological and non-pharmacological treatment approaches.

\section{Pharmacological}

There are no real effective pharmaceutical treatments available for the behavioral disturbances in dementia patients (Gezondheidsraad, 2002). Studies on pharmacological treatments in these patients show that only a small proportion is responsive to neuroleptics (e.g. antipsychotics and antidepressants) and that they induce many side-effects like falls, sedation and incontinence (Risse and Barnes, 1986; Schneider et al., 1990; Sultzer et al., 1997; Yeager et al., 1995). Lanctot et al.'s review on the efficacy and safety of neuroleptics in behavioral disorders associated with dementia (16 randomized controlled trials (RCTs)) demonstrated that the therapeutic effect (neuroleptics minus placebo) was small but significant. However, they also concluded that the efficacy rate for neuroleptics was equivalent to their side effect rate (Lanctot et al., 1998). Teri et al. recently concluded that effects of often used medications to manage agitation (haloperidol and trazodone) did not differ from placebo treatment (Teri et al., 2000).

The foregoing makes the development and evaluation of effective care interventions and approaches for lay and professional caregivers a major health care concern. 


\section{Non-pharmacological}

Over the last few decades several care approaches or therapies have been developed in the care for psycho-geriatric patients. The American Psychiatric Association (APA) developed practice guidelines for the treatment of patients with dementia and distinguished four types of psychosocial treatments: behavior-oriented (behavior therapy), stimulation-oriented (e.g. games, music), emotion-oriented (e.g. validation, reminiscence) and cognition-oriented (e.g. reality orientation) treatments, in addition to psychiatric management and pharmacological options (American Psychiatric Association, 1997).

The APA as well as Finnema and colleagues conducted a review on various nonpharmacological interventions in dementia (American Psychiatric Association, 1997; Finnema et al., 2000). The overall conclusions of these and other reviews was that there was insufficient scientific evidence yet for the treatments studied and that there is a clear need for well-designed RCTs.

\section{Validation}

One frequently used psychosocial approach in dementia care is 'validation' (Feil, 1967, 1984, 1985, 1989, 1990, 1992; Feil and Wetzler, 1979). Validation is an experience based approach, developed by Feil in day-to-day practice with demented elderly. She describes it as a process of communicating, both verbally and nonverbally, with disoriented elderly people by validating and respecting their feelings. Validation addresses the patient's need to maintain contact with the environment by confirming the patient's internal emotional state, rather than forcing an external environmental orientation. To validate means to accept the disoriented elderly persons as they are; to be non-judgmental, to share feelings that are freely expressed. Validation does not force disoriented elderly people into 'our reality'; instead the elderly person's perception of the environment is validated. The techniques used depend on the stage of disorientation and include, among other things, empathy, touch, eye contact, 'total listening' and mirroring body movements. Validation can be used in individual care or in a group setting.

According to Feil, empathy builds trust and trust brings safety. Safety brings strength and this renews feelings of worth resulting in reduced stress. In her opinion, validation stimulates communication with the demented elderly, restores well-being, increases positive affect (laughing, talking) and decreases negative affect (crying, hitting). Work-related factors like reduced burnout and frustration, and improved job satisfaction are positive effects mentioned for the caregivers involved (Feil, 1994).

Some authors state that the theoretical framework of validation is weak and unclear (Allewijn and Janssen, 1990; Kitwood, 1992; Verdult and Visser, 1990), others recognize parts of existing theories and therapies such as Maslow's 'Universal human needs hierarchy. Erikson's 'Developmental stage theory', Rogers 'Cliented Centered therapy' and psychodynamic coping strategies (Day, 1997; Deutzmanek, 1992; Dröes et al., 1999; Nooren-Staal et al., 1995).

Since 1963, validation has been used in thousands of institutions in the United States, Canada, Australia and Europe (Feil, 1994). Many articles about the content and use of validation have been published. In the Netherlands especially Van der Kooy wrote various articles about validation (van der Kooij, 1988, 1989, 1991a, 1991b). A survey on care approaches used in Dutch nursing homes showed that validation is used in many $(85 \%)$ nursing homes and that almost every $(97 \%)$ caregiver reports positive effects, mainly based on experience (Kruyver and Kerkstra, 1996). So, validation is a popular approach among professional caregivers who have a great belief in its effectiveness. 


\section{AVAILABLE EVIDENCE}

Given future demographic developments and the popularity of validation, we were interested in the scientific evidence regarding the usefulness of validation. Therefore a review of the literature on the effectiveness of validation was conducted (Schrijnemaekers et al., 1995; Schrijnemaekers et al., submitted). The latter updated review included sixteen studies of which seven were unpublished. It appeared that the methodological quality was limited and that there is as yet hardly any scientific evidence available to support the hypothesis that validation has positive effects on disoriented elderly and their caregivers. Therefore we decided to conduct a new study on the effectiveness of validation.

While preparing our study, it appeared that a somewhat broader approach was being increasingly introduced in the Netherlands, so-called emotion-oriented care ('belevingsgerichte zorg') (Bosscher and Goedhart, 1996; van der Kooij, 1996a, 1996b; Verdult, 1994). This approach uses validation in combination with other approaches such as sensory-stimulation and reminiscence. To link up with these developments in Dutch health care, it was then decided to evaluate the effectiveness of emotion-oriented care instead of validation. We decided to investigate the effects of emotion-oriented care on elderly people with moderate to severe cognitive impairment and behavioral problems and their professional caregivers in homes for the elderly.

\section{OUTLINE OF THE THESIS}

This thesis reports on the design, conduct and outcomes of the study into the effects of emotion-oriented care.

Chapter 2 reports the review of the literature on the effectiveness of validation. On the basis of this review it was concluded that new studies were needed to render additional evidence, before it is adopted and (widely) implemented.

Chapter 3 presents the design of our randomized controlled trial, evaluating the effects of emotion-oriented care on residents and professional caregivers in homes for the elderly. We describe the design of this study in detail, because it offers the possibility of a critical assessment of the methods regardless of the results of the study. The intervention conducted in the study is also described in this chapter.

Chapter 4 and 5 present the results of the trial. Chapter 4 addresses the effects of emotionoriented care on the behavior of the residents and chapter 5 reports the effects on professional caregivers in terms of their job satisfaction and other work-related factors.

Chapter 6 describes the results of an additional qualitative study. This study was conducted to obtain more insight into the implementation process of emotion-oriented care in the participating homes for the elderly.

Finally, in chapter 7 the results of our RCT are discussed. Besides a summary of the main findings, some methodological reflections are made. The results of our study are also compared with those of previous trials in this field, and recommendations for future research and practice are made. 


\section{REFERENCES}

Allen Burge, R, Stevens, AB, \& Burgio, LD. (1999). Effective behavioral interventions for decreasing dementia-related challenging behavior in nursing homes. Int. J. Geriatr. Psychiatry, 14(3), 213228.

Allewijn, M, \& Janssen, H. (1990). Validation...het nieuwe geloof? Denkbeeld. Tijdschrift voor psychogeriatrie, (Maart), 4-6.

American Psychiatric Association. (1995). Beknopte handleiding bij de diagnostische criteria van de DSM-IV (GASK van Groos, Trans.). Lisse: Swets \& Zeitlinger publishers.

American Psychiatric Association. (1997). Practice guideline for the treatment of patients with Alzheimer's disease and other dementias of late life. Am. J. Psychiatry, 154(5 Suppl), 1-39.

Boller, F, \& Forbes, MM. (1998). History of dementia and dementia in history: An overview. Journal of Neurological Sciences, 158, 125-133.

Bosscher, A, \& Goedhart, W. (1996). Belevingsgerichte hulpverlening. De beleving staat centraal, niet het gedragsprobleem. Denkbeeld. Tijdschrift voor psychogeriatrie, (Februari), 28-30.

Burgio, LD, Butler, F, \& Engel, BT. (1988). Nurses' attitudes towards geriatric behavior problems in long-term care settings. Clinical Gerontologist, 7(3-4), 23-34.

Davis, LL, Buckwalter, K, \& Burgio, LD. (1997). Measuring problem behaviors in dementia: Developing a methodological agenda. Advances in Nursing Science, 20(1), 40-55.

Day, CR. (1997). Validation therapy. A review of the literature. J. Gerontol. Nurs., 23(4), 29-34.

Deutzmanek, JC. (1992). Validation binnen de psychogeriatrie, een onderzoek naar de mogelijkheden en beperkingen. Nijmegen: Katholieke Universiteit Nijmegen.

Dröes, RM, Finnema, EJ, de Lange, J, van de Kooy, CH, Smit, F, Ettema, TP, Persoon, A, Pronk, M, Meertens, R, Ooms, ME, Smaling. A, Rigter, H, \& van Tilburg, W. (1999). Geïntegreerde belevingsgerichte zorg versus gangbare zorg voor dementerende ouderen in het verpleeghuis. Een klinisch experimenteel onderzoek naar de effecten en kosten. Amsterdam: Free Univerisity Amsterdam, department of Psychiatry.

Everitt, DE, Fields, DR, Soumerai, SS, \& Avorn, J. (1991). Resident behavior and staff distress in the nursing home. J. Am. Geriatr. Soc., 39(8), 792-798.

Feil, N. (1967). Group therapy in a home for the aged. Gerontologist, 7(3), 192-195.

Feil, N. (1984). Communicating with the confused elderly patient. Geriatrics, 39(3), 131-132.

Feil, N. (1985). Resolution: The final life task. Journal of Humanistic Psychology, 25(2), 91-105.

Feil, N. (1989). Validation: An empathic approach to the care of dementia. Clinical Gerontologist, $8(3)$. 89-94.

Feil, N. (1990). Validation therapy helps staff reach confused residents. Provider, (December), 33-34.

Feil, N. (1992). Validation therapy. Geriatric Nursing, 13(3), 129-133.

Feil, N. (1994). De validation methode in de praktijk. (Translation of: The validation breakthrough: simple techniques for communicating with people with Alzheimer's-type dementia) (I van Pinksteren, Trans.). Utrecht: Lemma b.v.

Feil, N. \& Wetzler, M. (1979). An innovative method of working with the severely disoriented aged. American Health Care Association Journal, (March), 41-44.

Finnema, E. Drobes, RM, Ribbe, M, \& Tilburg. WV. (2000). The effects of emotion-oriented approaches in the care for persons suffering from dementia: A review of the literature. Int. J. Geriatr. Psychiatry, 15(2), 141-161.

Frederiks JAM. (2001). Een eeuw dementie. Tijdschr. Gerontol. Geriatr., 32, 3-5.

Gezondheidsraad. (2002). Dementie. Den Haag: Gezondheidsraad.

Hofman, A, Rocca, WA, Brayne, C, Breteler, MM, Clarke, M, Cooper, B, Copeland, JR, Dartigues, JF, da Silva Droux, A, Hagnell, O, Heeren, TJ, Engedal, K, Jonker, C, Lindesay, J, Lobo, A, Mann, AH, Molsa, PK, Morgan, K, O'Connor, DW, Sulkava, R, Kay, DWK, \& Amaducci, L. (1991). The prevalence of dementia in Europe: a collaborative study of 1980-1990 findings. Eurodem Prevalence Research Group. Int. J. Epidemiol., 20(3), 736-748.

Kitwood, T. (1992). How valid is validation therapy. Geriatric Medicine, (April), 23.

Kruyver, I, \& Kerkstra, A. (1996). Begeleidingsmethodieken voor psychogeriatrische verpleeghuisbewoners: een overzicht. Utrecht: NIVEL.

Lanctot, KL, Best, TS, Mittmann, N, Liu, BA, Oh, PI, Einarson, TR, \& Naranjo, CA. (1998). Efficacy and safety of neuroleptics in behavioral disorders associated with dementia. J. Clin. Psychiatry. 59(10), 550-561. 
Lobo, A, Launer, LJ, Fratiglioni, L, Andersen, K, Di Carlo, A, Breteler, MM, Copeland, JR, Dartigues. JF, Jagger, C, Martinez Lage, J, Soininen, H, \& Hofman, A. (2000). Prevalence of dementia and major subtypes in Europe: A collaborative study of population-based cohorts. Neurologic Diseases in the Elderly Research Group. Neurology. 54(11 Suppl 5), S4-9.

Lyketsos, CG, Steinberg, M, Tschanz, JT, Norton, MC, Steffens, DC, \& Breitner, JC. (2000). Mental and behavioral disturbances in dementia: findings from the Cache County Study on Memory in Aging. Am. J. Psychiatry, 157(5), 708-714.

Nooren-Staal, WHC. Frederiks, CMA, \& te Wierik, MJM. (1995). Validation; effecten bij bewoners en personeel in een verzorgingshuis. Tijdschr. Gerontol. Geriatr., 26(3), 117-121.

Ott, A, Breteler, MM, van Harskamp, F, Claus, JJ, van der Cammen, TJ, Grobbee, DE, \& Hofman, A. (1995). Prevalence of Alzheimer's disease and vascular dementia: association with education. The Rotterdam study [see comments]. Br. Med. J., 310(6985), 970-973.

Risse, SC, \& Barnes, R. (1986). Pharmacologic treatment of agitation associated with dementia. J. Am. Geriatr. Soc., 34(5), 368-376.

Schneider, LS, Pollock, VE, \& Lyness, SA. (1990). A metaanalysis of controlled trials of neuroleptic treatment in dementia. J. Am. Geriatr. Soc., 38(5), 553-563.

Schrijnemaekers, VJ, Duijnhouwer, E, te Wierik, MJ, \& Frederiks, CM. (1995). De effectiviteit van validation. Een literatuuronderzoek. Tijdschr. Gerontol. Geriat., 26(5), 205-213.

Schrijnemaekers, VJJ, van Rossum, E, te Wierik, MJM, Frederiks, CMA, \& Kessels, AGH. (submitted). The effectiveness of validation: a review of the literature.

Selkoe, DJ. (2001). Alzheimer's Disease: Genes, Proteins, and Therapy. Physiol. Rev., 81(2), 741 766.

Sultzer, DL, Gray, KF, Gunay, I, Berisford, A, \& Mahler, ME. (1997). A double-blind comparison of trazodone and haloperidol for treatment of agitation in patients with dementia. Am. J. Geriatr. Psychiatry, 5(1), 60-69.

Swearer, JM, Drachman, DA, O'Donnell, BF, \& Mitchell, AL. (1988). Troublesome and disruptive behaviors in dementia. Relationships to diagnosis and disease severity. J. Am. Geriatr. Soc., 36(9), 784-790.

Teri, L. (1997). Behavior and caregiver burden: behavioral problems in patients with Alzheimer disease and its association with caregiver distress. Alzheimer Dis. Assoc. Disord., 11(8), 4s35-38

Teri, L, Borson, S, Kiyak, HA, \& Yamagishi, M. (1989). Behavioral disturbance, cognitive dysfunction, and functional skill. Prevalence and relationship in Alzheimer's disease. J. Am. Geriatr. Soc., 37(2), 109-116.

Teri, L, Larson, EB, \& Reifler, BV. (1988). Behavioral disturbance in dementia of the Alzheimer's type. J. Am. Geriatr. Soc., 36(1), 1-6.

Teri, L, Logsdon, RG, Peskind, E, Raskind, M, Weiner, MF, Tractenberg, RE, Foster, NL, Schneider, LS, Sano, M, Whitehouse, P. Tariot, P, Mellow, AM, Auchus, AP, Grundman, M, Thomas, RG, Schafer, K, \& Thal, LJ. (2000). Treatment of agitation in AD: a randomized, placebo-controlled clinical trial. Neurology. 55(9), 1271-1278.

Teri, L, Rabins, P. Whitehouse, P, Berg, L, Reisberg, B, Sunderland, T, Eichelman, B, \& Phelps, C. (1992). Management of behavior disturbance in Alzheimer disease: current knowledge and future directions. Alzheimer Dis. Assoc. Disord., 6(2), 77-88.

van der Kooij, C. (1988). Zijn waar de patient is. Validation therapy. Senior, (14), 298-302.

van der Kooij. C. (1989). Validation therapy. Doorbraak in de psychogeriatrische zorg? Denkbeeld. Tijdschrift voor psychogeriatrie, (Augustus), 12-16.

van der Kooij, C. (1991a). Validation: de veranderende kracht van een praktijktheorie. Tvz, 23(10). 339-343.

van der Kooij. C. (1991b). Validation in Nederland. Denkbeeld. Tijdschrift voor psychogeriatrie, (Februari), 15-17

van der Kooij, C. (1996a). Alles gebruiken wat je in huis hebt. TVV, 7/8(Juli), 25-30.

van der Kooij. C. (1996b). Op zoek naar gelijkwaardigheid. TVV, 6(Juni), 14-17

Verdult, R. (1994). Dement worden: omkering van de levensloop. MGZ, 22(Juni), 10-13.

Verdult, R, \& Visser, R. (1990). Ervaringen met validation. Tvz, 26(15), 474-478.

Yeager, BF, Farnett, LE, \& Ruzicka, SA. (1995). Management of the behavioral manifestations of dementia. Arch. Intern. Med., 155(3), 250-260. 


\section{The effectiveness of validation: a review of the literature}

Veron JJ Schrijnemaekers'

Erik van Rossum

Margreet JM te Wierik ${ }^{2}$

Carla MA Frederiks ${ }^{3}$

Alfons GH Kessels ${ }^{4}$

'Department of Epidemiology, Maastricht University

${ }^{2}$ Faculty of Health Sciences. Maastricht University

${ }^{3}$ Department of General Practice and Social Medicine, University of Nijmegen

${ }^{4}$ Research unit patient care, University Hospital Maastricht 


\section{ABSTRACT}

This literature review reports on the effectiveness of validation, an approach used in the care for disoriented elderly people. Various (computerized) data-sets and sources were used to search for relevant studies.

This resulted in 16 studies of which seven were unpublished. The sixteen studies used various designs: only three studies are randomized controlled trials (RCTs). Nearly all studies suffer from serious methodological shortcomings and the results are conflicting. It appears that the better the study, the less favorable the effectiveness of validation is.

In view of the conflicting results and the poor methodological quality of the majority of the studies, we conclude that there is insufficient evidence yet for the effectiveness of validation on disoriented elderly and their caregivers. Additional research using more rigorous methods is needed. 


\section{INTRODUCTION}

The number of elderly people will grow considerably during the next few decades. This demographic development will have consequences for health care facilities such as nursing homes and homes for the aged. These facilities will be faced, for instance, with increasing numbers of behaviorally and cognitively impaired elderly. Several approaches or therapies have been developed in the care for such elderly people. One promising approach to care management of disoriented elderly and to the management of problem behaviors is validation.

Validation has been developed by Feil who described it as a process of communicating, both verbally and nonverbally, with disoriented elderly people by validating and respecting their feelings (Feil, 1994). Validation, or validation therapy, is used in moderately to severely disoriented elderly people. To validate means to accept the disoriented old person as he or she is, to be non-judgmental, to share feelings that are freely expressed. Validation does not force disoriented elderly people in 'our reality'; instead the elderly person's perception of the environment is validated. The techniques used depend on the stage of disorientation and include, among others, empathy, touch, eye contact, 'total listening' and mirroring body movements. Validation can be used in individual care or in a group setting. According to Feil, validation stimulates communication with the demented elderly, restores well-being. increases positive affect and decreases negative affect. Reduced burnout and frustration. and improved satisfaction are presumed positive effects for the caregivers involved.

In 1982 Feil founded the Validation Training Institute in Ohio and ever since many workshops have been given in the United States and Canada. Over the past twenty years Feil has published many articles about the rationale and practical use of validation (Feil, 1984, 1985. 1990, 1991, 1992, 1994; Feil and Wetzler, 1979). According to Feil, validation is practiced in over 7,000 institutions in the United States, Canada, Europe and Australia, where thousands of elderly people and their caregivers receive the benefits (Feil, 1994). Validation has received a great deal of attention from practitioners.

In view of the future demographic developments and the popularity (and possibilities) of validation, we were interested in the scientific evidence regarding the usefulness of validation. We therefore conducted a review of the literature on the effectiveness of validation. This article reports about the methods and results of this review.

\section{METHODS}

\section{Search strategy}

An elaborate literature search was conducted to select relevant studies. We started in computerized data-sets like MEDLINE (among others Index Medicus, International Nursing Index, 1966-present), EMBASE (Excerpta Medica, 1984-present) and PSYCHLIT (1974present). Searches were performed with keywords, and combinations of them, such as validation, aged, cognition, cognitive therapy, geriatric assessment, geriatric nursing, geriatric psychiatry, (mental-)confusion, psychotherapy(-technique), empathy, dementia and names of authors (Feil, Babins, Peoples, Bleathman, Ducharme, Morton). We also searched in the Science Citation Index (computerized) and the Social Science Citation Index (printed). In these indices articles were sought with a reference to Feil. We used the computerized library system of Maastricht University to search for relevant books and theses. Furthermore, we went through all the references of relevant studies and we tried, by means of personal 
communication, to obtain information on unpublished but often cited studies. Feil sent us reports of six such studies.

\section{Review strategy}

Different approaches can be used to review the literature on the effectiveness of an intervention. Two main strategies are the narrative review and the systematic review.

A narrative review is often conducted by a (field) expert or authority who gives an 'overall' conclusion on a topic by discussing studies he or she is familiar with. A major disadvantage of this approach is that often the considerations and decisions on which the conclusions are based are not made explicit to the reader.

The main characteristic of a systematic review is that all steps of the search and review strategy are made explicit to the reader. The systematic review can be subdivided in a quantitative meta-analysis and a criteria-based blinded review. The latter is also referred to as a qualitative meta-analysis. The quantitative approach stresses the principle of statistical pooling of the outcomes of individual studies in order to obtain an overall estimation of the size of the intervention effect. The criteria-based blinded review emphasizes the need for critical and structured assessment of the methodological quality of each of the studies eligible for reviewing. The aim of this assessment is to give a final conclusion about the effectiveness on the basis of qualitative good studies.

We decided to conduct neither a narrative nor a systematic review but to use elements from both approaches. Given the heterogeneity in the designs and other aspects of the studies that we found (e.g. type of intervention, outcome measures, follow-up period), it was not possible to conduct a thorough systematic review. The best alternative in this case is to conduct a narrative review in which the decisions on which the final conclusions are based are made explicit to the reader.

Two of us critically reviewed all studies on the following relevant characteristics: design, study population (e.g. setting, age, sample size), interventions studied (e.g. full 24 hours per day implementation, group sessions), follow-up period, outcome measures and results.

As the study design is a key characteristic in assessing the validity of study outcomes, we will briefly discuss this characteristic.

Different experimental and quasi-experimental designs can be used to study the effectiveness of an experimental condition or intervention. There are four commonly used designs: (1) a randomized controlled trial (RCT); a quasi-experimental pretest-posttest design (2) with or (3) without control group; and (4) a one-group posttest-only design.

The RCT is the study design with the strongest empirical evidence mainly because of the random assignment of participants to the study groups. Random allocation is used to obtain prognostically comparable study groups at the start of the study. If the study groups are indeed comparable at the start, differences between the groups at the end of the study may be attributed to the experimental condition.

A quasi-experimental design with a control group differs from the RCT in the lack of a randomization procedure. This may lead to selection bias when, for example, the investigator or caregiver decides which person will be assigned to either the intervention or control group. As a consequence, inequality in important prognostic factors can easily arise between the study groups.

The third design (pretest-posttest without control group) has no control group at all. This hampers the interpretation of results as one cannot know what would have happened in the study population if there had been no intervention (information on the natural course is lacking). 
The one-group posttest-only design has major methodological shortcomings. Besides the problems mentioned above, the absence of a pretest causes an additional problem. When no pretest is available, no conclusions can be drawn about possible changes caused by the intervention.

\section{RESULTS}

The literature search resulted in sixteen studies. The main characteristics and results of the studies are presented in table 1. Because only a few studies evaluated the effects of validation on the caregivers, these results are omitted from table 1 but discussed at the end of this section.

Table 1 shows that seven of the sixteen studies are unpublished. The sixteen studies were conducted in different parts of the world: four in Europe, two in Australia and ten in North America (US and Canada). The study populations were selected from the following settings: nursing home (9), hospital (4), 'institutionalized elderly' (2), and home for the elderly (1). In all studies, except one (Toseland et al., 1997) the numbers of elderly people in the intervention and control groups were rather small $(\leq 20)$.

Various forms of validation therapy were studied. The majority of the studies (9) evaluated group sessions of validation. These studies show, however, a large variety in frequency of sessions and duration of therapy. The remaining seven studies focused on training of caregivers in validation and/or the implementation of validation therapy in the care setting.

The studies also differ widely regarding the time intervals between baseline and follow-up measurements (ranging from ten days to twelve months), as well as the outcome measures that were chosen. Appendix 1 presents an overview of these outcome measures and their operationalization.

None of the studies reported whether the validation approach had possibly already been used in the control group at the start of the study. Often it is also unclear to what extent the validation approach was actually used or implemented during the study in the intervention groups.

The studies are classified in table 1 according to the designs described in the methods section. In view of the stated limitations regarding the interpretation of results from studies without control groups and/or without pretest measurements (ten of the sixteen studies), only the three RCTs (Peoples, 1982; Robb et al., 1986; Toseland et al., 1997) and three quasiexperiments with a control group (Babins et al., 1988; Scanland and Emershaw, 1993; Sharp, 1989) will be discussed here.

\section{Evidence from RCTs $(n=3)$}

In North America three randomized controlled studies were performed to study the effectiveness of group sessions validation in moderately to severely disoriented nursing home residents (Peoples, 1982; Robb et al., 1986; Toseland et al., 1997).

The unpublished study by Peoples had follow-up measurements after six weeks in three groups: a validation group $(n=10)$, a reality orientation therapy (ROT) group $(n=10)$ and a control group $(n=11)$ (Peoples, 1982). The validation and ROT groups met for thirty minutes five times a week for six weeks. The author reports that the randomization procedure was 


\section{Chapter 2}

Table 1. Overview of (quasi-)experimental studies on the effectiveness of validation in the elderly by design

Author(s), year $\quad$ Study population
Country

\section{Randomized controlled trial}

$\begin{array}{lll}\text { Peoples, } 1982^{\circ} & \text { moderate/severe confused nursing } & \text { ROT: } 10 \\ \text { USA } & \text { home residents, age 80+ } & -2 \text { drop-outs } \\ & & \text { V: } 10\end{array}$

Robb et al.. 1986

Canada

Toseland et al., 1997

USA

$$
\begin{array}{ll}
\text { moderate/severe disoniented male } & 20.5 \text { drop-outs } \\
\text { nursing home residents, age } 60+ & -6 \text { non-compliers } \\
& \\
\text { moderate/severe demented nursing } & \mathrm{V}: 31 \\
\text { home residents, mean age } 88 & -8 \text { drop-outs }
\end{array}
$$

$30 \mathrm{~min}, 5 \times / \mathrm{wk}, 6$ wks group sessions $V$ and ROT

2x/wk, 9 months group sessions $V$

$30 \mathrm{~min}, 4 \times 1 \mathrm{wk}, 52 \mathrm{wks}$ 28 -6 drop-outs group sessions $V$ and SC

$2 x / w k, 11$ wks group sessions $\mathrm{V}$

$30 \mathrm{~min}, 5 \mathrm{x} / \mathrm{wk}, 4$ months group sessions $V$ and ROT

training $V$ staff ( 3 months) and implementation

implementation V

Alprin, $1980^{\circ}$

USA

Deutszmanek, $1992^{\circ}$

demented women in a psychiatric

Netherlands

Ducharme et al., 1994

Canada

moderate/severe demented women 4 in a nursing home, age $70+$

Feil, $1972^{\circ}$

USA

Fine \& Rouse-Bane, 1995 cognitively impaired older nursing USA home residents

deteriorated, senile, psychotic. institutionalized elderly, age 74-92

12

13 at pretest and 22 at posttest training $V$ nurses and implementation

$15-20 \mathrm{~min}, 7 \mathrm{x} / \mathrm{wk}, 2$ wks individual sessions $V$ : $20-30$ min, 6 wks, 23 group sessions $\mathrm{V}$

25 min, $4 x /$ wk, 6 months group sessions $\mathrm{V}$

training $V$ staff and implementation 
6 weeks

9 months

3 and 12 months

\subsection{2 weeks}

4 months

3 months

\section{5,10 and 15 weeks}

during 23 group sessions and after 8 wks

\section{social interaction:} individual goals:

$\begin{array}{ll}6 \text { months } & \begin{array}{l}\text { affect } \\ \text { interaction: }\end{array} \\ & \begin{array}{l}\text { problem behavior: } \\ \text { approach used: } \\ \text { (5 months: psychotropic } \\ \text { drug use }\end{array} \\ \begin{array}{l}\text { interaction fime: } \\ \text { opinion staff: }\end{array}\end{array}$

\section{$V$ no difference ROT no diflerence CG betler} $\checkmark$ better

\section{no difference \\ no difference \\ no difference}

hardly any differences hardly any differences no difference no difference no difference

no difference
not clear
no difference
no difference
no difference

better

no difference

no difference somewhat better achieved

better

better

not clear
better
$4.5 \rightarrow 8$ min
better

- randomization manipulated

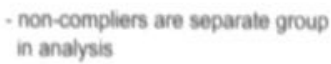
observers with regard to agitated behaviot

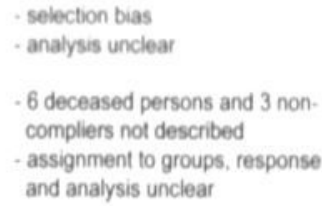

- baseline and follow-up measurement at the same time

- no measurements at individual level

- no data presented

- few data presented

- few data presented

- results and methods are unclear
- no data presented

- pretest and posttest are difterent persons 


\begin{tabular}{|c|c|c|c|c|}
\hline $\begin{array}{l}\text { Author(s), year } \\
\text { Country }\end{array}$ & Study population & Intervention group $(n)^{0}$ & Control group (n) & Interventrion" \\
\hline $\begin{array}{l}\text { Morton \& Bleathman, } \\
1991 \\
\text { UK }\end{array}$ & patients in an hospital, age 79-88 & $\begin{array}{l}5 \\
-1 \text { drop-out } \\
-1 \text { non-complier }\end{array}$ & - & $\begin{array}{l}1 \times / W k, 20 \text { wks group } \\
\text { sessions } V\end{array}$ \\
\hline $\begin{array}{l}\text { Nooren-Staal et al., } 1993 \\
\text { Netherlands }\end{array}$ & $\begin{array}{l}\text { demented residents of an home for } \\
\text { the elderly, age } 75-95\end{array}$ & 19 & . & $\begin{array}{l}\text { training } V \text { half of nurses } \\
\text { and implementation }\end{array}$ \\
\hline $\begin{array}{l}\text { Ronaldson \& Savy. } 1991 \\
\text { Australia }\end{array}$ & older patients in an hospital & $?$ & - & $\begin{array}{l}\text { training } V \text { nurses and } \\
\text { implementation }\end{array}$ \\
\hline \multicolumn{5}{|l|}{ One group posttest only } \\
\hline $\begin{array}{l}\text { Blanchard ef al., } 1991^{\circ} \\
\text { France }\end{array}$ & $\begin{array}{l}\text { 'short stay intensive care' patients in } \\
\text { an hospital, mean age } 84\end{array}$ & $?$ & . & $\begin{array}{l}\text { training } V \text { some nurses } \\
\text { and physicians and } \\
\text { implementation }\end{array}$ \\
\hline
\end{tabular}

*V=validation; ROT=Reality Orientation Therapy. SC=Social Contact group; CG=Control Group; wk=week; wks=weeks; min=minutes bunpublished research

unavoidably manipulated and that this may have introduced a source of bias (page 42). This manipulation had, as far as can be concluded from the report, to do with conflicts in schedules.

Data about confusion, ego integration and behavior were obtained from the three groups at baseline and follow-up. Instead of testing differences in effects between groups, Peoples only tested differences in effects within the study groups. None of the three groups showed a statistically significant change in confusion over time. The control group had, in contrast to the other two groups, a significant change (beneficial effect) after six weeks on the ego integration scale, whereas the validation group had a significant better behavior score after six weeks.

In Robb et al.'s study twenty subjects were randomly assigned to a validation group and sixteen to a control group (Robb et al., 1986). The validation group received twice a week validation sessions for a period of nine months. The outcome measures mental status, morale and social behavior were assessed nine months after baseline.

This study had a drop-out rate of $25 \%$, caused by illness and mortality among the study population during the follow-up period. In addition, there were six non-compliers in the validation group. These persons were included as a separate group in the analysis and as a consequence the advantage of randomization disappeared. No positive effects could be demonstrated in the subgroup of the nine remaining motivated persons in the intervention group.

Toseland et al.'s study is the most recent one and the one with the best methodological quality (Toseland et al., 1997). In this study 31 elderly people were assigned to the validation group, 29 to a social contact group and 28 to the control group. The group sessions in both the validation and the social contact group were held for thirty minutes, four times a week for one year. The follow-up measurements (regarding psycho-social functioning, agitated and positive behavior, medication and use of physical restraints) took place after three and twelve months. This study reported a drop-out rate of $25 \%$, mainly caused by mortality $(20 \%)$, after one year of follow-up. Fortunately, the drop-outs were almost equally distributed between the three groups and did not differ from the residents who completed the study. 
Follow-up after"

20 and 30 wks

$1 \%$ and 4 months

4 months
Outcome measure(s)

Eflects

Remaks

V: 2 better/1 worse

no difference

no difference

behavior

cognition:

mood:

social contact

social interaction:

agitation

distress:

communication

aggression:

medication

\section{better}

somewhat better

no differences

better

better

better

better

better

better

\author{
outcome measurement: \\ unstructured observation \\ no data presented
}

outcome measurement evaluation form

no data presented

Nursing staff reported that the validation group showed less physically and verbally aggressive behavior and more physically nonaggressive problem behavior. These outcome measures are sub-scales on the agitated behavior scale. Independent observers, however, did not find similar reductions of the agitated behavior subscales. On the contrary, these observers reported a significant lower score in verbally aggressive behavior, both at three and 12 months, for the social contact group compared to the validation and control group.

There were no significant effects on all the other outcome measures such as psychological functioning, positive behavior, medication and use of physical restraints.

\section{Evidence from pretest-posttest designs with control group $(n=3)$}

Babins et al. selected twelve disoriented institutionalized women; five in the intervention and seven in the control group (Babins et al., 1988). The women in the intervention group received twice a week group sessions validation for eleven weeks. After eleven weeks the outcome measurements (cognition and social behavior) took place in both groups.

Selection bias probably occurred, as there were large differences at baseline between the 2 groups. Furthermore, the data analyses remained unclear; the theoretical and empirical range of scores on the outcome measures and the interpretation of the results was lacking. whereas some numbers in the table did not correspond with the numbers in the text. Consequently, the results of this study were difficult to interpret.

In the study of Scanland and Emershaw, twelve confused male nursing home residents were included in the validation group, ten in the ROT group and twelve in the control group (Scanland \& Emershaw, 1993). Residents in the validation and ROT group were offered group sessions validation or ROT for thirty minutes, five times a week for four months. The follow-up measurements took place after four months.

The data showed no differences on mental status, depression and functional status after four months. Of the 34 people included in the study six died and three were non-compliers. It remained unclear how these nine people were distributed over the three groups. It was also unclear whether the three groups were prognostically comparable at baseline. Moreover, a basic description of outcomes, like mean scores, was lacking. 
Sharp's unpublished study was performed in two nursing homes (Sharp, 1989). In the intervention home nineteen residents were included and in the control home eighteen. The staff in the intervention home received a validation training for three months. After three months the outcome measurements were conducted.

Sharp concluded on the basis of the 'overall' opinion of 'the staff that eight intervention persons and one control person had improved. More objective outcome measures (behavior and disorientation) showed no differences between the two groups.

\section{Effects on the caregivers}

In addition to the effects on the disoriented elderly people, four studies investigated the effects for the caregivers (Alprin, 1980; Blanchard et al., 1991; Nooren Staal et al., 1995; Ronaldson and Savy, 1991). All four studies, with serious methodological limitations, reported positive results for the caregivers in terms of behavior and satisfaction.

\section{Discussion}

Reviewing the literature is an example of observational research. This implies that it is subject to the same potential sources of bias as other observational study designs. Usually the following sources of bias are distinguished: selection bias, information bias, confounding and effect modification. In a review or meta-analysis, in which explicit attention is paid to these potential types of bias, these sources correspond with, respectively, publication bias, validity problems within the trials and lack of comparability of outcome measures, study populations and interventions (Bouter and ter Riet, 1990).

Publication bias can result in underestimating or overestimating the effect of an intervention. Possible determinants of publication bias are the outcomes and the size of the study.

We were able to obtain many unpublished studies (seven out of sixteen). Especially studies with 'no' or negative results are at risk of not being published. In our review however, it appeared that a substantial percentage of all studies reported (almost) 'no' results and that the seven unpublished studies have somewhat more positive outcomes compared to the published studies. The study groups in the published as well as the unpublished studies were rather small. It seems unlikely that the outcome of our review was affected by publication bias.

Many studies turned out to have serious validity problems. This was even the case in two of the three 'randomized' trials that we found. In one study the randomization procedure was manipulated (Peoples, 1982), and in the other study the advantage of randomization disappeared because of the selection bias that the researchers introduced in their data analysis (Robb et al., 1986).

The studies in our review showed little comparability in outcome measures, study populations and interventions. Because the purpose of the review at issue is formulated very generally and only sixteen studies were found, we made no restrictions to achieve a better comparability in this respect.

To summarize the review of the literature, only nine of the sixteen studies found were published; there are only three randomized studies; the sample size of all studies, except one (Toseland et al., 1997), is small; there are many methodological shortcomings and crucial information and data are often not or not very clearly reported. Nearly all studies suffer from serious methodological shortcomings and the results are conflicting. It appears 
that the better the study, the less favorable the effectiveness of validation is. In general our review shows that the methodological quality and therefore the scientific evidence of the studies is limited.

This review shows that hardly any scientific evidence is available yet to support the hypothesis that validation has positive effects on disoriented elderly and their professional caregivers. Given the increasing numbers of psycho-geriatric patients and their impact on health care resources, it would of course be very attractive if a relatively simple and cheap approach, like validation, was useful. Because the effectiveness of any form of intervention should be assessed objectively before it is adopted and used widely, new research is needed to settle the discussion about the merits of validation.

\section{ACKNOWLEDGMENTS}

We wish to thank Ellen Duijnhouwer for her help in the literature search and in evaluating the studies.

\section{REFERENCES}

Alprin, SI. (1980). Staff attitudes after validation. Cleveland, Ohio: Cleveland State University.

Babins, LH, Dillion, JP, \& Merovitz, S. (1988). The effects of validation therapy on disoriented elderly. Activities, Adaptation and Aging, Vol 12(1-2), 73-86.

Blanchard, F, Prentczynski, J, Wong, C, Lamaze, B, Bocquet, P, Jolly, D, \& Lorton, O. (1991). An application of the validation method at the geriatrics care unit of the University Hospital in Reims, France. Reims: Hôspital Sebastopol, Service de Médicine Interne et Geriatrie.

Bouter, L, \& ter Riet, G. (1990). Meta-analyse van therapeutische experimenten I. Bronnen van vertekening in literatuuronderzoek. Tijdschrift voor Sociale Gezondheidszorg., 68, 179-185.

Deutzmanek, JC. (1992). Validation binnen de psychogeriatrie, een onderzoek naar de mogelijkheden en beperkingen. Nijmegen: Katholieke Universiteit Nijmegen.

Ducharme, F. Francoeur, L. \& Blanchard, D. (1994). Evaluation des effects d'un groupe de validation sur la communication de personnes agees atteintes de deficiences cognitives irreversibles., L' infirmiere du Quebec, (Novembre/Decembre), 22-23.

Feil, N. (1972). Summary of 1972 research data presented at the 25th annual meeting of the gerontological society. San Juan, Puerto Rico.

Feil, N. (1984). Communicating with the confused elderly patient. Geriatrics, 39(3), 131-132.

Feil, N. (1985). Resolution: The final life task. Journal of Humanistic Psychology, 25(2), 91-105.

Feil, N. (1990). Validation therapy helps staff reach confused residents. Provider, (December), 33-34.

Feil, N. (1991). Validation. Een nieuwe benadering in de omgang met gedesorienteerde ouderen. Dwingeloo: Kavanah.

Feil, N. (1992). Validation therapy. Geriatric Nursing. 13(3), 129-133.

Feil, N. (1994). De validation methode in de praktijk. (Translation of: The validation breakthrough: simple techniques for communicating with people with Alzheimer's-type dementia) (I van Pinksteren, Trans.). Utrecht: Lemma b.v.

Feil, N. \& Wetzler, M. (1979). An innovative method of working with the severely disoriented aged. American Health Care Association Journal, (March), 41-44.

Fine, JI, \& Rouse Bane, S. (1995). Using validation techniques to improve communication with cognitively impaired older adults. J. Gerontol. Nurs., 21(6), 39-45.

Fritz, PA. (1986). The language of resolution among the old-old: the effect validation therapy on two levels of cognitive confusion. Toledo, Ohio: University of Toledo.

Morton, I, \& Bleathman, C. (1991). The effectiveness of validation therapy in dementia: A pilot study. Int. J. Geriatr. Psychiatry, 6(5), 327-330.

Nooren Staal, WH. Frederiks, CM, \& te Wierik. MJ. (1995). Validation: effecten bij bewoners en personeel in een verzorgingshuis. Tijdschr. Gerontol. Geriatr., 26(3), 117-121 
Peoples, MM. (1982). Validation therapy versus reality orientation as treatment for the institutionalized disoriented elderly (thesis). Akron: University of Akron.

Robb, SS, Stegman, CE, \& Wolanin, MO. (1986). No research versus research with compromised results: a study of validation therapy. Nurs. Res., 35(2), 113-118.

Ronaldson, S, \& Savy, P. (1991). Validation therapy: a viable option for gerontic nursing practice. Geriaction, (Autumn), 7-10.

Scanland, SG, \& Emershaw, LE. (1993). Reality orientation and validation therapy. Dementia, depression, and functional status. J. Gerontol. Nurs., 19(6), 7-11.

Sharp, C. (1989). Validation therapy: An Australian Evaluation. Final Report. Melbourne.

Toseland, RW, Diehl, M, Freeman, K, Manzanares, T, Naleppa, M, \& McCallion, P. (1997). The impact of validation group therapy on nursing home residents with dementia. Journal of Applied Gerontology, 16(1), 31-50. 


\begin{tabular}{|c|c|c|}
\hline Author(s) & Outcome measure(s) & Instrument(s)a \\
\hline Alprin & behavior & rating scale frequency behaviors before and after validation \\
\hline Babins et al. & $\begin{array}{l}\text { cognition } \\
\text { social behavior }\end{array}$ & $\begin{array}{l}\text { Philadelphia Multi-level Assessment Instrument Cognitive Domain (PCI) (Lawton et } \\
\text { al., 1982) } \\
\text { Nurses' Observation Scale for In-Patient Evaluation (NOSIE-30) (Honingveld \& } \\
\text { Kett. 1965) }\end{array}$ \\
\hline Blanchard et al. & $\begin{array}{l}\text { communication } \\
\text { aggression } \\
\text { medication }\end{array}$ & $\begin{array}{l}\text { validation assessment chart } \\
\text { idem }\end{array}$ \\
\hline Deutszmanek & behavior & $\begin{array}{l}\text { Gedragsobservatieschaal Intramurale Psychogeriatrie (GIP) (Verstraten } 8 \text { van } \\
\text { Eekelen, 1987) }\end{array}$ \\
\hline Ducharme & $\begin{array}{l}\text { (non)verbal behavior } \\
\text { social interaction } \\
\text { individual goals }\end{array}$ & $\begin{array}{l}\text { observation grids (Blanchard, 1992) } \\
\text { interaction diagrams (Dimock, 1970) } \\
\text { individual intervention plans }\end{array}$ \\
\hline Fed & $\begin{array}{l}\text { affect } \\
\text { interaction }\end{array}$ & $\begin{array}{l}\text { rating sheets with } 23 \text { variables } \\
\text { rating sheets with } 7 \text { variables }\end{array}$ \\
\hline $\begin{array}{l}\text { Fine } 8 \text { Rouse- } \\
\text { Bane }\end{array}$ & $\begin{array}{l}\text { problem behavior } \\
\text { approach used } \\
\text { interaction time } \\
\text { opinion staff }\end{array}$ & $\begin{array}{l}\text { observation/records } \\
\text { idem } \\
\text { idem } \\
\text { idem }\end{array}$ \\
\hline Fritz & language use & Syntactic Language Computer Analysis (SLCA) (Cummings \& Renshaw, 1979) \\
\hline $\begin{array}{l}\text { Morton \& } \\
\text { Bleathman }\end{array}$ & $\begin{array}{l}\text { verbal interaction } \\
\text { communication } \\
\text { behavior }\end{array}$ & $\begin{array}{l}\text { observation method (modified version of the 'short Bleathman observation method } \\
\text { for the study of the activity and contacts of old people in residential seltings' } \\
\text { (Macdonald et al.,1985)) } \\
\text { Holden Communication Scale (Holden \& Woods, 1982) } \\
\text { MACC Behavioral Adjustment Scale (Ellsworth, 1966) } \\
\text { CAPE Behavioral Rating Scale (Pattie \& Galleard, 1979) }\end{array}$ \\
\hline $\begin{array}{l}\text { Nooren-Staal } \\
\text { et al. }\end{array}$ & $\begin{array}{l}\text { cognition } \\
\text { mood } \\
\text { social contact }\end{array}$ & $\begin{array}{l}\text { Beoordelingsschaal voor Psychische en Sociale problemen (BPS) (van Loveren- } \\
\text { Huyben et al., 1988) } \\
\text { Idem } \\
\text { Idem }\end{array}$ \\
\hline Peoples & $\begin{array}{l}\text { confusion } \\
\text { ego-integration } \\
\text { behavior }\end{array}$ & $\begin{array}{l}\text { Tool for Assessing Degree of Confusion in the Elderly (Hogstel, 1979) } \\
\text { Ego Integration Scale (Peoples, 1982) } \\
\text { Behavior Assessment Tool (Peoples, 1982) }\end{array}$ \\
\hline Robb et al. & $\begin{array}{l}\text { mental status } \\
\text { morale } \\
\text { social behavior }\end{array}$ & $\begin{array}{l}\text { Mental Status Questionnaire (MSQ) (Fishback, 1977) } \\
\text { Philadelphia Genatric Center Morale Scale (PGCMS) (Lawon, 1975) } \\
\text { Minimal Social Behavior Scale (MSBS) (Farina et al., 1957) }\end{array}$ \\
\hline $\begin{array}{l}\text { Ronaldson } \\
\text { \& Savy }\end{array}$ & $\begin{array}{l}\text { social interaction } \\
\text { agitation } \\
\text { distress }\end{array}$ & $\begin{array}{l}\text { Residents Progress Reports } \\
\text { Idem } \\
\text { Idem }\end{array}$ \\
\hline $\begin{array}{l}\text { Scanland } 8 \\
\text { Emershaw }\end{array}$ & $\begin{array}{l}\text { mental status } \\
\text { depression } \\
\text { functional status }\end{array}$ & $\begin{array}{l}\text { Mini Mental State Examination (MMSE) (Folstein, 1975) } \\
\text { Modified Beck Depression Inventory (Beck. 1961) } \\
\text { Katz Index of ADL Evaluation Form (Katz, 1963) }\end{array}$ \\
\hline Sharp & $\begin{array}{l}\text { adaptive functioning } \\
\text { disorientation } \\
\text { opinion staff }\end{array}$ & $\begin{array}{l}\text { Moorfields "Problem Checklist" (for adaptive functioning) } \\
\text { Benedictine Health Center Phase of Disorientation checklist }\end{array}$ \\
\hline Toseland et al. & $\begin{array}{l}\text { psychosocial functioning } \\
\text { agitated behavior } \\
\text { positive behavior } \\
\text { medication } \\
\text { use of physical restraints }\end{array}$ & $\begin{array}{l}\text { Multidimensional Observation Scale for Elderly Subjects (MOSES) (Pruncho et al., } \\
\text { 1988) } \\
\text { Cohen-Mansfieid Agitation Imventory (CMAI) (Cohen-Mansfield et al., 1989) } \\
\text { Geriatric Indices of Positive Behavior (GIPB) (Toseland et al.) } \\
\text { Minimum Data Set - Resident Assessment Protocol (MDS+) (Morris et al., 1990) } \\
\text { Minimum Data Set - Resident Assessment Protocol (MDS+) (Morris et al., 1990) }\end{array}$ \\
\hline
\end{tabular}

If possible, the name of the source of the instrument is presented. These sources are not listed in our reference ist. 


\title{
Design of a study to test the effects of emotion-oriented care
}

\author{
Veron JJ Schrijnemaekers ${ }^{1}$ \\ Erik van Rossum \\ Margreet JM te Wierik ${ }^{2}$ \\ Carla MA Frederiks ${ }^{3}$ \\ Mayke MA Derix ${ }^{4}$
}

'Department of Epidemiology, Maastricht University

${ }^{2}$ Faculty of Health Sciences, Maastricht University

${ }^{3}$ Department of General Practice and Social Medicine, University of Nijmegen

${ }^{4}$ Department of Clinical Psychology. Twenteborg Hospital

This chapter is an adapted version of the report: Schrijnemaekers, VJJ, van Rossum, E, te Wierik, MJM, Frederiks, CMA, \& Derix, MMA. (1997). Onderzoek naar de effecten van belevingsgerichte zorg in verzorgingshuizen. Maastricht: Universiteit Maastricht. 


\section{ABSTRACT}

This chapter describes the design of the randomized controlled trial into the effects of emotion-oriented care on elderly people with cognitive impairment and behavioral problems and their professional caregivers in homes for the elderly.

After pre-stratification sixteen homes were randomly allocated to an intervention or a control group. The eight intervention homes received a training program in emotion-oriented care. In the eight control homes usual care was continued.

Measurements were performed at baseline and after three, six and twelve months of followup. The primary outcome measure of the resident was the change in behavior and for the caregivers job satisfaction. Various multilevel analyses were conducted to study the differences between the two study groups. 


\section{INTRODUCTION}

This chapter presents the design of a Dutch experiment, which aims to study the effects of emotion-oriented care on elderly people with cognitive impairment and behavior problems and on their professional caregivers in homes for the elderly.

After a brief outline of the study, a division is made into five sections: 1. study population, 2. pre-stratification and randomization, 3. interventions, 4. outcome measures and measurements, and 5. data management and analyses.

\section{BRIEF OUTLINE OF THE STUDY}

The study was performed as a randomized controlled trial in sixteen homes for the elderly in Limburg. the Netherlands. After pre-stratification the homes were randomly allocated to an intervention or a control group. In the eight intervention homes eight caregivers received a six-day training in emotion-oriented care over a period of three months. In addition, three supervision-meetings (half-a-day each) were offered in the intervention homes to optimize the implementation of the new care model. In the eight control homes usual care was continued. Outcome measurements were performed after three, six and twelve months.

Figure 1 presents the outline of the study.

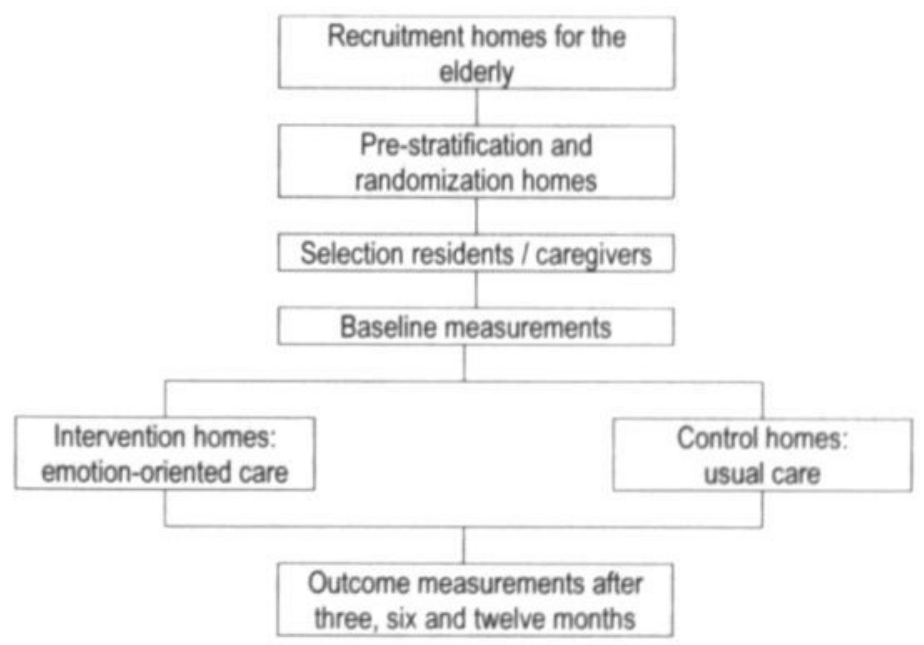

Figure 1. Design of the study to test the effects of emotion-oriented care in homes for the eiderly

Additional qualitative research methods (observations and semi-structured interviews) were used to study the compliance in the study groups and the experiences of the caregivers in using and implementing emotion-oriented care (see chapter 6 for details about the qualitative study). 


\section{STUDY POPULATION}

The study population was recruited from homes for the elderly and consisted of both residents and their professional caregivers.

As preparation for the recruitment of homes for the elderly, a postal questionnaire was sent to all homes in the province of Limburg $(n=77)$, the Netherlands. This questionnaire contained questions about, among other things, the presence of a day-care program for psycho-geriatric residents, the number of residents participating in this program, the number of caregivers in the home who had already attended a training program about validation or related care approaches.

Fifty-nine homes $(\mathbf{7 7} \%)$ responded to our questionnaire. The data of the questionnaires enabled us to make a first selection of homes eligible for and possibly interested in our study. These homes $(n=31)$ were invited to an informative meeting about our trial. Next, interviews were held with staff members in the homes that were still interested in our study. During these interviews more specific information about the homes was gathered.

The homes had to fulfill the following inclusion criteria.

1. Presence of a structured day-care unit' for at least ten residents with cognitive and behavioral problems (residents for the study were recruited from these units).

2. No structural implementation yet of emotion-oriented care approaches in the daily care for residents.

3. Willingness to create the conditions for conducting our trial and to implement the intervention in case of allocation to the intervention group.

4. In case of allocation to the control group, refrainment from emotion-oriented care training during the study period.

5. No substantial organizational changes (e.g. reorganization, merger) to be planned during the study period.

These criteria were checked in the postal questionnaires and the interviews with the staff members of the homes.

\section{Residents}

In order to be eligible for the trial residents had to meet the following criteria.

1. Presence of moderate to severe cognitive impairment and behavioral problems.

Cognitive impairment was assessed by means of the standardized Mini Mental State Examination (MMSE) (Folstein et al., 1975; Molloy et al., 1991). The screening interviews were conducted by three trained researchers. Residents with a score of 21 or more were excluded from the study (range 0-30).

The presence of behavioral problems was assessed by means of the short version of the Dutch Behavioral Rating Scale for Psychogeriatric Inpatients (Gedragsobservatieschaal voor de Intramurale Psychogeriatrie (GIP-28) (de Jonghe et al., 1997; Verstraten and van Eekelen, 1987). This scale was completed independently by caregivers of the structured day-care program and caregivers of the ward where the residents live. Residents who had a sum-score on both assessments of 31 or less on 24 items of this scale were excluded from the study (range 24-96).

1. These day-care units offer a structured day-care program to (usually 10 to 15) psycho-genatnc residents. Occupational therapists. geriatric attendants or nurses and some volunteers or trainees work at these units 
2. Participation in a structured day-care program for at least five half-days a week and residing in the home for the elderly for at least two months before the start of the study.

3. Single (or when a spouse or partner is present this person has to have a positive attitude towards a new or different care approach for his or her partner).

4. Not bedridden.

5. Sufficient hearing functions.

6. Absence of an unstable psychiatric disease (except dementia).

7. Presence of an adequate level of premorbid intellectual capacity.

8. Absence of expected loss to follow-up from the study during the first six months.

The complete selection process for the residents was conducted in several steps. First, as pre-selection the nursing staff completed short questionnaires on all the residents participating in the day-care unit of the home. This questionnaire contained questions about, among other things, background characteristics and the above-mentioned criteria 2 to 8 . At the same time we asked for the addresses of the representatives of the residents (usually a daughter or son) to inform them about our study and to ask them for a written informed consent. Next, residents whose representatives gave informed consent and who met our criteria 2 to 8 , were screened (see criterion 1). If residents also fulfilled this criterion (presence of moderate to severe cognitive impairment and behavioral problems), they were admitted to the study.

\section{Sample size residents}

To estimate the number of residents needed in our study, a power calculation was conducted. The group size was determined on the primary outcome measure for the resident, namely behavioral problems. Behavioral problems were measured with the short version of the Dutch Behavioral Rating Scale for Psychogeriatric Inpatients (Gedragsobservatieschaal Intramurale Psychogeriatrie (GIP-28) (de Jonghe et al., 1997; Verstraten and van Eekelen, 1987). This scale includes 28 items and has a range from 28 to 112 (the higher the score, the more behavioral problems).

De Jonghe (de Jonghe et al., 1996) obtained data on the GIP from a heterogeneous population $(n=2,845)$ of which 415 people originated from a day-care program in homes for the elderly (approximately the same population as our residents in the study). Via personal communication with de Jonghe (1997), we obtained data from the GIP-28 from these 415 residents. The mean score was 51.8 with a standard deviation of 12.0 .

On the basis of these data and our clinical judgment, we assumed that a difference of 10 points on the GIP-28 is clinically relevant. To be able to obtain a 10-point difference between the control and intervention group on the GIP-28, with a power of $90 \%$ (1-beta) and a twotailed level of significance (alpha) of $5 \%(p=0.025), 60$ residents per group were needed. Taking into account a loss to follow-up of about $25 \%$ during the one-year follow-up, 80 residents had to be included in each study group.

\section{Professional caregivers}

The caregivers were selected to study the effects of the intervention on job-related outcomes such as job satisfaction, burnout and sick leave. The caregivers had to meet the following criteria.

1. Being employed for at least half a year at the home for the elderly.

2. Being employed for at least eighteen hours a week.

Caregivers who were expected to be absent during the study period for a longer time (e.g. due to pregnancy leave) were excluded from the study. 
First all professional caregivers of the day-care units were included. Next, a random sample of caregivers of the wards where the residents live was made.

\section{Sample size professional caregivers}

The sample size for the professional caregivers was calculated on the primary outcome measure for the caregiver, namely job satisfaction. Job satisfaction was measured with a short version of the Maastricht Work Satisfaction Scale for Health Care (Maastrichtse Arbeidssatisfactie Schaal voor de gezondheidszorg (MAS-GZ) (Landeweerd et al., 1996a). We used five of the seven sub-scales (15 items). Each item ranges from 1 to 5 (the higher the score, the more job satisfaction).

Landeweerd et al. (Landeweerd et al., 1996a) obtained data from de MAS-GZ from a population of more than 3,000 employees in various health care settings. The mean score per item (concerning the five sub-scales) was 3.63 with a standard deviation of 0.63 .

On the basis of these data and clinical judgment we assumed that a difference of 0.5 points on the MAS-GZ is clinically relevant. To be able to obtain a 0.5-point difference on the MAS$\mathrm{GZ}$ between the intervention and control group, and based on the same assumptions as above ( 1 -bèta $=90 \%$, alpha $=5 \%, 25 \%$ loss to follow-up), the group size was determined at 80 caregivers per study group.

It is also interesting to test the job satisfaction separately for participants of the training program and the other caregivers in the intervention homes. To retain enough statistical power for such a subgroup analysis, it was decided to increase the number of caregivers with the (potential) number of participants of the training program ( 16 homes $x \pm 8$ participants $=$ \pm 128 ). This implies that we needed a total of approximately 290 caregivers in our study population.

\section{PRE-STRATIFICATION AND RANDOMIZATION}

The number of homes for the elderly needed in our study, depended on the available number of residents and caregivers per home. It was concluded that probably a selection of 16 homes for the elderly would be needed to obtain the desired numbers of residents and professional caregivers.

The randomization took place at the level of the homes. Because randomization does not guarantee comparability of the study groups at the start of the study, the homes were prestratified before randomization on two important prognostic characteristics:

1. capacity of the day-care unit for psycho-geriatric residents; and

2. degree of care innovation in the homes. The presence of resident-oriented care-plans and a system of resident-allocation were chosen as operationalizations of care innovation.

On the basis of these two characteristics eight pairs of homes were generated. After prestratification, randomization was performed by computer within each pair. 


\section{INTERVENTIONS}

It was decided to contrast the experimental intervention (intervention homes) with no intervention, i.e., usual care (control homes). This choice implies that the comparison between intervention and no intervention contains both specific and nonspecific elements. An example of a nonspecific element in our intervention is that caregivers who get the opportunity to follow the training may have an improved (short-term) job satisfaction regardless of the content of the training. However, it was difficult to choose a suitable 'placebo' or control intervention which contains only nonspecific elements.

The eight control homes had our promise that they would obtain the emotion-oriented care training program at the end of our study. We thought this commitment was a necessary condition to obtain the participation of the homes. Besides, this promise gave us more certainty that in case of allocation to the control group, no validation or comparable training would be started during our study period.

The intervention offered to the eight intervention homes consisted of three successive elements: clinical lessons, the emotion-oriented care training program and supervision meetings, spread over a total period of eight months.

All three elements of the intervention were organized and given by the same qualified teacher of an external organization, who was experienced in the topic and setting at issue.

\section{Clinical lessons}

The intervention started with clinical lessons. Every intervention home received two identical lessons of approximately one-and-a-half hours. These lessons were given in-company and were meant for all employees (e.g. receptionist, domestic staff, nurses). We offered the lessons twice, to increase the opportunity for employees to attend at least one of them. The goal of these lessons was to inform employees about the study and the general ideas behind emotion-oriented care.

\section{Emotion-oriented care training program}

After the clinical lessons, at least eight caregivers (students) in each intervention home received an emotion-oriented care training program. The students had to be key figures in the daily care for residents with cognitive impairment and behavioral problems and had to be able to implement the care approach in their home.

First, about five caregivers were selected from the day-care unit. Next, some key figures of the wards were selected for the training $(n= \pm 3)$.

The students had to meet the following criteria:

1. working for at least half a year at the home for the elderly:

2. being employed for at least eighteen hours a week;

3. working for at least one year in geriatric care; and

4. having at least secondary vocational training.

Caregivers who were expected to be absent during the study period for a longer time (e.g. pregnancy leave) were excluded from the training.

The selected students received a six-day emotion-oriented care training program. The first four days were given at intervals of two weeks and the last two days had an interval of four 
weeks. Given the limited number of about sixteen participants per training and the phased inclusion of the homes in the study, two parallel training programs started in November 1997 and two parallel programs in February 1998. The eight participants per home were divided over the two parallel training programs.

The training was organized in-company in four of the eight intervention homes. These four homes had suitable accommodation for the training and were geographically centrally located for the other homes.

The training program had various goals. First, participants obtained some knowledge about and insight into the dementia syndrome and various care models for interacting with demented elderly (e.g. Reality Orientation, Validation, Reminiscence, 'snoezelen'). Besides, much attention was paid to the inequality of the resident-caregiver relation, the importance of going deeply into and trying to understand the residents' perception of the environment and the attitude and verbal and non-verbal language towards the resident (including the use of sensory perceptions like touch, smell, vision, hearing). Finally, the naming and implementation of practical skills received attention.

To enhance the implementation of emotion-oriented care in the homes, the introduction of a so-called emotion-oriented care platform was discussed. During the training, suggestions, possibilities and eventually the first organizational steps were discussed with the participants. Table 1 gives an example of one day of the program.

Various didactical methods, such as teaching, homework, class assignments and exercises, role-playing and video-presentations, were used during the training.

Table 1. Program of the first day of the emotion-oriented care training

\begin{tabular}{|c|c|c|}
\hline Time & Subject & Didactical method \\
\hline $9.30 \cdot 9.40$ & Introduction teacher and explanation of the program & Plenary teacher \\
\hline $9.40 \cdot 10.15$ & Introduction students with homework attributes & Class \\
\hline $10.15 \cdot 10.45$ & Discussion about homework assignment & Plenary teacher + class \\
\hline $10.45 \cdot 11.00$ & Break & - \\
\hline $11.00-11.30$ & Theoretical outine (validation, ROT, sensory stimulation, snoezelen etc.) & Plenary teacher + overhead projector \\
\hline $11.30 \cdot 12.00$ & Emotion-oriented care platform & Plenary \\
\hline $12.00 \cdot 12.30$ & Observation 1 & Individual assignment + photograph \\
\hline $12.30 \cdot 13.30$ & Lunch & $\cdot$ \\
\hline $13.30-14.00$ & Observation (objective, subjective, selective) & Plenary + practical examples \\
\hline $14.00 \cdot 14.45$ & Observation 2 & Group assignment + photograph \\
\hline $14.45 \cdot 15.00$ & Break & - \\
\hline $1500 \cdot 15.30$ & Summary observation assignments & Plenary teacher + class \\
\hline $15.30-16.00$ & Reporting & Plenary teacher + overhead projector \\
\hline $16.00 \cdot 16.15$ & Explanation homework day 2 & Plenary teacher \\
\hline $16.15-16.30$ & Evaluation day 1 & Plenary teacher + class \\
\hline
\end{tabular}




\section{Supervision meetings}

In addition to the clinical lessons and the emotion-oriented care training program, three supervision meetings (half-a-day each) were offered in the intervention homes to support the implementation of the new care model in the care setting. These meetings were offered incompany over a period of four months after the training was finished.

The main goal of these appointments was to evaluate and discuss the (possible) bottlenecks in the implementation of emotion-oriented care and the organization of the emotion-oriented care platform. The meetings were 'tailor-made' for every intervention home. Depending on the bottlenecks mentioned in the first supervision meeting. goals, agreements and evaluations were discussed with those involved.

\section{OUTCOME MEASURES AND MEASUREMENTS}

In choosing instruments (e.g. questionnaires, observation scales) to measure the outcomes. we used the following criteria:

1. preferably there is a valid and reliable Dutch version of the instrument available;

2. the instrument should be feasible for the target population (for instance not too long); and

3. where possible and desirable the instruments were attuned to the instruments used in a (comparable) Dutch study in which the effects of emotion-oriented care were tested in nursing homes.

\section{Outcome measures residents}

The primary outcome measures for the residents were some behavioral problems. Secondary outcomes for the residents related to some other behavior outcomes and to outcomes such as functional status, change in psychotropic drug use and nursing home admissions.

\section{Primary}

Behavior

To measure the behavior of residents we used parts of the Dutch Behavior Observation Scale for Psycho-geriatric Inpatients (Gedragsobservatieschaal voor de Intramurale Psychogeriatrie (GIP)) (Verstraten and van Eekelen, 1987).

The GIP is an extensive psycho-geriatric behavior observation scale for institutionalized elderly people. The scale contains 82 items divided over fourteen sub-scales ${ }^{1}$ that can be used separately. For every item the observer has to rate the frequency of the behavior during the last two weeks on a 4-point scale. For our study seven of the fourteen sub-scales were selected, namely: nonsocial behavior, apathetic behavior, loss of decorum, rebellious behavior, restless behavior, dependent behavior and anxious behavior. Various authors have reported on the validity and reliability of the GIP. De Jonghe et al. and Verstraten found Cronbach's alpha values ranging from 0.72 to 0.89 and 0.61 to 0.90 respectively for the fourteen sub-scales (de Jonghe et al., 1994; Verstraten, 1988). The interrater-reliability ranged from 0.27 to 0.56 (de Jonghe et al., 1994) and 0.53 to 0.90 (Verstraten. 1988). The

\footnotetext{
1. The fourteen sub-scales of the GIP are: nonsocial behavior ( 8 tems), apathetc behavior (6 tems), distorted consciousness (7 items) loss of decorum ( 5 tems), rebellious behavior ( 5 items), incoherent behavor ( 5 tems), distonted memory ( 7 tems), disonented behavior ( 5 thems). senseless repetitive behavior ( 5 tems), restless behavior ( 5 tems), suspicous behavior ( 7 tems), melancholic or sorrowhul behavor ( 6 tems). dependent behavor ( 5 tems) and anwious behavior ( 6 tems).
} 
(concurrent) validity tests showed high correlations with other instruments (de Jonghe et al., 1994).

\section{Secondary}

Secondary outcome measures regarding the residents were other behavior measures such as communication, agitation and resident-specific behaviors, and functional status, depressive complaints, a global assessment of functioning, change in psychotropic drug use, nursing home admissions and mortality.

\section{Other aspects of behavior}

In addition to the seven GIP sub-scales, the short version of the GIP, the GIP-28 (de Jonghe et al., 1997) was included. The GIP-28 includes two items of every sub-scale of the GIP and is nearly equivalent to the fourteen sub-scales of the GIP (de Jonghe et al., 1997).

\section{Communication}

Communication was measured by means of seven items of the Geriatric Residents Goal Scale (GRGS) (Cornbleth, 1978; Dröes, 1991). The GRGS (Cornbleth, 1978) is a listing of 85 observable behaviors, which are organized into six subscales: eating, dressing. grooming. communication, locomotion, and 'other'. A yes-no response format is used to indicate whether or not a resident independently engages in each behavior. In our study we included seven of the seventeen communication items. These seven items ( 30 to 34,40 and 41$)$ relate to (social) interaction. The remaining ten items were omitted. Information about these items was gathered already elsewhere in our questionnaires (e.g. GIP) or not relevant for residents with moderate to severe cognitive impairment (e.g. 'writes letter').

According to Cornbleth, the GRGS is highly reliable and valid (Cornbleth, 1978). Dröes also conducted some reliability analyses for the Dutch version of the communication subscale separately (interrater reliability: $r=0.69$, internal consistency: Spearman-Brown $=0.88$ ) (Dröes, 1991).

\section{Agitation}

The Cohen Mansfield Agitation Inventory(-Dutch version) (CMAI-D) (Cohen Mansfield, 1986; de Jonghe and Kat, 1996) was used to measure agitation. The CMAI-D is a nurses' rating questionnaire. It consists of 29 behaviors, each rated on a 7-point scale of frequency (1: never ... 7: several times an hour). The CMAI covers three syndromes of agitation: aggressive behavior, physically non-aggressive behavior and verbally agitated behavior (Cohen Mansfield et al., 1989; Cohen Mansfield et al., 1992).

Miller et al. studied the reliability and validity of the CMAI (Miller et al., 1995). They concluded that the internal consistency of the scale is good (varying from 0.63 to 0.82 across shifts), the interrater reliability ranges from adequate $(0.47)$ to good $(0.85)$ on the three syndromes, and the (concurrent) validity is satisfying $(r=0.64$ to $0.95(p<0.01))$. De Jonghe reported a Cronbach's alpha of 0.82 and an interrater agreement of 0.89 for the CMAI-D, when used on a psychiatric observation clinic for older persons (de Jonge and Kat, 1996).

\section{Resident-specific approach}

The GIP, GRGS and the CMAI(-D) are all pre-structured scales concerning behavior.

As it is also important to evaluate the specific problem behavior of participating residents, we included a more resident-specific approach to measure disturbing behavior. Such an approach has been described and tested by, among others. Beurskens et al. (Beurskens et al., 1999). They concluded that the responsiveness of the 'patient'-specific approach was 
comparable with more established outcome measures and that the approach was able to detect changes on complaints that were highly relevant for the patient.

At baseline we asked the observer first to list the three most disturbing behaviors of a specific resident. Next we asked them to make a hierarchy in the level of disturbance of these behaviors and to rate the frequency of each of the three behaviors on a 6-point scale ranging from (1) 'less than once a week' to (6) 'several times an hour'. During the follow-up measurements we asked the observers again to rate the frequency of the initially reported disturbing behaviors. Besides we asked them whether the frequency of those disturbing behaviors had changed in comparison with the baseline measurement. This change could be rated on a 5-point scale ranging from (1) improvement to (5) deterioration.

\section{Functional status}

An Activities of Daily Living (ADL) scale (Schrijnemaekers and Haveman, 1993) was used to measure functional status. This scale is derived from Katz's classic ADL scale (Katz and Akpom, 1976). Our ADL scale contains twelve items ${ }^{1}$ with four answering categories: (1) independently (whether or not with effort), (2) partly dependently, (3) only with help and (4) unable to evaluate. By assigning one point to every activity that could not be performed independently, a score was computed between 0 (no disabilities) and 12 points (completely dependent).

\section{Depressive symptoms}

The Cornell Scale (Alexopoulos et al., 1988; Dröes, 1993, 1996) was used to measure depressive symptoms. This scale was designed for the rating of symptoms of depression in demented elderly and in contrast with many other depression scales, the Cornell Scale uses information obtained from the patients' caregiver. The scale covers nineteen symptoms, with four answering categories: (0) absent, (1) mild or intermittent, (2) severe and (3) unable to evaluate.

According to Alexopoulos et al., the scale has a high interrater reliability (weighted Kappa $=0.67$ ), internal consistency (Cronbach's alpha $=84$ ) and sensitivity. The Cohen's Kappa of the individual items ranges from 0.60 to 0.96 (Alexopoulos et al., 1988).

\section{Global assessment of functioning}

At the follow-up measurements we asked the caregivers and representatives to assess the general functioning of residents compared to the start of the study (5-point scale ranging from 'much improved' to 'much deteriorated').

\section{Change in psychotropic drug use}

We received information about the psychotropic drug use at baseline and during follow-up measurements. By means of this information the change in use was determined as: decrease (0), the same (1), or increase (2).

Nursing home admission and mortality

Information about nursing home admissions and mortality during our study period was obtained via the administration in the homes for the elderly.

\footnotetext{
1. The 12 tems of the ADL scale are: rising from the bed, washing face and hands, dressing. putting on shoes and stockings. preparing a sandwich meal, moving around, bathing, eating and drinking, getting seated, getting into bed. using loilet duning the day and using toilet during the night
} 
Appendix 1 at the end of this thesis presents an example of a questionnaire regarding the residents.

\section{Outcome measures professional caregivers}

Job satisfaction was the primary outcome measure for the professional caregivers. Secondary outcome measures for the caregivers relate to additional job satisfaction measures, burnout, sick-leave and the general opinion about the work situation.

\section{Primary \\ Job satisfaction}

To measure the job satisfaction of the caregivers, we used specific subscales of the Maastricht Work Satisfaction Scale for Healthcare (Maastrichtse Arbeidssatisfactie Schaal voor de gezongdheidszorg (MAS-GZ)) (Landeweerd et al., 1996a; Landeweerd et al., 1996b). This scale was specifically developed for healthcare workers and has been studied in various Dutch healthcare settings including homes for the elderly. The MAS-GZ consists of 7 sub-scales with three items each and the items have a range from 0 (very dissatisfied) to 4 (very satisfied). In our study five of the seven sub-scales were selected for use, namely: satisfaction with head of the ward, quality of care, contact with colleagues, contact with residents and opportunities for self-actualization. The other two sub-scales (possibilities for promotion and clarity of tasks and rules) were considered to be less relevant for our study.

The psychometric properties of the MAS-GZ are adequate. The internal consistency (Cronbach's alpha) of the five sub-scales used, range from 0.67 to 0.87 . Its validity (factorial and construct) also appears to be satisfactory (Landeweerd et al., 1996a; Landeweerd et al., 1996b).

\section{Secondary}

Other aspects of job satisfaction

Besides the five sub-scales of the MAS-GZ, we included the short version of the MAS-GZ (one item from every sub-scale) (Landeweerd et al., 1996a).

Further, we added two study-specific satisfaction-items and one general satisfaction item. These items were formulated as follows:

- the extent to which you really have contact with residents with cognitive impairment and behavioral problems;

- the extent to which you can give good care to residents with cognitive impairment and behavioral problems; and

- the extent to which you have pleasure in your work.

These items had the same answering categories as the MAS-GZ, ranging from 0 (very dissatisfied) to 4 (very satisfied).

\section{Burnout}

Burnout was measured with the Dutch version of the Maslach Burnout Inventory (MBI-NL) (Maslach and Jackson, 1986; Schaufeli and Van Dierendonck, 1994). The MBI is specifically developed for persons with people professions, like caregivers. This frequently used scale consists of 22 items that are divided over three sub-scales: emotional exhaustion ( 9 items). depersonalization ( 5 items), and personal accomplishment ( 8 items). The items have to be rated on a 7 -point scale ranging from $(0)$ never to $(6)$ daily. 
Based on their own and other studies, Schaufeli and Dierendonck conclude that the threefactor structure of the MBI-NL was confirmed. The internal consistency (alpha $=0.70$ to 0.88 ) and test-retest reliability $(0.73$ to 0.83$)$ was satisfactory and the congruent and discriminant validity were shown well established.

\section{Sick-leave}

We asked the caregivers to inform us about their sick-leave before and during the intervention period. We asked them how often they were sick and the number of calendar days of absenteeism due to sickness. Possibly pregnancy leave was not included in the sickleave.

\section{Opinion about work situation}

At every time point we asked the caregivers to give their general opinion about their work situation compared to the baseline measurement. They had to rate their answer on a 7-point scale ranging from very much improved to very much deteriorated.

Additionally, we asked them to comment briefly on the possible change in their work situation.

Appendix 2 at the end of this thesis presents an example of a questionnaire for the professional caregivers.

\section{Co-interventions}

In addition to the outcome measures, information was gathered about co-interventions and events that might interfere with the intervention in our study. Some potential events and cointerventions for the residents are for example death of a relative, illness, use of day-care in a nursing home and admission to a hospital. At every time point, we asked the caregivers whether the resident had experienced such events. In addition, we asked them to assess the impact of the event on the functioning of the resident.

There are also potential co-interventions for the caregivers. Therefore we asked them whether there had been changes in their function, the ward where they work and/or the hours of work per week. We also asked two questions about possible negative or positive lifeevents.

\section{Measurements}

The outcome measures were measured at baseline and after three, six and twelve months of follow-up. Information about a specific outcome measure was often collected from several sources. Table 2 presents the timing and sources of the (outcome) measures.

In case of a nursing home admission during the study, we tried to obtain information about the resident's primary and secondary outcome measures (except the 'resident-specific approach') from the caregivers in the nursing home. 
Chapter 3

Table 2. Overview of outcome measures used (including sources) for the residents and professional caregivers

Outcome measures $\quad \begin{gathered}\text { Theoretical range } \\ \begin{array}{l}\text { Measurement occasions Sources } \\ \text { in months }\end{array}\end{gathered}$

\section{Residents}

Primary

Behavior (GIP) $)^{c}$

$\begin{array}{ll}\text { nonsocial behavior } & \underline{0-24} \\ \text { apathetic behavior } & \underline{0}-18 \\ \text { loss of decorum } & \underline{0}-15 \\ \text { rebellious behavior } & \underline{0}-15 \\ \text { restless behavior } & \underline{0-15} \\ \text { dependent behavior } & \underline{0-15} \\ \text { anxious behavior } & \underline{0-18}\end{array}$

$0,3,6,12$

$\mathrm{U}+\mathrm{W}$

2-18

Q-15

0-15

Q-15

0-15

Secondary

Behavior (GIP-28)

Communication (GRGS)

0-84

0.7

$0,3,6,12$

$\mathrm{U}+\mathrm{W}+\mathrm{R}$

Agitation (CMAI-D)

verbal aggression

$0,3,6,12$

$U+W$

Q.30

aggression $\quad 2-36$

physical non-aggression $\quad 0$-36

Resident-specific approach $\quad 0.4$

$0,3,6,12$

$\mathrm{U}+\mathrm{W}$

Functional status (ADL)

$0-12$

$3,6,12$

$U+W+R$

Global assessment functioning

$0-4$

$0,3,6,12$

$U+W$

Change in psychotropic drug use

Nursing home admission and mortality

0-2

$3,6,12$

$3,6,12$

not applicable

$3,6,12$

$U+W+R$

W

$\mathrm{s}$

\section{Professional caregivers}

\section{Primary}

Job satisfaction (MAS-GZ):

$\begin{array}{ll}\text { head of the ward } & 0-12 \\ \text { quality of care } & 0-12 \\ \text { contact with colleagues } & 0-12 \\ \text { contact with residents } & 0-12 \\ \text { opportunities for self-actualization } & 0-12\end{array}$

$0,3,6,12 \quad U / W$

$0-12$

$0-12$

$0-12$

Secondary

Job satisfaction

short version MAS.GZ

$0-\underline{28}$

$0,3,6,12$

U/W

2 study-specific satisfaction-items 'contact with residents' 'good care residents

$0-4$

$0-4$

$0-4$

Bumout (MBI)

general satisfaction-item

depersonalization

Q. 30

emotional exhaustion

0-48

personal accomplishment

$0 . \underline{-42}$

Sick-leave in last $3 / 6$ months (number of days)

Opinion work situation

$\begin{array}{lll}0.92 / 183 & 0,3,6,12 & U / W \\ 0-6 & 3,6,12 & U / W\end{array}$

The underlined scores indicate the most favorable score for each scalelquestion

U: Caregiver(s) day-care Unit, W. Caregiver(s) Ward, R. Representative of the Resident. S: Staff

'The GIP items were scored by two caregivers from the day-care unit (U) and two caregivers of the ward (W) 


\section{DATA MANAGEMENT AND ANALYSES}

A telephonic reminder procedure was used to maximize the response on the various questionnaires and to optimize the completeness of the questionnaires. To prevent dataentry errors, the data were entered twice.

\section{Handling of missing data}

Missing values on items that were a part of a scale or sub-scale were replaced according to the 'mean value of valid sub-tests' principle, i.e., replacement by the mean value calculated from the valid item scores of the scale obtained for the same subject at the same measurement time point. This replacement strategy was only used if less than $25 \%$ of the items of a scale were missing. Missing values on 'single' items were not replaced.

\section{Data analyses}

The data can be characterized as having a hierarchical structure: repeated measurements are nested within residents, and residents are nested within homes for the elderly. This hierarchical structure results in dependencies between measurements at the level of measurement occasions (due to being nested within residents and homes) and at the level of residents (due to being nested within homes) and makes multilevel analysis an appropriate technique for analyzing these data (Bryk and Raudenbush, 1992; Snijders and Bosker, 1999). This technique not only accommodates for such dependencies, but also handles missing data in an adequate way. First of all, all available data are included in the analysis. which implies more power for the analysis than the 'complete cases only' approach employed by other techniques. The multilevel analyses were performed using the MLwiN program (Rasbash et al., 1999).

The analyses focused on differences between the intervention and control homes. Assuming a linear trend for the outcome measures across time, we compared the (unadjusted and adjusted) rate of change (deterioration in most cases) across the two groups.

In addition, the effects of the intervention at short (three months), medium (six months) and long-term intervals (twelve months) were tested. In these analyses no specific relations were assumed between the outcome measure and time. In case a linear trend adequately describes the change across time, the latter approach is a less powerful analysis. To the extent that a linear trend is not present, however, it may offer a more adequate test of the intervention effect.

In these 'overall' analyses, differences between intervention and control homes were tested without considering potential effect modifiers. Therefore additional subgroup analyses were performed. These analyses aim at studying potential modifiers of the effects of emotionoriented care.

All statistical analyses were carried out following the 'intention-to-treat' principle: all homes. regardless of their degree of compliance, were included in the analyses. In addition, per protocol analyses were performed to examine the effect of the intervention as a function of the success of its implementation. These additional (overall and subgroup) analyses were restricted to the primary outcomes measures. In these analyses, the control homes were compared to intervention homes with a good implementation, and to intervention homes with a moderate to poor implementation. To conduct these analyses we asked the teacher of the 
course to give an overall judgment of the success of the implementation of emotion-oriented care (good, moderate or poor) for each of the eight intervention homes. The teacher was blinded with respect to outcomes. The teacher rated three homes as good, three moderate and two poor. In the per protocol analyses, the control homes $(n=8)$ were compared to intervention homes with a good implementation $(n=3)$, and to intervention homes with a moderate to poor implementation $(n=5)$.

\section{REFERENCES}

Alexopoulos, GS, Abrams, RC, Young, RC, \& Shamoian, CA. (1988). Cornell Scale for Depression in Dementia. Biol. Psychiatry, 23(3), 271-284.

Beurskens, AJ, de Vet, HC, Koke, AJ, Lindeman, E, van der Heijden, GJ, Regtop, W, \& Knipschild, PG. (1999). A patient-specific approach for measuring functional status in low back pain. J. Manipulative Physiol. Ther., 22(3), 144-148.

Bryk, AS, \& Raudenbush, SW. (1992). Hierarchical Linear Models, Applications and Data Analysis Methods. Newbury Park, CA: Sage.

Cohen Mansfield, J. (1986). Agitated behaviors in the elderly. II. Preliminary results in the cognitively deteriorated. J. Am. Geriatr. Soc., 34(10), 722-727.

Cohen Mansfield, J, Marx, MS, \& Rosenthal, AS. (1989). A description of agitation in a nursing home. J. Gerontol., 44(3), M77-84

Cohen Mansfield, J, Marx, MS, \& Werner, P. (1992). Agitation in elderly persons: an integrative report of findings in a nursing home. Int. Psychogeriatr., 4 Suppl 2, 221-240.

Cornbleth, T. (1978). Evaluation of goal attainment in geriatric settings. J. Am. Geriatr. Soc., 26(9), 404-407.

de Jonghe, JF, Calis, PJ, \& Boom Poels, PG. (1996). Gedragsdimensies van oudere patienten: Factorstructuur van de Gedragsobservatieschaal voor de Intramurale Psychogeriatrie (GIP). Tijdschr. Gerontol. Geriatr., 27(4), 159-164.

de Jonghe, JF, \& Kat, MG. (1996). Factor structure and validity of the Dutch version of the CohenMansfield Agitation Inventory (CMAI-D) [letter]. J. Am. Geriatr. Soc., 44(7), 888-889.

de Jonghe, JF, Kat, MG, \& de Reus, R. (1994). De validiteit van de Gedragsobservatieschaal voor de Intramurale Psychogeriatrie (GIP): een vergelijking met de BOP en NOSIE-30 in een psychiatrische observatiekliniek voor ouderen. Tijdschr. Gerontol. Geriatr., 25(3), 110-116.

de Jonghe, JF, Ooms, ME, \& Ribbe, MW. (1997). Verkorte Gedragsobservatieschaal voor de Intramurale Psychogeriatrie (GIP-28). Tijdschr. Gerontol. Geriatr., 28(3), 119-123

Dröes, RM. (1991). In beweging. Over psychosociale hulpverlening aan demente ouderen. Meppel: Krips Repro

Droes, RM. (1993). Cornell scale for depression in dementia (Ned. vertaling).

Dröes, RM. (1996). Amsterdamse ontmoetingscentra een nieuwe vorm van ondersteuning voor dementerende mensen en hun verzorgers. Amsterdam: Thesis Publishers.

Folstein, MF, Folstein, SE, \& McHugh, PR. (1975). "Mini-mental state". A practical method for grading the cognitive state of patients for the clinician. J. Psychiatr. Res., 12(3), 189-198.

Katz, S, \& Akpom, CA. (1976). A measure of primary sociobiological functions. Int. J. Health Serv. 6(3), 493-508.

Landeweerd, JA, Boumans, NPG, \& Nissen, JMF. (1996a). Arbeidsvoldoening bij verplegenden en verzorgenden. De Maastrichtse arbeidssatisfactieschaal voor de gezondheidszorg. In CC van Beek \& TC van Dorsten \& GJ Stam (Eds.). Handboek Verpleegkundige innovatie Loghem/Houten: Bohn Stafleu

Landeweerd, JA, Boumans, NPG, \& Nissen, JMJF. (1996b). Bedrijfsgezondheidszorg Studies nr. 11. De Maastrichtse arbeidssatisfactie schaal voor de gezondsheidszorg (MAS-GZ). Maastricht: Universiteit Maastricht.

Maslach, C, \& Jackson, SE. (1986). MBI: Maslach Burnout Inventory; manual research edition. Palo Alto: University of California: Consulting Psychologists Press.

Miller, RJ, Snowdon, J, \& Vaughan, R. (1995). The use of the Cohen-Mansfield Agitation Inventory in the assessment of behavioral disorders in nursing homes. J. Am. Geriatr. Soc., 43(5), 546-549. 
Molloy, DW, Alemayehu, E, \& Roberts, R. (1991). Reliability of a Standardized Mini-Mental State Examination compared with the traditional Mini-Mental State Examination. Am. J. Psychiatry, 148(1), 102-105.

Rasbash, J, Browne, W, Healy, M, Cameron, B, \& Chartton, C. (1999). MLwiN (Version Beta version 1.09.0001). London: Multilevel Models Project Institute of Education.

Schaufeli, W, \& Van Dierendonck, D. (1994). Burnout, een begrip gemeten. De Nederlandse versie van de Maslach Burnout Inventory (MBI-NL). Gedrag and Gezondheid: Tijdschrift voor Psychologie and Gezondheid, 22(4), 153-172.

Schrijnemaekers, VJJ, \& Haveman, MJ. (1993). Eindrapport. Effecten van preventieve poliklinischgeriatrische interventie. Maastricht: Rijksuniversiteit Limburg. Vakgroep Epidemiologie \& Maaslandziekenhuis.

Snijders, TAB, \& Bosker, RJ. (1999). Multilevel Analysis: An introduction to basic and advanced multilevel modeling. London: Sage.

Verstraten, PF. (1988). The GIP: an observational ward behavior scale. Psychopharmacol. Bull., 24(4), 717-719.

Verstraten, PFJ, \& van Eekelen, CWJM. (1987). Handleiding voor GIP. Gedragsobservatieschaal voor de intramurale psychogeriatrie. Nijmegen: Van Loghum Slaterus. 


\title{
Effects of emotion-oriented care on elderly people with cognitive impairment and behavioral problems
}

\author{
Veron JJ Schrijnemaekers' \\ Erik van Rossum ${ }^{1}$ \\ Math JJM Candel ${ }^{2}$ \\ Carla MA Frederiks \\ Mayke MA Derix ${ }^{4}$ \\ Hilde Sielhorst ${ }^{5}$ \\ Piet A van den Brandt ${ }^{\dagger}$
}

\footnotetext{
'Department of Epidemiology, Maastricht University

${ }^{2}$ Department of Methodology and Statistics. Maastricht University

${ }^{3}$ Department of General Practice and Social Medicine, University of Nijmegen

${ }^{4}$ Department of Clinical Psychology. Twenteborg Hospital

${ }^{5}$ Department of General Practice, Maastricht University
} 


\section{ABSTRACT}

This study investigates the effects of emotion-oriented care on the behavior of elderly people with cognitive impairment and behavioral problems. This approach is mainly based on the validation approach, but uses also insights from other approaches like reminiscence and sensory stimulation.

Sixteen homes for the aged with structured day care units were randomly allocated to an intervention or control group. 151 Residents with cognitive impairment and behavioral problems were included in the study. The eight intervention homes received a training program with regard to emotion-oriented care. In the eight control homes usual care was continued. Measurements were performed at baseline and after three, six and twelve months of follow-up (assessment by caregivers and relatives). The primary outcome measure was the change in behavior of the residents.

The results of multilevel analyses (overall, subgroup and per protocol) showed no statistically significant, nor clinically relevant effects in favor of the intervention group on the behavioral outcome measures.

There is insufficient evidence yet to justify the implementation of emotion-oriented care on a large scale. Additional studies are needed in which special attention is given to the implementation process. 


\section{INTRODUCTION}

The aging of the population in western countries has consequences for long term care facilities such as nursing homes and homes for the aged. These facilities will be faced, for instance, with increasing numbers of demented residents with behavior problems. As yet, no effective cure for these residents is available: emphasis is therefore on providing 'the best care possible'.

Several approaches have been developed in psycho-geriatric care. One popular approach to care management of disoriented elderly is so-called 'validation' or 'validation therapy'. Validation has been developed by Feil (Feil, 1967, 1984, 1985, 1989, 1990, 1992; Feil and Wetzler, 1979), who described it as a process of communicating, both verbally and nonverbally, with disoriented elderly people by validating and respecting their feelings. Validation, or validation therapy, can be used for moderately to severely disoriented elderly people. It implies to accept the disoriented elderly person as he or she is, be non-judgmental and share feelings that are freely expressed. Disoriented persons are not forced in 'our reality', instead their perception of the environment is validated. According to Feil (Feil, 1994), validation increases positive affect, decreases negative affect, stimulates communication and restores well-being in disoriented elderly.

Since 1963 validation is more and more used in many institutions in the United States, Canada, Australia and Europe (Feil, 1994). In general, validation is a popular approach among professional caregivers who have a great believe in its effectiveness. In the Netherlands validation is used in $81 \%$ of the nursing homes (Kruyver and Kerkstra, 1996).

We conducted a review of the literature on the effectiveness of validation (Schrijnemaekers et al., 1995). We found sixteen studies of which seven were unpublished. Four studies were conducted in Europe, two in Australia and ten in North America. The sixteen studies used various designs; only three studies were randomized controlled trials (Peoples, 1982; Robb et al., 1986; Toseland et al., 1997). Nearly all studies suffered from serious methodological shortcomings and the results were conflicting. It appeared that the better the methodological quality of the study, the less favorable the outcomes were. From this review it was concluded that there was insufficient evidence yet for the claimed effectiveness of validation and that additional research, using more rigorous methods, was needed.

In the Netherlands there is a tendency to apply validation in combination with other approaches such as sensory-stimulation and reminiscence. This combined approach, mainly based on the validation approach, is called emotion-oriented care (Finnema, 2000; Finnema et al., 1998). In a randomized controlled trial (RCT) we studied the effects of emotionoriented care on elderly people with moderate to severe cognitive impairment and behavioral problems and on professional caregivers in homes for the elderly. In this chapter we present the results for the elderly people.

\section{METHODS}

Details of the study design have already been discussed in chapter 3 . In this chapter we confine ourselves to a general outline of the design and focus on the outcomes for the residents.

The study was performed among residents with cognitive and behavioral problems who attended the structured day-care unit in 16 homes for the elderly in the Netherlands (province of Limburg) in the years 1997-1999. After pre-stratification the sixteen homes were randomly allocated to an intervention or control group and subsequently a selection of the residents 
was made. The eight intervention homes received an emotion-oriented care training. In the eight control homes usual care was continued. Measurements were performed at baseline and after three, six and twelve months of follow-up.

The study was approved by the medical ethical committee (IRB approval) of the Maastricht University Hospital.

\section{Homes for the elderly}

Homes for the elderly are residential care facilities with residents with care needs, in terms of physical and mental impairments, that resemble almost those of nursing homes patients. The sixteen homes included in the study had not yet implemented an emotion-oriented care approach in the daily care for their residents and had a day-care unit for psycho-geriatric residents. At these care units a structured day-care program is offered to psycho-geriatric residents by occupational therapists and nursing caregivers. The residents involved stay at the day-care unit in the daytime and return to their rooms during the evening.

\section{Pre-stratification and randomization}

Randomization was performed on the level of homes. The homes were pre-stratified before randomization on two prognostic characteristics: the capacity of the day-care unit and the degree of care innovation in the homes (presence of resident-oriented care-plans and a system of resident-allocation). On the basis of these two characteristics eight pairs of homes were formed. Next, the homes within each pair were randomly assigned to the intervention or control group.

\section{Participants}

Residents had to fulfill the following selection criteria.

Presence of moderate to severe cognitive impairment and behavioral problems. Cognitive impairment was assessed by means of the standardized Mini Mental State Examination (MMSE) (Folstein et al., 1975; Molloy et al., 1991). The screening interviews were conducted by three trained researchers. Residents with scores below 21 were included in the study (range of scores: $0-30$ ).

The presence of behavioral problems was assessed by means of a short version of the Dutch Behavioral Rating Scale for Psycho-geriatric Inpatients (Gedragsobservatieschaal voor de Intramurale Psychogeriatrie (GIP-28) (de Jonghe et al., 1997; Verstraten and van Eekelen, 1987). This scale was completed independently by caregivers of the structured daycare program and caregivers of the ward where the residents lived. Residents with scores of 30 or more were included in the study (range of scores: 24-96).

Written informed consent, obtained by a legal representative of the resident (usually a daughter or son).

Participation in a structured day-care program for at least five half-days a week and residence in the home for the elderly for at least two months before the start of the study.

Not bedridden, sufficient hearing functions, absence of an unstable psychiatric disorder (except dementia), presence of an adequate level of premorbid intellectual capacity, and absence of expected loss to follow-up from the study during the first six months.

According to a conservative (1-bèta $=90 \%$, alpha $=5 \%$ (two-sided)) sample size calculation, 60 persons per group were needed to detect a clinical relevant effect on the behavior of the residents (a difference of 10 points on the average score of the GIP-28 between the two 
groups). Taking into account a loss to follow-up of about $25 \%$ during the one-year follow-up, 80 residents were needed in each study group.

\section{Intervention}

The experimental intervention (intervention homes) was compared to usual care (control homes). The intervention offered to the eight intervention homes consisted of three successive elements: clinical lessons, a training program, and supervision meetings, spread over a total period of eight months. All three elements of the intervention were organized and given by the same qualified and experienced teacher of a professional training organization.

\section{Clinical lessons}

Every intervention home first received two identical lessons of approximately one hour. These lessons were offered to all employees (e.g. receptionist, domestic staff, nurses) and aimed at informing employees about the study and the general ideas behind emotionoriented care.

\section{Training program}

Eight caregivers ('students') in each intervention home received a training program in emotion-oriented care. These students had to be key figures in the daily care for residents with cognitive impairment and behavioral problems and had to be able to implement the emotion-oriented care approach in their home. In addition they had to meet the following inclusion criteria: 1 . work for at least half a year in the home for the elderly: 2 . being employed for at least 18 hours a week; 3 . work for at least one year in geriatric care; and 4. have at least a secondary vocational training. On average five caregivers from the day-care unit and three from the wards were selected for the training. The students received a six-day training program. The first four days were given at intervals of two weeks and the last two training days had an interval of four weeks. The training was organized in-company.

The training program had various goals. First, participants were taught on the dementia syndrome and various care models for communicating with demented elderly (e.g. Validation, Reminiscence, sensory stimulation). Furthermore, much attention was paid to the inequality of the resident-caregiver relation, the importance of going deeply into and trying to understand the residents' perception of the environment, and the attitude towards and verbal and nonverbal communication with the resident (including the use of sensory perceptions like touch, smell, vision, hearing). Finally, the implementation of practical skills received much attention. Various didactic methods, such as teaching, homework, class assignments and exercises, role-playing and video-presentations, were used during the training.

\section{Supervision meetings}

Three supervision meetings (half-a-day each) were offered to support the implementation of emotion-oriented care in daily care. These meetings were again offered in-company over a period of four months after the training was finished. The meetings were 'tailor-made' for every intervention home. Depending on the bottlenecks mentioned by the participants in the first supervision meeting. goals, agreements and evaluations were discussed with those involved.

In the eight control homes the usual care was continued. To increase the willingness to participate, the control homes were promised to receive the training program after the end of the study. 


\section{Outcome measures and timing of measurements}

The primary outcome measure was the behavior of the residents. We used parts of the Dutch Behavior Observation Scale for Psycho-geriatric Inpatients (Gedragsobservatieschaal voor de Intramurale Psychogeriatrie (GIP)) (Verstraten and van Eekelen, 1987). The GIP is a psycho-geriatric behavior observation scale for institutionalized elderly people. The scale contains 82 items divided over fourteen sub-scales ${ }^{1}$ that can be used separately. For every item the observer has to rate the frequency of the behavior during the last two weeks on a 4point scale. For our study seven of the fourteen sub-scales were selected, namely: nonsocial behavior, apathetic behavior, loss of decorum, rebellious behavior, restless behavior, dependent behavior and anxious behavior.

The validity and reliability of the GIP is adequate to good (de Jonghe et al., 1996; de Jonghe et al., 1994; de Jonghe et al., 1997; Verstraten, 1988a, 1988b; Verstraten and van Eekelen, 1987).

Secondary outcome measures were some other behavior measures, namely a short version of the GIP, called GIP-28 (de Jonghe et al., 1997; Verstraten and van Eekelen, 1987), communication, measured by means of 7 items $(30$ to $34,40,41)$ of the Geriatric Residents Goal Scale (GRGS) (Cornbleth, 1978; Dröes, 1991), three syndromes of agitation, measured with the CMAI(-D) (Cohen Mansfield Agitation Inventory (Dutch version)) (Cohen Mansfield, 1986; de Jonghe and Kat, 1996), the change in frequency of three resident-specific disturbing behaviors listed at baseline $(0=$ improvement $/ 4=$ deterioration), functional status, measured by means of an Activities of Daily Living (ADL) scale (Schrijnemaekers and Haveman, 1993), a global assessment of functioning on a 5-point scale ( $0=$ very improved $/ 4=$ very deteriorated), change in psychotropic drug use $(0=$ decrease, $1=$ the same, $2=i n c r e a s e)$ and number of nursing home admissions and mortality.

The primary and secondary outcome measures were measured at various time points and often information about a specific outcome measure was collected from several sources. Table 1 presents the timing and sources of the measurements.

The assessment of the primary outcomes by the caregivers of the day-care unit after twelve months was considered as the key outcome in our study. These caregivers are most closely involved in the daily care for the study participants and because it takes some time to implement a new care approach, the possible effects are most likely to occur after twelve months.

Staff received oral and written information about the use of the scales. The same staff rated the same resident throughout the follow-up.

\footnotetext{
1. The fourteen sub-scales of the GIP are: nonsocial behavior (8 tems), apathetic behavior ( 6 tems), distorted consciousness (7 tems), loss of decorum ( 5 items), rebellious behavior ( 5 items), incoherent behavior ( 5 items), distorted memory ( 7 tems), disonented behavior ( 5 items), senseless repetitive behavior ( 5 tems), restless behavior ( 5 items), suspicious behavior ( 7 hems). melancholic or sorrowtul behavior ( 6 items), dependent behavior ( 5 items) and anxious behavior ( 6 tems)
} 
Table 1. Overview of outcome measures used (including sources) for the 151 residents in 16 homes for the elderly

\begin{tabular}{|c|c|c|c|}
\hline Outcome measures & Theoretical ranges & $\begin{array}{l}\text { Measurement } \\
\text { cccasions in months }\end{array}$ & Sources" \\
\hline \multicolumn{4}{|l|}{ Primary } \\
\hline Behavior $(G I P)$ : & & $0,3,6,12$ & $U+W$ \\
\hline nonsocial behavior & $0-24$ & & \\
\hline apathetic behavior & Q-18 & & \\
\hline loss of decorum & Q-15 & & \\
\hline rebellious behavior & Q-15 & & \\
\hline restless behavior & Q-15 & & \\
\hline dependent behavior & Q-15 & & \\
\hline anxious behavior & Q-18 & & \\
\hline \multicolumn{4}{|l|}{ Secondary } \\
\hline Behavior (GIP-28) & $0-84$ & $0,3,6,12$ & $U+W+R$ \\
\hline Communication (GRGS) & Q-7 & $0,3,6,12$ & $U+W$ \\
\hline Agitation (CMAL-D): & & $0,3,6,12$ & $U+W$ \\
\hline verbal aggression & $0-30$ & & \\
\hline aggression & Q-36 & & \\
\hline physical non-aggression & Q-36 & & \\
\hline Resident-specific approach & $0-4$ & $3,6,12$ & $U+W+R$ \\
\hline Functional status (ADL) & $\underline{0}-12$ & $0,3,6,12$ & $U+W$ \\
\hline Global assessment functioning & $0-4$ & $3,6,12$ & $U+W+R$ \\
\hline Change in psychotropic drug use & $\underline{0}-2$ & $3,6,12$ & w \\
\hline Nursing home admission and mortality & not applicable & $3,6,12$ & $\mathrm{~S}$ \\
\hline
\end{tabular}

"The underlined scores indicate the most favorable score for each scale/question

U: Caregiver(s) day-care Unit, W: Caregiver(s) Ward, R. Representative of the Resident, S Staff

The GIP items were scored by two caregivers from the day-care unit (U) and two caregivers of the ward (W)

\section{Data management and analysis}

Handling of missing data

Missing values on items that were a part of a scale or sub-scale were replaced according to the 'mean value of valid sub-tests' principle, i.e., replacement by the mean value calculated from the valid item scores of the scale obtained for the same subject at the same measurement time point. This replacement strategy was only used if less than $25 \%$ of the items of a scale were missing. Missing values on 'single' items were not replaced.

Data analysis

In view of the hierarchical structure of the data (measurement occasions nested within caregivers, who are nested within homes for the elderly), resulting in dependencies between measurements, multilevel analysis was used for analyzing the data (Bryk and Raudenbush. 1992; Snijders and Bosker, 1999). This technique not only accommodates dependencies, but also handles missing data in an adequate way (all available data are included in the analysis) (Snijders and Bosker, 1999). Ordinal outcome measures (i.e. resident-specific approach, global assessment of functioning and change of psychotropic drug use) were analyzed according to a multilevel ordered logit model. All other outcome measures were analyzed 
with a linear multilevel model, which is apt for continuous outcome measures. Both types of analyses were performed using the MLwiN program (Rasbash et al., 1999).

Assuming a linear trend for the outcome measures across time, we compared the (unadjusted and adjusted) rate of change (deterioration in most cases) across the two groups. Covariates in the adjusted analyses were the following baseline characteristics: psychotropic drug use, cognitive impairment (MMSE) and age. In addition, the effects of the intervention at short (three months), medium (six months) and long term intervals (twelve months) were tested. In the latter analyses, no specific relations were assumed between the outcome measure and time of measurement.

In these 'overall' analyses differences between intervention and control homes were tested without considering potential effect modifiers. Therefore additional subgroup analyses were performed. These analyses aim at studying potential modifiers of the effects of emotionoriented care, based on three characteristics measured at baseline: psychotropic drug use, cognitive impairment and age.

All statistical analyses were carried out following the 'intention-to-treat' principle. In addition, per protocol analyses were performed to examine the effect of the intervention as a function of the success of its implementation. These additional analyses were restricted to the primary outcomes measures as obtained from the caregivers of the day-care unit. In these analyses, the control homes were compared to intervention homes with a good implementation, and to intervention homes with a moderate to poor implementation. To conduct these analyses we asked the teacher of the course to give an overall judgment of the success of the implementation of emotion-oriented care (good, moderate or poor) for each of the eight intervention homes. The teacher was blinded with respect to outcomes. The teacher rated three homes good, three moderate and two poor. In the per protocol analyses, the control homes $(n=8)$ were compared to intervention homes with a good implementation $(n=3)$, and to intervention homes with a moderate to poor implementation $(n=5)$.

\section{RESULTS}

The residents were recruited from 228 residents who attended the day-care units in the sixteen homes for the elderly. After pre-selection 38 residents were excluded, mainly because of expected transfer to another housing facility (in particular to a nursing home) in short-term. Subsequently, the legal representatives of the remaining 190 residents were asked for a written informed consent of which 20 refused. The remaining 170 residents were screened on cognitive and behavioral impairment. Eleven residents were excluded because their cognitive impairment was only mild. No resident had to be excluded because of the absence of behavioral problems. From the remaining 159 residents, eight dropped out just before the start of the intervention (four persons died and four moved to a nursing home). Finally, 151 residents were included and the homes were randomized: 77 residents in the intervention homes and 74 in the control homes.

Ninety percent of the study population was female and the average age was 85 years. The residents had already lived on average for 3.5 years in the homes and participated on average twelve daily periods (mornings, afternoons or evenings) per week in the day-care program. Table 2 shows that the intervention and control group were to a large extent comparable at baseline. As far as small differences were present these were accounted for in the analyses. 
Table 2. Comparison between the intervention $(n=77)$ and control $(n=74)$ group residents on baseline characteristics

\begin{tabular}{|c|c|c|c|c|c|}
\hline \multirow{2}{*}{$\begin{array}{l}\text { Characteristic } \\
\text { Gender: female (n, \%) }\end{array}$} & \multirow{2}{*}{ Empirical range" } & \multicolumn{2}{|c|}{ Intervention group ( $n=77$ ) } & \multicolumn{2}{|c|}{ Control group } \\
\hline & & 70 & $(90 \%)$ & 66 & $(89 \%$ \\
\hline Psychotropic drug use: yes (n, \$) & - & 42 & $(55 \%)$ & 42 & $(57 \times$ \\
\hline Age (years, sd) & $77 \cdot 99$ & 84.3 & $(5.5)$ & 85.9 & $(5.6)$ \\
\hline Residing in home for the elderly (years, sd) & $0-19$ & 3.5 & $(3.4)$ & 3.7 & (2.3) \\
\hline Cognitve impairment (MMSE) (average score, sd) & $0-20$ & 10.8 & (5.1) & 11.3 & (5.1) \\
\hline \multicolumn{6}{|l|}{ Behavior (7 GIP sub-scales): } \\
\hline nonsocial behavior (average score, sd) & $0-21$ & 8.2 & $(4.7)$ & 9.5 & (5.3) \\
\hline apathetic behavior (average score, sd) & Q-18 & 7.5 & $(3.4)$ & 7.3 & $(40)$ \\
\hline loss of decorum (average score, sd) & Q-13 & 3.6 & $(3.4)$ & 38 & (3.1) \\
\hline rebellious behavior (average score, sd) & Q-11 & 42 & $(2.4)$ & 4.5 & (29) \\
\hline restless behavior (average score, sd) & $0-14$ & 4.8 & (2.9) & 4.2 & (2.8) \\
\hline dependent behavior (average score, sd) & Q-15 & 6.0 & (3.3) & 5.8 & (3.7) \\
\hline anxious behavior (average score, sd) & Q-18 & 3.4 & $(3.8)$ & 3.4 & (38) \\
\hline
\end{tabular}

The underlined scores indicate the most favorable score for each scale

Morning, aftemoon, evening: per week

"Scores from the day-care unit

"p<0.05; $"$ p $<0.01 ; \cdots p<0.001$

Table 3 shows the response and loss to follow-up over time per study group. The response rates are equal for the intervention and control groups at the various time points. The cumulative mortality rate in the total population was $6 \%, 14 \%$ and $27 \%$ after three, six and twelve months respectively. There were no differences in mortality between the two groups. The cumulative rates of loss to follow-up caused by nursing home admission were $1 \%, 4 \%$ and $9 \%$ after the three, six and twelve months respectively. These rates also showed no differences between the intervention and control groups.

Table 3. Numbers (percentages) response and loss-to-follow-up for the measurements at the day-care unit per group $(1=$ Intervention $(n=77), C=$ Control $(n=74))$

\begin{tabular}{|c|c|c|c|c|c|c|c|c|c|c|c|c|}
\hline \multirow[t]{3}{*}{ Measurement } & \multicolumn{4}{|c|}{ Response } & \multicolumn{8}{|c|}{ Loss-to-follow-up } \\
\hline & \multirow{2}{*}{\multicolumn{2}{|c|}{1}} & \multirow{2}{*}{\multicolumn{2}{|c|}{ C }} & \multicolumn{4}{|c|}{ Cumulative mortality } & \multicolumn{2}{|c|}{$\begin{array}{l}\text { Cumulative nursing home } \\
\text { admission }\end{array}$} & \multicolumn{2}{|l|}{ Other" } \\
\hline & & & & & 1 & & C & & 1 & C & 1 & C \\
\hline Baseline & 77 & $(100)$ & 74 & $(100)$ & - & & . & & . & - & . & . \\
\hline 3 months & 69 & $(90)$ & 69 & (93) & 5 & (6) & 4 & ( 5$)$ & 1 (1) & . & $2(3)$ & 1 (1) \\
\hline 6 months & 61 & ( 79) & 59 & $(80)$ & 10 & (13) & 11 & (15) & $3(4)$ & 3 (4) & $2(3)$ & $2(3)$ \\
\hline 12 months & 48 & $(62)$ & 45 & (61) & 21 & $(27)$ & 20 & (27) & $7(9)$ & $6(8)$ & $2(3)$ & $2(3)$ \\
\hline
\end{tabular}

Residents no longer participating at the day-care unit or admitted to long-term hospital care 
Table 4. Unadjusted and adjusted estimated differences between the intervention and control group on the primary and secondary outcome measures according to the caregivers of the residents (linear trend multilevel analyses)

\begin{tabular}{|c|c|c|c|c|}
\hline \multirow[t]{3}{*}{ Outcome measures } & \multicolumn{4}{|c|}{ Estimated differences per months in linear trend analyses ${ }^{a}$} \\
\hline & \multicolumn{2}{|c|}{ Caregivers of day-care unit about residents } & \multicolumn{2}{|c|}{ Caregivers of ward about residents } \\
\hline & Unadjusted & Adjusted & Unadjusted & Adjusted \\
\hline \multicolumn{5}{|l|}{ Behavior (GIP): } \\
\hline nonsocial behavior & +0.02 & +0.04 & +0.05 & +0.05 \\
\hline apathetic behavior & +0.08 & +0.09 & -0.02 & -0.01 \\
\hline loss of decorum & +0.01 & +0.01 & -0.00 & -0.00 \\
\hline rebellious behavior & +0.02 & +0.02 & +0.07 & +0.07 \\
\hline restless behavior & +0.05 & +0.05 & -0.07 & -0.07 \\
\hline dependent behavior & +0.03 & +0.03 & +0.06 & +0.06 \\
\hline anxious behavior & +0.08 & +0.08 & +0.02 & +0.03 \\
\hline Behavior (GIP-28) & +0.10 & +0.12 & +0.10 & +0.07 \\
\hline Communication (GRGS) & -0.03 & -0.02 & -0.00 & -0.00 \\
\hline \multicolumn{5}{|l|}{ Agitation (CMAI-D): } \\
\hline verbal aggression & +0.04 & +0.04 & -0.14 & -0.14 \\
\hline aggression & +0.03 & +0.04 & -0.13 & -0.13 \\
\hline physical non-aggression & +0.03 & +0.03 & -0.14 & -0.14 \\
\hline \multicolumn{5}{|l|}{ Resident-specific approach: } \\
\hline first disturbing behavior & +0.01 & +0.01 & +0.01 & +0.01 \\
\hline second disturbing behavior & +0.00 & +0.00 & +0.00 & +0.00 \\
\hline third disturbing behavior & +0.00 & +0.00 & -0.01 & -0.01 \\
\hline Functional status (ADL) & b & b & -0.00 & +0.00 \\
\hline Global assessment functioning & -0.00 & -0.00 & -0.00 & -0.00 \\
\hline Change in psychotropic drug use & t & c & -0.00 & -0.00 \\
\hline
\end{tabular}

-The estimated difference is the difference in deterioration per month between the control and intervention group. A positive difference implies a higher deterioration in the control group

- Excluded because of too many remaining missing values after substitution (many ADL activities are not performed at the day-care unit) Only measured at the ward "p<0.05: $" p<0.01, \cdots p<0.001$

Table 4 presents the unadjusted and adjusted estimated differences per months of the linear trend analyses according to the observations of the caregivers of the day-care units and the caregivers of the wards on the primary and secondary outcome measures. An estimated difference of, for example, +0.02 per month for nonsocial behavior, assessed by caregivers of the day-care unit, means that the control group deteriorates on average +0.02 points more on nonsocial behavior than the intervention group. Assuming a linear trend, the estimated difference after twelve months (the end of our study) is $+0.2\left(=12^{*} 0.02\right)$.

Although many estimated differences are in favor of the intervention group (especially according to the caregivers of the day-care units), the differences are small and not clinically relevant. All differences are also not statistically significant. 
Next, separate analyses were performed for the short ( 3 months), medium (6 months) and long term (12 months) for the same outcome measures and sources as described in table 4 (see table 5). These analyses do not assume a specific relationship between the outcome measure and time. Only after six months statistically significant differences were found between the two study groups for two outcome measures: anxious behavior (GIP) and physical non-aggressive behavior (CMAI-D). The control group had 1.8 points $(p<0.05)$ more deterioration after six months compared to the intervention group on the sub-scale anxious behavior and the control group had a $2.3(p<0.01)$ higher (better) score after six months in comparison with the intervention group on the sub-scale physical non-aggressive behavior.

Table 5. Estimated differences between the intervention and control group on the primary and secondary outcome measures according to the caregivers of the residents (multilevel analyses per time period)

Outcome measures

Estimated differences per time period"

Caregivers of day-care unit about residents Caregivers of ward about residents

After 3 months After 6 months Affer 12 months After 3 months After 6 months After 12 months

Behavior (GIP)

nonsocial behavior

apathetic behavior

loss of decorum

rebellious behavior

restless behavior

dependent behavior

anxious behavior

Behavior (GIP-28)

Communication (GRGS)

Agitation (CMAI-D):

verbal aggression

aggression

physical non-aggression

Resident-specific approach:

first disturbing behavior

second disturbing behavior

third disturbing behavior

Functional status (ADL)

Global assessment functioning

Change in psychotropic drug

use

+0.35
+0.52
+0.47
+0.36
+0.25
+0.31
+0.81

$+1.13$

$-0.06$

$-021$

$+1.54$

$+0.59$

$+0.70$

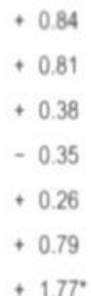

$+0.08$

$+0.94$

$+0.18$

$+0.21$

$+0.37$

$+0.24$

$+0.87$

$+0.77$

$-0.27$

$+1.33$

- 0.37

$+1.52$

$-0.34$

$+0.90$

$-0.06$

$+0.78$

$+0.41$

- 0.07

$-1.10$

$-1.41$

$+0.67$

$-0.87$

- 0.83

- 1.18

$+0.97$

- 0.28

$-2.26 "$

$-1.27$

The estimated difference is the difference in deterioration after 3,6 and 12 month between the control and intervention group. A positive difference implies a higher deterioration in the control group

"Excluded because of too many remaining missing values after substitution (many ADL activities are not performed at the day-care unit) Only measured at the ward

"p<0.05: $\cdots p<0.01: \cdots p<0.001$ 

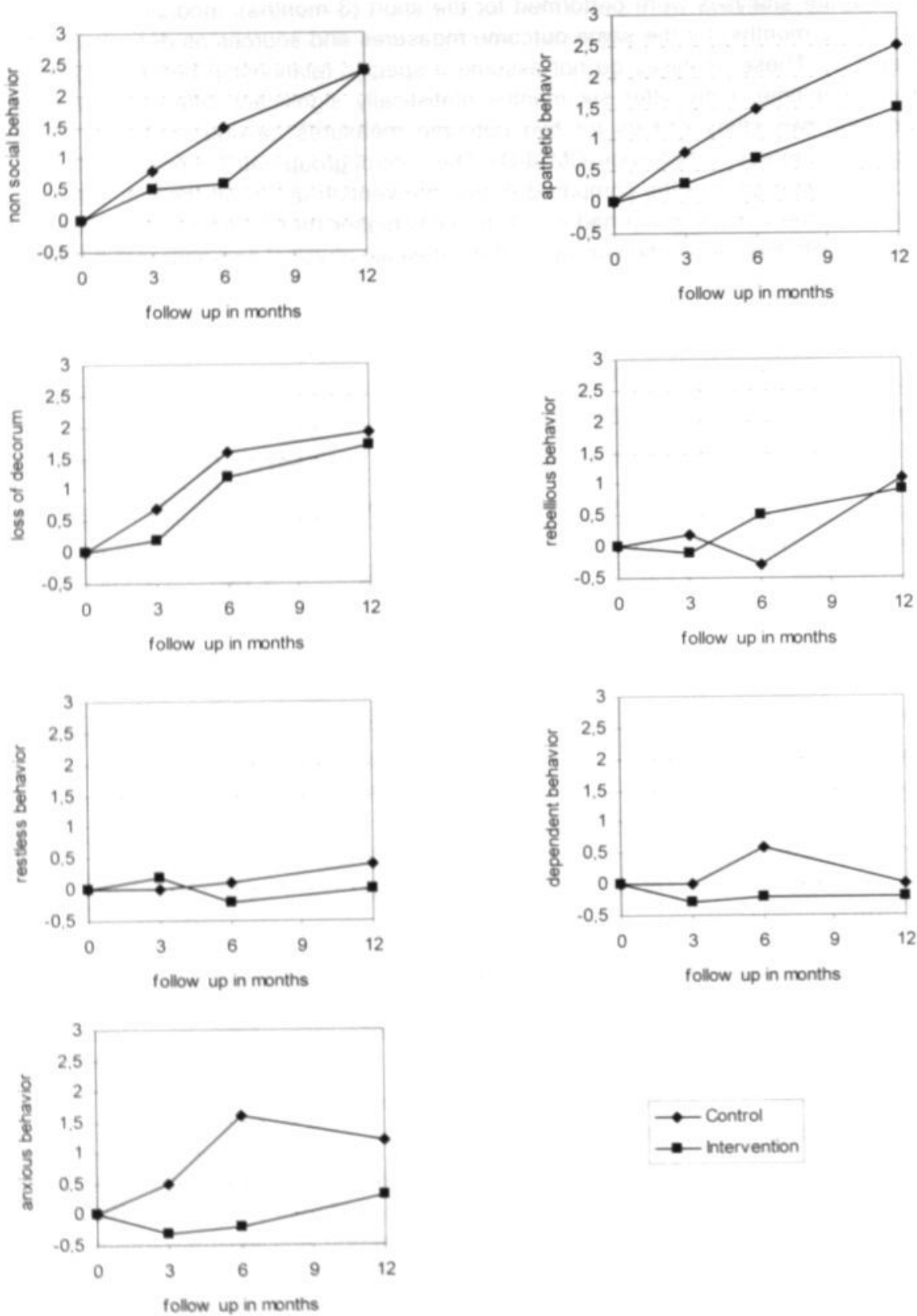

Figure 1. The average deterioration and/or improvement on the primary outcome measures (7 GIP scales) according to the caregivers of the day-care unit for different time points 
Figure 1 shows the average change over time for the three time points (3,6 and 12 months) on the primary outcome measures ( 7 GIP scales) assessed by the caregivers of the day-care unit. These graphs show that the deterioration is somewhat less for the intervention group on five GIP scales (loss of decorum, nonsocial, apathetic, dependent and anxious behavior) over the period of one year. However, only one assessment (anxious behavior after six months) is, as mentioned earlier, statistically significant.

With respect to the observations of the representatives of the residents, restricted to three outcome measures, the same unadjusted and adjusted linear trend analyses as well as analyses per time period (three, six and twelve months) were performed. These results also showed only small and no statistically significant differences between the study groups (see table 6). Table 6. Estimated differences between the intervention and control group according to the representatives of the residents
(linear trend multilevel analyses and multievel analyses per time penod)

Outcome measures

Analyses linear trends Analyses per time period

Estimated difference per month Estimated difference Estimated difference Estimated difference

Behavior (GIP-28)

Resident-specific approach:

first disturbing behavior

second disturbing behavior

third disturbing behavior

Global assessment functioning

\section{Analyses linear trend"
Estimated difference per month
Unadjusted Adjusted}

$\begin{array}{ll}-0.07 & -0.07\end{array}$

$-0.00$

$+0.01$

$+0.00$

$+0.01$
$-0.04$

$+0.06$

$+0.05$

$+0.04$

$-0.01$
$-1.42$

$+0.03$

$+0.12$

$+0.01$

$-0.01$
$-0.52$

$-0.04$

$+006$

$+0.03$

$-0.24$

The estimated difference is the difference in deterioration or improvement per month between the control and intervention group the estimated difference is the difference in detenoration or improvement after 3,6 and 12 months between the control and intervention group

Positive difference implies a better score for the intervention group ; $p<0$ 0. $;$; $p<0.01 ; \cdots p<0.001$

The subgroup analyses showed no statistically significant results. The effect of the intervention apparently does not depend on the age of the resident, the degree of cognitive impairment and psychotropic drug use at baseline.

Finally, per protocol analyses (overall and subgroup) were conducted for the primary outcomes as measured by the caregivers of the day-care unit. In these analyses, the control homes $(n=8)$ were compared to intervention homes with a good implementation $(n=3)$, and to intervention homes with a moderate to poor implementation $(n=5)$.

Only for the analyses for the short, medium and long term separately, three statistically significant results were found after six months and one after twelve months. The intervention homes with a moderate to poor implementation showed less deterioration after six months compared to the control homes on the sub-scales nonsocial behavior $(p<0.01)$ and anxious behavior $(p<0.05)$. The control homes had a lower (=better) score after six months in comparison with the intervention homes with a good implementation on the sub-scale rebellious behavior $(p<0.05)$. The intervention homes with a good implementation scored better on anxious behavior after twelve months of follow-up $(p<0.05)$. 


\section{Discussion}

One of the aims of emotion-oriented care is to reduce problem behavior in elderly people with moderate to severe cognitive impairment. We were unable to confirm this presumed beneficial effect. The various behavioral outcome measures showed no statistically significant nor clinically relevant results in favor of the intervention group. These results were consistent for all analyses that were performed (overall, subgroup and per protocol) and for the different sources (caregivers day-care units and wards and representatives of the resident). The six statistically significant results after six and twelve months (only partly in favor of the intervention homes), which were probably due to chance (multiple-testing), do not alter these overall findings.

Several explanations for these findings can be considered. One may be that emotionoriented care has no effect on the behavior of residents in homes for the elderly with moderate to severe cognitive impairment and behavioral problems. Other reasons may relate to various sources of bias and choices in the design and conduct of our study. We will therefore discuss the adequacy and comparability of the study population, outcome measures and intervention.

\section{Adequacy}

The study population in our study consisted of 151 residents in homes for the elderly with moderate to severe cognitive impairment and behavioral problems. This target population was in accordance with the target population for emotion-oriented care approaches.

The outcome measures used assess the most important characteristics of interest (problem behavior) and were the most sensitive, reliable and valid scales available in Dutch versions.

The relatively intensive intervention (two clinical lessons, a six-day training for eight caregivers and three supervision meetings) was organized and given by a qualified and motivated teacher. An evaluation at the end of the six-day training showed that the participants were (very) positive about the training and the teacher. The absence-rate at the training was (only) $9 \%$, of which almost half (4\%) was caused by illness.

\section{Comparability}

To enhance the comparability of our two study groups, the homes were pre-stratified and randomized at the level of the homes. A comparison of various baseline characteristics showed hardly any differences between the two groups. Nevertheless, adjusted analyses were performed to control for small differences. Also the loss to follow-up during the one-year period was equally distributed over the study groups.

To assess the outcome measures for the residents we used three sources: caregivers of the day-care unit, caregivers of the ward and representatives of the residents. They were, from different perspectives, capable of assessing the behavior of the residents. Blinded observations were not possible. However, because non-blinded observations usually lead to an overestimation of effects, this does not explain the absence of an effect in our study.

The intervention in our trial was far more intensive than the usual training programs caregivers receive in homes for the elderly. Nevertheless, it is still possible that the intervention did not result in enough contrast between the study groups. On the one hand it is possible that the control homes already use the emotion-oriented care approach 'spontaneously' (contamination), and on the other hand the implementation may not have been optimal in the intervention homes. 
To obtain some insight into the implementation of emotion-oriented care, a qualitative study (observations and interviews) was additionally performed. The observations (one day at the day-care unit in four intervention and four control homes), eleven months after the baseline measurement, showed that the emotion-oriented care seemed not (yet) very well observable in the homes. Besides, no clear differences in communication and interaction with the residents between the intervention homes and control homes became visible. Interviews with management and caregivers (twelve months after the start of the study) in half of the intervention homes indicated that there may be many (mainly organizational) bottlenecks which can hinder the implementation of the intervention (van Heusden et al., 1999). It appears to be 'hard work' to implement new care approaches 'home-wide'.

On the other hand, no clear effects were found in our per protocol analyses, where intervention homes with a successful implementation were compared to the control homes. Given the foregoing, it is not likely that possible (organizational) bottlenecks were of overriding importance for the absence of effects in our study.

Our results on the behavior of residents are to a large extent consistent with other quantitative studies on the effectiveness of validation or emotion-oriented care approaches. Among the many studies conducted on the effectiveness of validation (Schrijnemaekers et al., 1995) there are only three randomized controlled studies (Peoples, 1982; Robb et al., 1986; Toseland et al., 1997). The methodologically best performed study with larger study groups was that of Toseland et al. (1997). They compared nursing home residents who were assigned to a validation group $(n=31)$, a social contact group $(n=29)$ and a control group $(n=28)$ in the USA. The duration of the group sessions in both the validation and the social contact group was thirty minutes, four times a week for one year. The follow-up measurements (regarding psycho-social functioning, agitated and positive behavior, medication and use of physical restraints) took place after three and twelve months. The results of this study provided limited support for the effectiveness of group validation for nursing home residents with dementia. Although the nursing staff reported some reduction on agitated behavior, the non-participant observers did not confirm these reductions. There were no significant effects on all the other outcome measures such as psychological functioning, positive behavior, medication and use of physical restraints.

Approximately simultaneously with our study, another study started on the effectiveness of emotion-oriented care in nursing homes (Finnema, 2000; Finnema et al., 1998). Finnema (2000) studied the effects (cognitive, emotional and social adaptation) of emotion-oriented care on demented residents $(n=146)$ in nursing homes in the Netherlands. All sixteen selected wards in nursing homes first received a basic training to meet the conditions for quality of care of the Dutch Association for Nursing Home Care. Next, employees on eight intervention wards received an extensive training: 230 nurses and many persons from paramedical disciplines received a basic training of two days, 75 caregivers received additionally a 'workers' training of seven days and fourteen participants also received a 10day consultant training. Besides, there was training on the job for the wards and consultants. The follow-up measurement took place after seven months. The results of this study provide also limited support for the effectiveness of emotion-oriented care. Only for two (small) subgroups statistically significant results were found on one of the 9 outcome measures. So even in case of a more intensive intervention (Finnema, 2000), no substantial reduction in problem behavior could be identified in a well-performed RCT.

In conclusion, our results, and those of the other large scale RCTs (Finnema, 2000; Toseland et al., 1997), do not confirm the presumed beneficial effects of emotion-oriented care on problem behavior in elderly people with cognitive impairment. These findings are in 
contrast with the general positive opinion in the nursing field regarding approaches like emotion-oriented care or validation.

In our opinion, there is insufficient scientific evidence yet to justify the implementation of emotion-oriented care on a large scale. Additional evidence from new studies is needed, in which special attention is given to the optimization of the training and the implementation strategy of emotion-oriented care.

\section{ACKNOWLEDGEMENTS}

The authors are grateful to the residents and their representatives as well as to the caregivers and their staff for their commitment to our study. We also would like to thank Jos Slangen and Marijke Moll (department of Epidemiology, Maastricht University) for their help in data collection and management and Hilde Ham (teacher CEREIN) for organizing and performing the intervention in our study.

This study was financially supported by grants from the National Center for Nursing \& Care (LCVV), the Province of Limburg and the VSB-fund.

\section{REFERENCES}

Bryk, AS, \& Raudenbush, SW. (1992). Hierarchical Linear Models, Applications and Data Analysis Methods. Newbury Park, CA: Sage.

Cohen Mansfield, J. (1986). Agitated behaviors in the elderly. II. Preliminary results in the cognitively deteriorated. J. Am. Geriatr. Soc., 34(10), 722-727.

Cornbleth. T. (1978). Evaluation of goal attainment in geriatric settings. J. Am. Geriatr. Soc., 26(9), 404-407.

de Jonghe, JF, Calis, PJ, \& Boom Poels, PG. (1996). Gedragsdimensies van oudere patienten: Factorstructuur van de Gedragsobservatieschaal voor de Intramurale Psychogeriatrie (GIP). Tijdschr. Gerontol. Geriatr., 27(4), 159-164.

de Jonghe, JF, \& Kat, MG. (1996). Factor structure and validity of the Dutch version of the CohenMansfield Agitation Inventory (CMAI-D) [letter]. J. Am. Geriatr. Soc., 44(7), 888-889.

de Jonghe, JF, Kat, MG, \& de Reus, R. (1994). De validiteit van de Gedragsobservatieschaal voor de Intramurale Psychogeriatrie (GIP): een vergelijking met de BOP en NOSIE-30 in een psychiatrische observatiekliniek voor ouderen. Tijdschr. Gerontol. Geriatr., 25(3), 110-116.

de Jonghe, JF, Ooms, ME, \& Ribbe, MW. (1997). Verkorte Gedragsobservatieschaal voor de Intramurale Psychogeriatrie (GIP-28). Tijdschr. Gerontol. Geriatr., 28(3), 119-123.

Dröes, RM. (1991). In beweging. Over psychosociale hulpverlening aan demente ouderen. Meppel: Krips Repro.

Feil, N. (1967). Group therapy in a home for the aged. Gerontologist, 7(3), 192-195.

Feil, N. (1984). Communicating with the confused elderly patient. Geriatrics, 39(3), 131-132.

Feil, N. (1985). Resolution: The final life task. Journal of Humanistic Psychology. 25(2), 91-105.

Feil, N. (1989). Validation: An empathic approach to the care of dementia. Clinical Gerontologist, $8(3)$. 89-94

Feil, N. (1990). Validation therapy helps staff reach confused residents. Provider, (December), 33-34.

Feil, N. (1992). Validation therapy. Geriatric Nursing. 13(3), 129-133.

Feil, N. (1994). De validation methode in de praktijk. (Translation of: The validation breakthrough: simple techniques for communicating with people with Alzheimer's-type dementia) (I van Pinksteren, Trans.). Utrecht: Lemma b.v.

Feil, N. \& Wetzler, M. (1979). An innovative method of working with the severely disoriented aged American Health Care Association Journal, (March), 41-44

Finnema, EJ. (2000). Emotion-oriented care in dementia. A psychosocial approach. Groningen: Stichting Drukkerij C. Regenboog. 
Finnema, EJ, Dröes, RM, van der Kooij, CH, de Lange, J, Rigter, H, van Montfort, APWP, \& van Tilburg. W. (1998). The design of a large-scale experimental study into the effect of emotionoriented care on demented elderly and professional carers in nursing homes. Archives of Gerontology and Geriatrics, suppl 6, 193-200.

Folstein, MF, Folstein, SE, \& McHugh, PR. (1975). "Mini-mental state". A practical method for grading the cognitive state of patients for the clinician. J. Psychiatr. Res., 12(3), 189-198.

Kruyver, I, \& Kerkstra, A. (1996). Begeleidingsmethodieken voor psychogeriatrische verpleeghuisbewoners: een overzicht. Utrecht: NIVEL.

Molloy, DW, Alemayehu, E, \& Roberts, R. (1991). Reliability of a Standardized Mini-Mental State Examination compared with the traditional Mini-Mental State Examination. Am. J. Psychiatry. 148(1), 102-105.

Peoples, MM. (1982). Validation therapy versus reality orientation as treatment for the institutionalized disoriented elderly (thesis). Akron: University of Akron.

Rasbash, J, Browne, W. Healy, M, Cameron, B, \& Chariton, C. (1999). MLwiN (Version Beta version 1.09.0001). London: Multilevel Models Project Institute of Education.

Robb, SS, Stegman, CE, \& Wolanin, MO. (1986). No research versus research with compromised results: a study of validation therapy. Nurs. Res., 35(2), 113-118.

Schrijnemaekers, VJ, Duijnhouwer, E, te Wierik, MJ, \& Frederiks, CM. (1995). De effectiviteit van validation. Een literatuuronderzoek. Tijdschr. Gerontol. Geriatr., 26(5), 205-213.

Schrijnemaekers, VJJ, \& Haveman, MJ. (1993). Eindrapport. Effecten van preventieve poliklinischgeriatrische interventie. Maastricht: Rijksuniversiteit Limburg. Vakgroep Epidemiologie \& Maaslandziekenhuis.

Snijders, TAB, \& Bosker, RJ. (1999). Multilevel Analysis: An introduction to basic and advanced multilevel modeling. London: Sage.

Toseland, RW, Diehl, M, Freeman, K, Manzanares, T, Naleppa, M, \& McCallion, P. (1997). The impact of validation group therapy on nursing home residents with dementia. Journal of Applied Gerontology, Vol 16(1), 31-50.

van Heusden, M, Widdershoven, G, Schrijnemaekers, V, \& van Rossum, E. (1999). Een kwalitatief onderzoek naar compliance en ervaringen met belevingsgerichte zorg in verzorgingshuizen. Maastricht: Universiteit Maastricht.

Verstraten, PF. (1988a). De GIP. Veertien observatieschalen voor psychogeriatrische gedragsproblemen. Tijdschr. Gerontol. Geriatr., 19(4), 147-151.

Verstraten, PF. (1988b). The GIP: an observational ward behavior scale. Psychopharmacol. Bull., 24(4), 717-719.

Verstraten, PFJ, \& van Eekelen, CWJM. (1987). Handleiding voor GIP. Gedragsobservatieschaal voor de intramurale psychogeriatrie. Nijmegen: Van Loghum Slaterus. 


\section{Effects of emotion-oriented care on work-related outcomes in professional caregivers in homes for the elderly}

Veron JJ Schrijnemaekers'

Erik van Rossum

Math JJM Candel ${ }^{2}$

Carla MA Frederiks ${ }^{3}$

Mayke MA Derix ${ }^{4}$

Hilde Sielhorst ${ }^{5}$

Piet A van den Brandt

\footnotetext{
'Department of Epidemiology, Maastricht University

${ }^{2}$ Department of Methodology and Statistics, Maastricht University

'Department of General Practice and Social Medicine, University of Nijmegen

"Department of Clinical Psychology. Twenteborg Hospital

5epartment of General Practice, Maastricht University
} 


\section{ABSTRACT}

A randomized controlled trial was conducted on the effects of emotion-oriented care on professional caregivers in homes for the elderly. Emotion-oriented care is used in the care for cognitively impaired elderly persons and is mainly based on the validation approach.

Sixteen homes for the aged were randomly allocated to an intervention or control group. Three hundred professional caregivers were included in the study. The eight intervention homes received a training program in emotion-oriented care. In the eight control homes usual care was continued. Measurements about job satisfaction, burnout and sick-leave were performed at baseline and after three, six and twelve months of follow-up.

Modest positive effects were found in favor of the intervention group. These related to various aspects of job satisfaction and burnout. The effects were not very consistent over time. No differences in sick-leave were found.

From this study as well as other studies in this field no strong effects were found of emotionoriented care on work-related outcomes in professional caregivers. Additional research is therefore needed. In these new studies special attention should be given to the optimization of the implementation process of emotion-oriented care programs. 


\section{INTRODUCTION}

Increasing numbers of elderly persons are living in long-term care facilities. In the Netherlands these facilities include so-called homes for the elderly of which there are approximately 1,400 with more than 100,000 residents and about 49,000 professional caregivers (CBS, 2000). Until the 1980s these homes were mainly a sheltered living facility. From then on they became more and more a residential care facility. At the moment, the care needs of residents resemble those of residents in nursing homes. Many residents in homes for the elderly are highly dependent, partly due to psycho-geriatric problems. This has resulted in an increased workload and increased complexity of work for the professional caregivers involved (in particular nursing assistants and geriatric assistant nurses). In general, these caregivers have received little training in psycho-geriatric care, entailing a need for extra education and instruction on how to approach psycho-geriatric patients.

Several approaches or therapies have been developed in the care for these patients. One potentially promising approach to care management of disoriented elderly and to the management of problem behavior is so-called 'validation' (Feil, 1967, 1984, 1985, 1989. 1990, 1992; Feil and Wetzler, 1979). This approach has been developed by Feil, who described it as a process of communicating, both verbally and nonverbally, with disoriented elderly people by validating and respecting their feelings. Validation, or validation therapy, can be used for moderately to severely disoriented elderly people. It strives to accept the disoriented elderly person as he or she is, to be non-judgmental and share feelings that are freely expressed. Disoriented persons are not forced into 'our reality', instead their perception of the environment is validated. In addition to positive effects for disoriented elderly, Feil claims that validation increases job satisfaction, reduces frustration and prevents burnout in professional caregivers (Feil, 1994).

A review of the literature on the effectiveness of validation (Schrijnemaekers et al., 1995) revealed that only a few studies addressed the effects on work-related outcomes of caregivers (Alprin, 1980; Blanchard et al., 1991; Nooren Staal et al., 1995; Ronaldson and Savy, 1991). Besides being small, none of these four studies included a control group. We therefore concluded that there was insufficient evidence to support the claimed effects of validation on caregivers and that additional research, using more rigorous methods, was needed.

In the Netherlands there is a tendency to apply validation in combination with other psychosocial care approaches, such as sensory-stimulation and reminiscence. This combined approach, mainly based on the validation approach, is called emotion-oriented care (Finnema, 2000; Finnema et al., 1998). In a randomized controlled trial (RCT) we studied the effects of emotion-oriented care on disoriented elderly with behavioral problems and on professional caregivers in homes for the elderly. In this chapter we present the results for the professional caregivers.

\section{METHODS}

Details of the study design have already been discussed in chapter 3 . In this chapter we confine ourselves to a general outline of the design and focus on the outcomes with respect to the professional caregivers.

The study was performed among caregivers in sixteen homes for the elderly in the Netherlands (province of Limburg) in the years 1997-1999. After pre-stratification the sixteen homes were randomly allocated to an intervention or control group and subsequently a 
selection of professional caregivers was made. The eight intervention homes received emotion-oriented care training, whereas the eight control homes continued usual care. Measurements were performed at baseline and after three, six and twelve months of followup. The study was approved by the medical ethical committee (IRB approval) of the Maastricht University Hospital.

\section{Homes for the elderly}

To select homes for the elderly, a postal questionnaire was sent to all 77 homes in the province of Limburg. Of those responding $(n=59), 31$ homes fulfilled the eligibility criteria and were interested in the study. These homes were invited for an informative meeting about the trial. Next, interviews were held with staff members in the homes that were still interested in our study. Finally, sixteen homes were selected. None had yet implemented an emotionoriented care approach in the daily care for their residents and they all had a day-care unit for psycho-geriatric residents. These day-care units offer a structured day-care program to (usually 10 to 15 ) psycho-geriatric residents.

\section{Pre-stratification and randomization}

Randomization was performed on the level of homes. The homes were pre-stratified before randomization on two prognostic characteristics: the capacity of the day-care unit for psychogeriatric residents and the degree of care innovation in the homes (presence of residentoriented care-plans and a system of resident-allocation). On the basis of these two characteristics eight pairs of homes were formed. Next, within each pair one home was randomly assigned to the intervention or control group and the other home was assigned to the alternate state.

\section{Study population}

A selection of caregivers was made for the study. They had to have been working for at least six months in the homes and to be employed for at least 18 hours a week. Caregivers who were expected to be absent during the study period for a longer time (e.g. pregnancy leave) were excluded from the study. First all caregivers of the day-care units were included in the study population. Next, a random sample of caregivers in the wards where the residents live was included.

To calculate the number of caregivers needed for the study, a difference of 1.5 points between the study groups on the job satisfaction sub-scales (primary endpoint, theoretical range from 0 to 12 points) was judged to be of clinical relevance. Based on a power of $90 \%$ (1-bèta), an alpha of $5 \%$ (two-sided) and an estimated loss to follow-up of $25 \%$, this led to a minimum of 80 caregivers per group. To obtain enough power for the subgroup analyses (see "analyses"), the number of caregivers per group was increased to 150 . 


\section{Interventions}

The experimental intervention (intervention homes) was compared to standard care (control homes). The intervention offered to the eight intervention homes consisted of three successive elements: clinical lessons, a training program, and supervision meetings, spread over a total period of eight months. All three elements of the intervention were organized incompany and given by the same qualified and experienced teacher of a professional training organization.

\section{Clinical lessons}

Every intervention home first received two identical lessons of approximately one hour. These lessons were offered to all employees (e.g. receptionist, domestic staff, nurses) and aimed at informing them about the study and the general ideas behind emotion-oriented care.

\section{Training program}

Eight caregivers in each intervention home received a training program in emotion-oriented care. They had to be key figures in the daily care for cognitively impaired residents and had to be able to implement the emotion-oriented care approach in their home. In addition they had to meet the following inclusion criteria: 1. working for at least half a year in the home for the elderly; 2 . being employed for at least eighteen hours a week; 3 . working for at least one year in geriatric care; and 4 . having at least a secondary vocational training. On average five caregivers from the day-care unit and three from the wards were selected for the training in each intervention home.

These caregivers received a six-day training program. The first four days were given at intervals of two weeks and the last two training days had an interval of four weeks. The training program had various goals. First, participants were taught about the dementia syndrome and various care models for communicating with demented elderly (e.g. reality orientation, validation, reminiscence). Next, much attention was paid to the inequality of the resident-caregiver relation, the importance of going deeply into and trying to understand the residents' perceptions of the environment, and the attitude and (non-) verbal communication of staff towards the resident (including the use of sensory perceptions such as touch, smell, vision, hearing). Finally, the implementation of practical skills received much attention. Various didactic methods, such as lecturing, homework, class assignments and exercises, role-playing and video presentations, were used during the training.

\section{Supervision meetings}

Three supervision meetings (half-a-day each) were offered to support the implementation of emotion-oriented care in daily care. They were held over a period of four months following the training. The meetings were 'tailor-made' for each intervention home. Depending on the problems mentioned by the participants in the first supervision meeting. goals, agreements and evaluations were discussed with those involved.

The eight control homes continued their usual care. To increase the willingness to participate, the control homes were offered the training program after the end of the study. 


\section{Outcome measures and timing of measurements}

Table 1 gives an overview of the outcome measures as well as the different measurement occasions.

The primary outcome measure was the job satisfaction of the professional caregivers. For this we used some specific sub-scales of the Maastricht Work Satisfaction Scale for Healthcare (MAS-GZ) (Landeweerd et al., 1996a; Landeweerd et al., 1996b). This questionnaire was specifically developed for healthcare workers and has been used in various Dutch healthcare settings including homes for the elderly. The MAS-GZ consists of seven sub-scales with three items, each of which have to be answered on a 5-point scale ranging from 0 (very dissatisfied) to 4 (very satisfied). In our study five of the seven subscales were selected: satisfaction with head of the ward, quality of care, contact with colleagues, contact with residents, and opportunities for self-actualization. The other two sub-scales (possibilities for promotion and clarity of tasks and rules) were considered to be less relevant for our study. The psychometric properties of the MAS-GZ are adequate. The internal consistency (Cronbach's alpha) of the five subscales used range from .67 to .87 . Its validity (factorial and construct) also appears to be satisfactory (Landeweerd et al., 1996a; Landeweerd et al., 1996b).

Table 1. Overview of outcome measures used for the 300 professional caregivers in sixteen homes for the elderly

\begin{tabular}{|c|c|c|}
\hline Outcome measures & Theoretical range: & Measurement occasions \\
\hline \multicolumn{3}{|l|}{ Primary } \\
\hline \multicolumn{3}{|l|}{ Job satisfaction (MAS-GZ): } \\
\hline head of the ward & 0.12 & $0,3,6,12$ \\
\hline uality of care & 0.12 & \\
\hline contact with colleagues & $0-12$ & \\
\hline contact with residents & $0-12$ & \\
\hline opportunities for self-actualization & $0-12$ & \\
\hline
\end{tabular}

Secondary

\begin{tabular}{|c|c|c|}
\hline \multicolumn{2}{|l|}{ Job satisfaction: } & \multirow[t]{2}{*}{$0,3,6,12$} \\
\hline short version MAS-GZ & $0-\underline{28}$ & \\
\hline \multicolumn{3}{|l|}{2 study-specific satisfaction-items: } \\
\hline 'contact with residents' & $0-4$ & \\
\hline 'good care residents' & $0-4$ & \\
\hline 1 general satisfaction-item & $0-4$ & \\
\hline Bumout & & $0,3,6,12$ \\
\hline depersonalization & Q-30 & \\
\hline emotional exhaustion & Q-48 & \\
\hline personal accomplishment & $0-42$ & \\
\hline Sick-leave in last 3.6 months (number of days) & Q-92/183 & $0,3,6,12$ \\
\hline Opinion work situation & $0-6$ & $3,6,12$ \\
\hline
\end{tabular}

The underined score indicates the most favorable score for each scale/question 
Secondary outcome measures were additional job satisfaction measures, burnout, sick-leave and the general opinion of the professional caregivers about their work situation. Additional job satisfaction outcomes were the short version of the MAS-GZ (an overall job satisfaction score) (Landeweerd et al., 1996a; Landeweerd et al., 1996b), two study-specific job satisfaction-items (on actual contact with and being able to provide good care to cognitively impaired residents) and one general satisfaction item (relating to pleasure in one's work). Burnout was measured with the Dutch version of the Maslach Burnout Inventory (MBI-NL) (Schaufeli and Van Dierendonck, 1994; Schaufeli et al., 1993), a scale specially developed for evaluating burnout in the human services sector. The MBI consists of three sub-scales with a total of 20 items: emotional exhaustion (eight items), depersonalization (five items) and personal accomplishment (seven items), which have to be rated on a 7-point scale ranging from never $(0)$ to daily $(6)$. The internal consistency of the three $\mathrm{MBI}$ scales has been extensively tested in many samples with Cronbach's alpha values ranging form .71 to .91 . The convergent validity as well as the factorial validity seems quite acceptable (Schaufeli et al., 1993).

Caregivers were asked to inform us about their sick-leave before and during the intervention period (pregnancy leave excluded) and to rate the number of calendar days of absenteeism due to sickness. At every time point we also asked the caregivers to give their general opinion about their work situation compared to the baseline measurement. They had to rate their answer on a 7-point scale ranging from extreme improvement $(0)$ to extreme deterioration (6).

\section{Analyses}

\section{Handling of missing data}

Missing values on items that were part of a scale or subscale were replaced according to the 'mean value of valid sub-tests' principle, i.e., replacement by the mean value calculated from the valid item scores of the (sub-)scale obtained for the same subject at the same time point. This replacement strategy was only used if less than $25 \%$ of the items of a scale or subscale had missing values. Missing values on questions in single-item scales were not replaced.

\section{Data analysis}

The hierarchical structure of the data (measurement occasions nested with caregivers, who are nested within homes for the elderly) results in dependencies among measurements, which makes multilevel analysis an appropriate tool for analyzing the data (Bryk and Raudenbush, 1992; Snijders and Bosker, 1999). This technique not only accommodates for dependencies, but also handles missing data in an adequate way (Snijders and Bosker, 1999). All analyses were performed using the MLwiN program (Rasbash et al., 1999).

Assuming a linear trend for the outcome measures across time, we compared the intervention and control group. Besides unadjusted analyses, adjusted analyses were conducted in which the following covariates were added: age, workplace (ward versus daycare unit), work experience, number of sick-reports and hours of employment. In the linear trend analyses, the linear trend starting from the measurement at baseline is analyzed, which implies that possible differences on the outcome measures at baseline were also accounted for. In addition to the linear trend analysis, the effects of the intervention at short (three months), medium (six months) and long-term intervals (twelve months) were examined. In the latter analysis, no specific relation was assumed between the outcome measure and time of measurement. 
In these 'overall' analyses differences between intervention and control homes were tested without considering potential effect modifiers. Therefore additional subgroup analyses were performed, based on five characteristics measured at baseline: age, workplace (ward versus day-care unit), years of working experience, hours of employment per week and number of sick-reports.

All statistical analyses were carried out following the 'intention-to-treat' principle. In addition, per protocol analyses (unadjusted and adjusted linear trend analyses, analyses per time period as well as subgroup analyses as mentioned above) were performed to examine the effect of the intervention as a function of the success of its implementation. These additional analyses were restricted to the primary outcomes. To conduct these analyses we asked the teacher of the course to give an overall judgment of the success of the implementation of emotion-oriented care (good, moderate or poor) for each of the eight intervention homes. The teacher was blinded with respect to the outcomes. She rated the implementation in three homes as 'good', in three others as 'moderate' and in two as 'poor'. In the per protocol analyses, the control homes $(n=8)$ were compared to intervention homes with a good implementation $(n=3)$, and to intervention homes with a moderate to poor implementation $(n=5)$.

\section{RESULTS}

Three hundred and eight caregivers were selected and invited to participate. Eight of them refused to participate, resulting in a study population of 300 caregivers: 155 in the intervention and 145 in the control group. Ninety-four percent of the study population was female with an average age of 36 years. The average work experience of these caregivers was twelve years. On average they were employed for 27 hours a week.

Table 2. Comparison between the intervention $(n=154)$ and control $(n=139)$ group professional caregivers on baseline characteristics

\begin{tabular}{|c|c|c|c|c|c|}
\hline \multirow{2}{*}{$\begin{array}{l}\text { Characteristic } \\
\text { Gender female }(n, \%)\end{array}$} & \multirow{2}{*}{$\begin{array}{l}\text { Empirical range in } \\
\text { study population" }\end{array}$} & \multicolumn{2}{|c|}{ Intervention group $(n=154)^{b}$} & \multicolumn{2}{|c|}{ Control group $(n=139)^{t}$} \\
\hline & & 147 & $(96 \%)$ & 129 & $(93 \%)$ \\
\hline Workplace day-care unit (n, \%) & & 42 & $(27 \%)$ & 37 & $(27 \%)$ \\
\hline Age (mean years, sd) & $20-58$ & $35.2^{\circ}$ & $(9.3)$ & $37.7^{*}$ & $(8.6)$ \\
\hline Work experience (mean years. sd) & 0.36 & 11.7 & (7.1) & 13.3 & $(7.2)$ \\
\hline Hours employment per week (mean hours, sd) & $18-40$ & 276 & (7.2) & 26.6 & $(7.6)$ \\
\hline Numbers of sick reports last half year (mean numbers, sd) & $0-4$ & 07 & $(0.8)$ & 0.5 & $(0.8)$ \\
\hline \multicolumn{6}{|l|}{ Job satisfaction (MAS-GZ) (mean, sd): } \\
\hline head of the ward & $0-12$ & $75^{* *}$ & (25) & $8.2^{* *}$ & (23) \\
\hline quality of care & 0.12 & 6.0 & $(2.5)$ & 6.1 & $(2.4)$ \\
\hline contact with colleagues & 3-12 & 9.0 & $(16)$ & 9.3 & $(1.3)$ \\
\hline contact with residents & $5 \cdot 12$ & 9.6 & (1.3) & 9.6 & (1.1) \\
\hline opportunities for self-actualization & $1-12$ & $7.3^{* *}$ & $(2.3)$ & $8.0^{* *}$ & $(1.8)$ \\
\hline
\end{tabular}

-The underlined score is the most favorable sore

"Seven caregivers were unable to respond to the questionnaires at baseline (see also table 3)

" $p<0.05, \cdots p<0.01, \cdots p<0.001$ 
Table 2 shows that the intervention and control groups were to a large extent comparable at baseline. As far as differences were present (e.g. regarding age and two sub-scales of job satisfaction), these were accounted for in the analyses.

Table 3 shows the response and loss to follow-up over time per study group. The response rate ranged from $98 \%$ at baseline to $81 \%$ after twelve months for the total population. The response was at every time point somewhat higher in the intervention group. Loss-to-followup due to structural dropout was almost equal for the two study groups. The number of discharged or transferred employees was comparable up to six months, but was higher after twelve months in the intervention group. (Five of the twelve discharged or transferred caregivers in intervention homes worked in one home with organizational changes.) The numbers of incidental non-responders were higher in the control group at every time point, probably due to a lower commitment with our study. None of these differences, however, was statistically significant (Fisher exact test, two-tailed, $p>0.05$ ).

Table 3. Numbers (percentages) response and loss-to-follow-up per group professional caregivers ( $1=\ln$ tervention ( $n=155)$. $C=$ Control $(n=145))$

\begin{tabular}{|c|c|c|c|c|c|c|c|c|c|c|c|c|}
\hline \multirow[t]{3}{*}{ Measurement } & \multicolumn{4}{|c|}{ Response } & \multicolumn{8}{|c|}{ Loss-to-follow-up } \\
\hline & \multirow{2}{*}{\multicolumn{2}{|c|}{1}} & \multirow{2}{*}{\multicolumn{2}{|c|}{ C }} & \multicolumn{3}{|c|}{ Structural dropout } & \multicolumn{3}{|c|}{ Discharge or transter } & \multicolumn{2}{|c|}{ Incidental non-responder } \\
\hline & & & & & 1 & & $\mathrm{C}$ & 1 & & C & 1 & C \\
\hline Baseline & 154 & (99) & 139 & (96) & - & & & . & & 1 (1) & $1(1)$ & $5(3)$ \\
\hline 3 months & 143 & $(92)$ & 126 & (87) & 1 & (1) & & 1 & (1) & $2(1)$ & $10(6)$ & $17(12)$ \\
\hline 6 months & 141 & (91) & 120 & (83) & 1 & (1) & & 3 & (2) & 2 (1) & $10(6)$ & $23(16)$ \\
\hline 12 months & 126 & (81) & 116 & $(80)$ & & (1) & 1 (1) & 12 & (8) & $4(3)$ & $16(10)$ & $24(17)$ \\
\hline
\end{tabular}

Mainly due to sickness or vacation

Table 4 presents the unadjusted and adjusted estimated differences on the outcome measures between the two groups per month (assuming a linear trend), as well as the differences after three, six and twelve months of follow-up (not assuming a particular trend). The adjusted analyses included the baseline covariates age, workplace, work experience, number of sick-reports and hours of employment.

The interpretation of the results for the linear trend analyses is as follows. An estimated difference of, for example, -0.08 per month on the 'head of the ward' sub-scale (job satisfaction, second column), indicates that the control group deteriorates on average 0.08 points more (or improves less) on this dimension compared to the intervention group. assuming a linear trend between outcome and time. The estimated differences after three, six and twelve months (fourth to sixth column) do not assume a specific relationship between the outcome measure and time and simply reflect the difference between the two groups after three, six and twelve months, adjusting for baseline differences.

Table 4 shows that the majority of the differences in the linear trend analyses are in favor of the intervention group. Of these, 4 are statistically significant $(p<0.05)$ : the job satisfaction sub-scale 'opportunities for self-actualization', the short version of the job satisfaction scale, 
the study-specific satisfaction item 'contact with residents', and the sub-scale 'personal accomplishment' of the burnout questionnaire. Hardly any differences in results were found between the adjusted and unadjusted analyses (table 4).

Table 4. Estimated differences between the intervention and control group professional caregivers on the primary and secondary outcome measures

\begin{tabular}{|c|c|c|c|c|c|}
\hline \multirow[t]{3}{*}{ Outcome measures } & \multirow{2}{*}{\multicolumn{2}{|c|}{$\begin{array}{l}\text { Analyses linear trend } \\
\text { Estimated difference } \\
\text { per month }\end{array}$}} & \multicolumn{3}{|c|}{ Analyses per time period } \\
\hline & & & \multirow[t]{2}{*}{$\begin{array}{l}\text { Estimated difference } \\
\text { after } 3 \text { months }\end{array}$} & $\begin{array}{l}\text { Estimated difference } \\
\text { after } 6 \text { months }\end{array}$ & \multirow[t]{2}{*}{$\begin{array}{l}\text { Estimated difference } \\
\text { after } 12 \text { months }\end{array}$} \\
\hline & Unadjusted & Adjusted & & & \\
\hline \multicolumn{6}{|l|}{ Job satisfaction (MAS-GZ): } \\
\hline head of the ward & -0.08 & -0.08 & -0.28 & -0.04 & $-1.08^{*}$ \\
\hline quality of cares & -0.04 & -0.05 & -0.52 & -0.45 & -0.62 \\
\hline contact with colleagues ${ }^{d}$ & -0.01 & -0.01 & -0.16 & -0.03 & -0.23 \\
\hline contact with residents & +0.01 & +0.01 & -0.10 & +0.10 & +0.06 \\
\hline opportunities for self-actualization ${ }^{4}$ & $-0.05^{\circ}$ & $-0.05^{\circ}$ & -0.28 & -0.49 & -0.73 \\
\hline \multicolumn{6}{|l|}{ Job satisfaction: } \\
\hline short version MAS-GZ ${ }^{d}$ & $-0.09^{\circ}$ & $-0.10^{*}$ & $-0.77^{*}$ & -0.49 & $-1.28^{\circ}$ \\
\hline \multicolumn{6}{|l|}{2 study-specific satisfaction items: } \\
\hline 'contact residents'd & $-0.02^{*}$ & -0.02 & -0.05 & $-0.15^{\circ}$ & -0.22 \\
\hline 'good care residents'd & -0.02 & -0.02 & -0.20 & -0.11 & $-0.22 *$ \\
\hline 1 general satisfaction item & -0.01 & -0.01 & -0.10 & -0.01 & -0.16 \\
\hline \multicolumn{6}{|l|}{ Bumout (MBI): } \\
\hline depersonalization" & +0.05 & +0.05 & +0.40 & +0.40 & +0.55 \\
\hline emotional exhaustion & +0.14 & +0.17 & +1.58 & $+2.17^{*}$ & +1.85 \\
\hline personal accomplishments & $-0.11^{\circ}$ & -0.11 & -0.87 & -0.61 & $-1.46^{\circ}$ \\
\hline Sick-leave (number of days) ${ }^{\circ}$ & -0.01 & -0.14 & -0.86 & +0.70 & -0.60 \\
\hline Opinion work situation" & -0.00 & -0.00 & +0.23 & -0.07 & +0.00 \\
\hline
\end{tabular}

-The estimated difference is the difference in deterioration or improvement per month between the control and intervention group

The estimated difference is the difference in deterioration or improvement after 3.6 and 12 months between the control and intervention group

Adjusted for age, workplace (ward versus unit), work experience, number of sick reports and hours of employment

Negative difference implies a better score for the intervention group

- Positive difference implies a better score for the intervention group

" $p<0.05, \cdots p<0.01 ; \cdots<0.001$

The analyses per time period also show modest effects in favor of the intervention homes. The differences between the groups are not very consistent over time and as far as they are statistically significant they mainly appear after twelve months of follow-up.

Figure 1 presents graphically the average change over time for the three time points (three, six and twelve months) on the five job satisfaction sub-scales. These graphs show that the differences in favor of the intervention homes are most consistent (but not statistically significant) on the sub-scales 'quality of care' and 'opportunities for self-actualization'. 

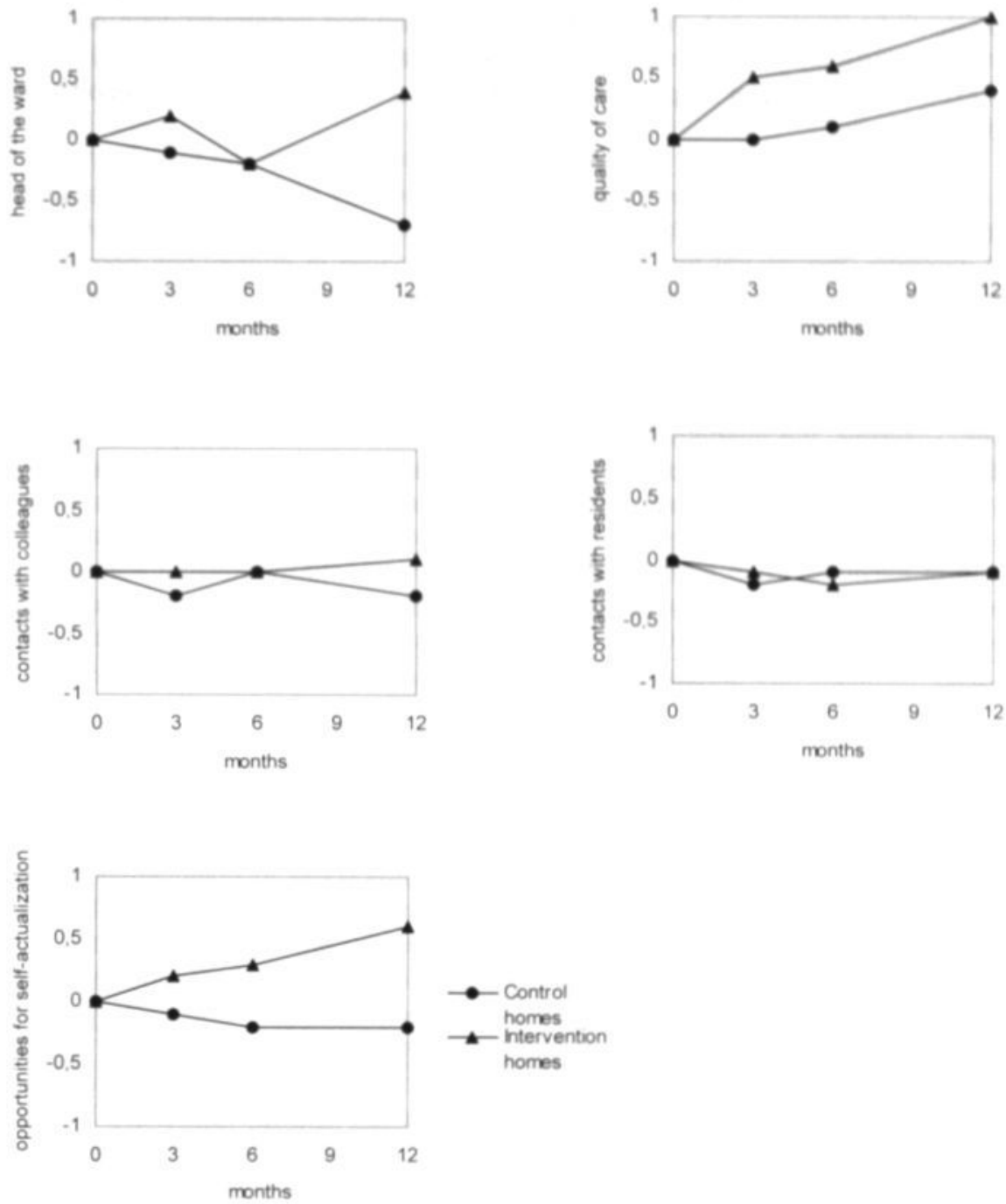

Figure 1. The average deterioration and/or improvement on 5 job satisfaction subscales for different fime points in the intervention and control group

The results of the estimated differences between the two groups per month (assuming a linear trend) and the effects after three, six and twelve months of follow-up (not assuming a particular trend) yield more or less the same results for the primary and secondary outcome measures. 
Next, subgroup analyses were conducted. These analyses did not reveal subgroups of caregivers with specific characteristics, which benefited clearly more, or less, from the emotion-oriented care approach. The effect of the intervention apparently does not depend on the age of the caregiver, his or her workplace (ward versus day-care unit), years of working experience, hours of employment per week and the number of sick-reports before the start of the study.

Finally, per protocol analyses were conducted for the primary outcomes. In these analyses the teacher's overall judgment of the success of the implementation was used. In the per protocol analyses, the control homes $(n=8)$ were compared to intervention homes with a good implementation $(n=3)$, and to intervention homes with a moderate to poor implementation $(n=5)$.

The linear trend analyses (unadjusted as well as adjusted) showed no differences between the control homes and the homes with a good implementation on the primary outcome measures. However, the intervention homes with a moderate to poor implementation had better scores on three job satisfaction sub-scales (satisfaction with head of the ward, quality of care and opportunities for self-actualization) than the control homes (table 5).

Table 5. Unadjusted and adjusted differences between the intervention and control group professional caregivers on the primary outcome measures in case of the per protocol analyses

Primary outcome

Estimated difference per month in linear trend analyses

\begin{tabular}{|c|c|c|c|c|}
\hline & & & & \\
\hline & \multicolumn{2}{|c|}{ 'Intervention+' versus controlP } & \multicolumn{2}{|c|}{ 'Intervention-' versus control' } \\
\hline & Unadjusted & Adjusted & Unadjusted & Adjusted \\
\hline \multicolumn{5}{|l|}{ Job satisfaction (MAS-GZ) } \\
\hline head of the ward & -0.03 & -0.03 & $-0.11^{*}$ & $-0.10^{\circ}$ \\
\hline quality of care & +0.03 & +0.02 & $-0.09^{*}$ & $-0.09^{*}$ \\
\hline contacts with colleagues & +0.01 & +0.01 & -0.03 & -0.03 \\
\hline contacts with residents & +0.01 & +0.01 & +0.01 & +0.01 \\
\hline opportunities for self-actualization & -0.03 & -0.04 & $-0.07^{*}$ & $-0.08^{*}$ \\
\hline \multirow{2}{*}{\multicolumn{5}{|c|}{$\begin{array}{l}\text { "The estimated difference is the difference in deterioration or improvement per month between the control and interventio } \\
\text { A negative difference implies a better score for the intervention homes } \\
\text { 'Intervention +' represents the } 3 \text { intervention homes with a good implementation, whereas intervention-' relates to the } 5 \\
\text { intervention homes with a moderate to poor implementation }\end{array}$}} \\
\hline & & & & \\
\hline \multicolumn{5}{|c|}{$\begin{array}{l}\text { 'Adjusted for age, workplace (ward versus unit), work experience, number of sick reports and hours of employment } \\
\text { " } p<0.05 ;{ }^{\prime}, p<0.01 ; \cdots p<0.001\end{array}$} \\
\hline
\end{tabular}

These intervention homes also had a statistically significant better score in the analyses per time period after twelve months of follow-up on four of the five job-satisfaction scales compared to the control homes (data not shown).

\section{Discussion}

One of the goals of emotion-oriented care is the improvement of job satisfaction and reduction of burnout and sick-leave in (professional) caregivers. We found only modest positive effects in favor of the intervention group on some aspects of job satisfaction and 
burnout, and no differences in sick-leave. These findings give rise to some questions. These will be addressed below, where we specifically will discuss the implementation of emotionoriented care in the intervention homes, the results of the per protocol analyses, possible sources of bias, and the results of other studies on the effectiveness of validation or emotionoriented care.

\section{Implementation of emotion-oriented care}

The relatively intensive intervention was organized and given by a highly experienced and motivated teacher. An evaluation at the end of the six-day training showed that the participants were (very) positive about the training and the teacher. The absence-rate at the training was -only- $9 \%$, mainly due to illness.

To obtain some insight into the implementation process of emotion-oriented care in the intervention homes, an additional qualitative study using observations and interviews was performed. The observations (restricted to one day at the day-care unit in four intervention and four control homes) indicated that the practice of emotion-oriented care was not clearly observable in the homes eleven months after baseline. No clear differences in communication and interaction with the residents between the intervention homes and control homes became visible. Interviews with management and caregivers in half of the intervention homes indicated that the caregivers had become more aware of their own actions and that their attitude toward the residents had changed. The interviewees also mentioned that organizational problems may have hindered the implementation of the intervention (van Heusden et al., 1999).

\section{Results of the per protocol analyses}

In conducting the per protocol analyses, we anticipated a clear relation between the quality of the implementation of emotion-oriented care and the study outcomes. However, there were no differences between the intervention homes with a good implementation and the control homes. Instead, some positive effects were found for the intervention homes with a moderate to poor implementation. A possible explanation is that a difficulty in implementing emotion-oriented care reflects organizational problems in the homes involved, leading to lower job satisfaction scores at baseline. Additional analyses indeed showed lower job satisfaction scores at baseline in intervention homes with a moderate to poor implementation compared to the intervention homes with a good implementation. Therefore, the training program may have been most effective for caregivers with relatively low job satisfaction scores at the start. However, the fact that caregivers with low scores improved more may also be attributed to regression toward the mean.

\section{Sources of bias}

Although much precaution was taken to prevent bias, our study may still have been subjected to it. Selection bias seems not obvious. After pre-stratification and randomization the homes and caregivers in the two groups appeared to be comparable. Also the response rate was almost equally distributed over the study groups during the one-year follow-up period.

The outcome measurements could not be blinded. Usually non-blinded observations lead to an overestimation of effects. Given the modest effects found, it seems not very likely that information bias masked real existing effects. It is, however, possible that the effects found were caused by non-blinding. 
The study showed some statistically significant $(p<0.05)$ effects of the intervention. When a Bonferroni correction is made for multiple testing (alpha/5=0.01), none of these effects turned out to be significant. This demands for an evaluation of the power of the tests performed. We therefore conducted post hoc power analyses to clarify the power of this study, given the data collected. These analyses were based on an assumed clinically relevant difference of 1.5 points between the two groups on the job satisfaction sub-scales (ranging from 0 to 12 points), linear trend analyses accounting for clustering, five primary endpoints, a Bonferroni adjusted alpha of 0.01 and two-sided testing. The post hoc power ranges from 0.69 to 1.0 on the five primary endpoints, implying that the study had sufficient power to detect meaningful differences between the two groups.

It was difficult to choose a suitable 'placebo' or control intervention. Consequently, the intervention was compared to standard care. This implies that the outcomes contain specific and nonspecific elements. As a result, it is unclear whether the modest effects result from nonspecific elements such as increased social interaction and attention, or from the emotionoriented care training.

\section{Comparison with other studies}

Only a few studies about the effectiveness of validation or emotion-oriented care have addressed the effects on caregivers. Four small-scale studies without a control group on the effects of validation do not allow firm conclusions (Alprin, 1980; Blanchard et al., 1991; Nooren Staal et al., 1995; Ronaldson and Savy, 1991). In a recent Dutch trial by Finnema (Finnema, 2000) the effects of emotion-oriented care were examined. This trial studied, among other things, the effects on the general health of nursing assistants $(n=99)$ in nursing homes. General health was measured by feelings of stress, stress reactions, feeling of competence and illness. For the total population no statistically significant effects were found. Fewer stress reactions were found for one subgroup: nursing assistants in the experimental group who felt that they had obtained more emotion-oriented care skills during the study, showed less stress reactions than comparable assistants in the control group.

Because the outcome measures differ considerably, the findings of Finnema (2000) are only to a small extent comparable to our results. Both Finnema's and our study show no differences on sick-leave.

From this study as well as other studies in this field, no strong effects were found of emotionoriented care on work-related factors in professional caregivers. Additional research is therefore needed. In these new studies special attention should be given to the optimization of the implementation process of emotion-oriented care programs.

\section{ACKNOWLEDGEMENTS}

The authors are grateful to the caregivers and their staff for their commitment to our study. We also would like to thank Jos Slangen en Marijke Moll (department of Epidemiology. Maastricht University) for their help in data collection and data management and Hilde Ham (teacher CEREIN) for organizing and performing the intervention in our study. This study was financially supported by grants from the National Center for Nursing \& Care (LCVV), the Province of Limburg and the VSB fund. 


\section{REFERENCES}

Alprin, SI. (1980). Staff attitudes after validation. Cleveland, Ohio: Cleveland State University.

Blanchard, F. Prentczynski, J, Wong. C, Lamaze, B, Bocquet, P. Jolly, D, \& Lorton, O. (1991). An application of the validation method at the geriatrics care unit of the University Hospital in Reims, France. Reims: Hóspital Sebastopol, Service de Médicine Interne et Geriatrie.

Bryk, AS, \& Raudenbush, SW. (1992). Hierarchical Linear Models, Applications and Data Analysis Methods. Newbury Park, CA: Sage.

CBS. (2000). Verzorgingshuizen 1998 . Voorburg/Heerlen: CBS

Feil, N. (1967). Group therapy in a home for the aged. Gerontologist, 7(3), 192-195.

Feil, N. (1984). Communicating with the confused elderly patient. Geriatrics, 39(3), 131-132.

Feil, N. (1985). Resolution: The final life task. Journal of Humanistic Psychology, 25(2), 91-105.

Feil, N. (1989). Validation: An empathic approach to the care of dementia. Clinical Gerontologist, 8(3). 89-94.

Feil, N. (1990). Validation therapy helps staff reach confused residents. Provider, (December), 33-34.

Feil, N. (1992). Validation therapy. Geriatric Nursing. 13(3), 129-133.

Feil, N. (1994). De validation methode in de praktijk. (Translation of: The validation breakthrough: simple techniques for communicating with people with Alzheimer's-type dementia) (I van Pinksteren, Trans.). Utrecht: Lemma b.v.

Feil, N, \& Wetzler, M. (1979). An innovative method of working with the severely disoriented aged. American Health Care Association Journal, (March), 41-44.

Finnema, EJ. (2000). Emotion-oriented care in dementia. A psychosocial approach. Groningen: Stichting Drukkerij C. Regenboog.

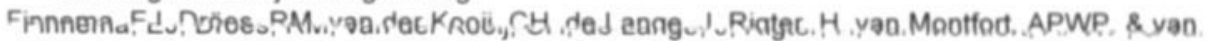
Tilburg, W. (1998). The design of a large-scale experimental study into the effect of emotionoriented care on demented elderly and professional carers in nursing homes. Archives of Gerontology and Geriatrics, suppl 6, 193-200.

Landeweerd, JA, Boumans, NPG, \& Nissen, JMF. (1996a). Arbeidsvoldoening bij verplegenden en verzorgenden. De Maastrichtse arbeidssatisfactieschaal voor de gezondheidszorg. In CC van Beek \& TC van Dorsten \& GJ Stam (Eds.). Handboek Verpleegkundige innovatie. Loghem/Houten: Bohn Stafleu

Landeweerd, JA, Boumans, NPG, \& Nissen, JMJF. (1996b). Bedrijfsgezondheidszorg Studies nr. 11. De Maastrichtse arbeidssatisfactie schaal voor de gezondsheidszorg (MAS-GZ). Maastricht: Universiteit Maastricht.

Nooren Staal, WH, Frederiks, CM, \& te Wierik, MJ. (1995). Validation: effecten bij bewoners en personeel in een verzorgingshuis. Tijdschr. Gerontol. Geriatr., 26(3), 117-121.

Rasbash, J, Browne, W. Healy, M, Cameron, B, \& Chariton, C. (1999). MLwiN (Version Beta version 1.09.0001). London: Multilevel Models Project Institute of Education.

Ronaldson, S, \& Savy, P. (1991). Validation therapy: a viable option for gerontic nursing practice. Geriaction, (Autumn), 7-10.

Schaufeli, W, \& Van Dierendonck, D. (1994). Burnout, een begrip gemeten. De Nederlandse versie van de Maslach Burnout Inventory (MBI-NL) Gedrag and Gezondheid: Tijdschrift voor Psychologie and Gezondheid, 22(4), 153-172.

Schaufeli, WB, Maslach, C, \& Marek, T (Eds.). (1993). Professional burnout: Recent developments in theory and research. Washington, DC, USA: Taylor and Francis.

Schrijnemaekers, VJ, Duijnhouwer, E, te Wierik, MJ, \& Frederiks, CM. (1995). De effectiviteit van validation. Een literatuuronderzoek. Tijdschr. Gerontol. Geriatr., 26(5), 205-213.

Snijders, TAB, \& Bosker, RJ. (1999). Multilevel Analysis: An introduction to basic and advanced multilevel modeling. London: Sage

van Heusden, M. Widdershoven, G. Schrijnemaekers, V. \& van Rossum, E. (1999). Een kwalitatief onderzoek naar compliance en ervaringen met belevingsgerichte zorg in verzorgingshuizen. Maastricht: Universiteit Maastricht. 


\section{Compliance in a randomized controlled trial: the implementation of emotion-oriented care in psycho- geriatric care}

Veron JJ Schrijnemaekers

Erik van Rossum ${ }^{1}$

Michèle $\mathrm{JT}$ van Heusden ${ }^{2}$

Guy AM Widdershoven ${ }^{2}$

'Department of Epidemiology, Maastricht University

${ }^{2}$ Department of Healthcare Ethics and Philosophy, Maastricht University 


\section{ABSTRACT}

The aim of this study was to gain some insight into the compliance with the introduction of a new care model (emotion-oriented care (EOC)) as part of an intervention study (RCT) in psycho-geriatric care. The success of the implementation (compliance), as well as the expectations and experiences concerning the training were studied.

In four intervention homes and four control homes observations were conducted, and careplans of residents were also analyzed to see whether the implementation had succeeded. Semi-structured interviews were conducted with four persons in each of the four intervention sites (a total of sixteen interviews) to study the experiences with the training and implementation.

The observations showed no clear differences between intervention and control homes with regard to the interactions between residents and professional caregivers. Analysis of the reporting systems revealed differences within, as well as between, the intervention and control homes. The content of the reports showed no differences between the intervention and control homes. The interviewees had different expectations of the EOC training. depending on their disciplinary background. The caregivers regarded the training as a confirmation of their current practice. They experienced some changes at the individual level and some of them reported that the co-operation between units had become better. At the home-level no changes were reported. Every interviewee indicated that the implementation of EOC was difficult and laborious and that there were (mainly organizational) obstacles that could hinder the implementation of the EOC training.

Observations and the analysis of the reporting systems indicated that there was no clear difference between intervention homes and control homes as to the actual implementation of the intervention, indicating that the compliance with the new care model was not optimal. The interviews gave some insight into factors that caused lack of compliance. 


\section{INTRODUCTION}

The main interest in nursing intervention studies concerns the question whether a new or experimental intervention performs better than usual care, a placebo intervention, or no intervention at all. If possible, randomized controlled trials (RCTs) are conducted to study the effects of interventions. In rigorous (quantitative) research methods like RCTs, emphasis is placed on elements such as strict eligibility criteria for study subjects, random allocation of study subjects to the study groups, and blinding of the treatment and outcome measurements. In general, less emphasis is placed -at least in the study reports- on the implementation process of the intervention and the compliance of the study subjects with the intervention protocol. Although the intervention may have been designed and implemented carefully, these aspects are usually addressed only briefly in study reports, which may partly be attributed to the limited space in journal articles for implementation aspects.

Implementation of the intervention and compliance to the intervention protocol are important issues in intervention research. Problems in these domains may hinder an optimal contrast between the study groups, leading to biased study outcomes. The risk of these problems depends partly on the type of intervention and care setting. For instance, the risk is relatively low in drug trials under controlled clinical conditions, whereas the risk increases when studying, for example, the effects of a community health promotion program.

We specifically focused upon compliance in the context of a randomized controlled trial that aimed to study the effects of a new care model, emotion-oriented care (EOC), on disoriented and behaviorally impaired elderly people and their professional caregivers in long-term psycho-geriatric care. A brief outline of this trial is presented in box 1 .

As part of this trial we studied the following two questions:

1. To what extent did the intervention sites, one year after the start of the training program, comply with 'the rules' of the new care model?

2. What were the expectations and experiences of employees (staff and caregivers) in the intervention homes concerning the training in and implementation of the new care model? This article reports on this compliance study. The results of the RCT have been reported elsewhere (Schrijnemaekers et al., 2002a, 2002b).

\section{METHODS}

A qualitative approach was used to study the compliance with the new care model in the intervention homes. Before presenting information about the methods, we will first describe the setting of the study.

\section{Setting}

The study was performed in homes for the elderly. These homes are long-term care facilities with residents who have an average age of 84 at admission. These residents have care needs in terms of physical and mental impairments that resemble those of nursing home patients. The homes included in the study had not yet implemented an emotion-oriented care approach in the daily care for their residents. Each home had a day-care unit for psychogeriatric residents. At these units, a structured day-care program is offered to psychogeriatric residents by occupational therapists and nursing caregivers. The residents involved stay at the day-care unit in daytime and return go back to their rooms during the evening. 


\section{Background}

Emotion-oriented care (EOC) is a psychosocial care model for cognitively and behaviorally impaired eiderly people. EOC integrates various psychosocial care approaches, such as reminiscence and sensory-stimulation, with 'validation' as a key model (Finnema, 2000). Validation, or validation therapy, has been developed by Feil who described it as a process of communicating, both verbally and nonverbally, with disoriented elderly people by validating and respecting their feelings (Feil, 1984, 1985, 1989, 1990, 1992; Feil and Wetzler. 1979). We studied the effects of EOC on demented elderly with behavioral problems and on professional caregivers in homes for the eiderly.

\section{Research methods}

The study was performed among patients and professional caregivers in sixteen homes for the elderly in the south of the Netherlands (province of Limburg) in the years 1997-1999. None of these homes had yet implemented EOC or validation therapy in the daily care for their residents and they all had a day-care unit for psycho-geriatric residents. These units offer a structured day-care program to (usually ten to fifteen) psycho-genatric residents.

The main eligibility criteria for the residents related to the presence of moderate to severe cognitive impairment and behavioral problems. Written informed consent was obtained for every resident by a legal representative of the resident (usually a son or daughter). A sample of caregivers of the day-care units and of the wards where residents live was selected to study the effects of EOC on work-related outcomes. A total of 151 residents and 300 caregivers were selected for the study. The sixteen homes were randomly allocated to the intervention or control group.

The intervention offered to the eight intervention homes consisted of three successive elements: clinical lessons, a training program, and supervision meetings. All three elements of the intervention were organized and given by the same qualified and expenienced teacher of a professional training organization. Two identical clinical lessons of approximately one hour were offered to all employees in every intervention home. In these lessons, some background information about EOC and the study was presented. Subsequently, a six-day training program in EOC was offered. On average eight caregivers per home attended this program; they were key figures in the daily care for psycho-geriatric patients and had to be able to implement the emotion-oriented care approach in their home. On average five caregivers from the day-care unit and three from the ward were selected for the training. It was the intention that the EOC approach, would spread home-wide through the caregivers who attended the training. The training was organized over a period of four months, followed by three supervision meetings to support the implementation of EOC in daily practice (again over a period of four months). The training program focused on the knowledge of the participants of the dementia syndrome, the ideas behind and the practical skills needed for EOC. and the attitude towards the residents. Various didactic methods, like teaching. homework, class assignments and exercises, role-playing and video-presentations, were used during the training. All three elements of the intervention were organized and given by the same qualified and experienced teacher of a professional training organization. The eight control homes continued their usual care during the study penod.

Measurements were performed at baseline and after three, six and twelve months of follow-up. The main outcome measure for the residents was changes in problem behavior, for the caregivers the primary outcome measure related to job satisfaction.

The study was approved by the medical ethical committee (IRB approval) of Maastricht University HospitalMaastnicht University

\section{Data collection}

The compliance study was performed between ten and twelve months after the training in EOC started in the years 1998 and 1999. In view of the available time, the study was restricted to half of the homes that participated in the intervention study. Of these eight homes, four were intervention and four were control homes. There were no differences between the homes selected and other homes regarding organizational and patient characteristics. 
In both the intervention and control sites, observations on the day-care units were conducted and care plans were studied to see whether the intervention homes had succeeded in implementing EOC in daily practice (research question 1).

The observations had to be restricted to only one day at the day-care unit of each home (about eleven months after the training program had started). The intervention homes were asked to schedule caregivers who had received the training. The observations, conducted by one person, were mainly focused on the interaction, both verbally and non-verbally, between residents and caregivers. Detailed notes of all communication at the day-care units were made and transcribed afterwards.

Another indication of the compliance to a new care model is the extent to which the relevant aspects of the model can be retrieved from the (written) reports in the care plan for the residents. Reporting about residents is important for the continuity of care especially when residents are transferred frequently from a ward to a day-care unit and visa versa. In each of the eight homes, reports in the care plans of two residents were studied (randomly selected among residents who participated in the intervention study). All reports related to week ten after the EOC training; which seemed a fair timing for the homes to have implemented the elements of the training program in the reporting in the care plans.

To study the experiences of the caregivers with the training and implementation of EOC (research question 2), semi-structured interviews were conducted with four persons in each of the four intervention sites (a total of sixteen interviews). The following sixteen persons were interviewed: four care managers, four heads of day-care units or wards, three caregivers of the wards and five caregivers of day-care units. Nine of them, mainly the caregivers of the wards and day-care units, had received the EOC training. The main topics of the interviews related to the expectations regarding the new model, the changes that occurred in daily care, and the implementation of the care model. The interviews lasted on average one hour. All interviews were audio-taped and transcribed.

\section{Data analyses}

The observations resulted in detailed notes about verbal and non-verbal interactions between residents and caregivers at the day-care units. Special points of interest in analyzing these data were the person who initiated the communication, and how these initiatives were reacted to. We were specifically interested in whether the EOC training had contributed to the development of a more responsive attitude of the caregivers towards the disoriented residents, in contrast to a correcting attitude. A responsive attitude can be characterized by resident-oriented and demand-oriented care whereas a directing attitude relates to task-oriented and supply-oriented care.

For the analyses of the care-plans, the various reporting systems and citations from reports were compared for the intervention and control homes.

The interview data were analyzed in accordance with the method of grounded theory (Strauss and Corbin, 1990). Central issues were clustered in various rounds of analyses. Three topics were addressed in particular: expectations regarding the new model, the changes that occurred in daily care, and the implementation of the care model. We assumed that the meaning of the EOC training would vary across the various disciplines (Guba and Lincoln, 1989). Consequently, the interviews were analyzed separately for staff members and caregivers. If relevant, a distinction between caregivers of the ward and the day-care unit was made. 


\section{RESULTS}

\section{Observations at the day care units}

The observations focused on interaction patterns between caregivers at the day-care units and the residents. These were compared for the intervention and control homes.

It turned out that the day-care units in both the intervention and control homes all had a fixed program for activities. In all homes, eating, drinking, toileting, resting and activities like reading a newspaper, singing and solving riddles were important components of the program. The fixed structure implies that the organization of the activities at the day-care units is mainly supply-oriented. Such an approach is in general not very favorable for emotion-oriented care.

Given the overall supply-oriented care offered at the units, we focused our analysis mainly on spontaneous initiatives of residents and the reactions of caregivers to these initiatives. These spontaneous interactions interfere with the structured day-program and allow one to observe non-structured reactions of caregivers. Registered spontaneous initiatives from residents and the reactions of caregivers could be categorized in four types of reactions: ignoring, correcting, responding and a mix of various responses. Whereas ignoring and correcting are clearly not examples of emotion-oriented care, responding is. Below some examples are presented.

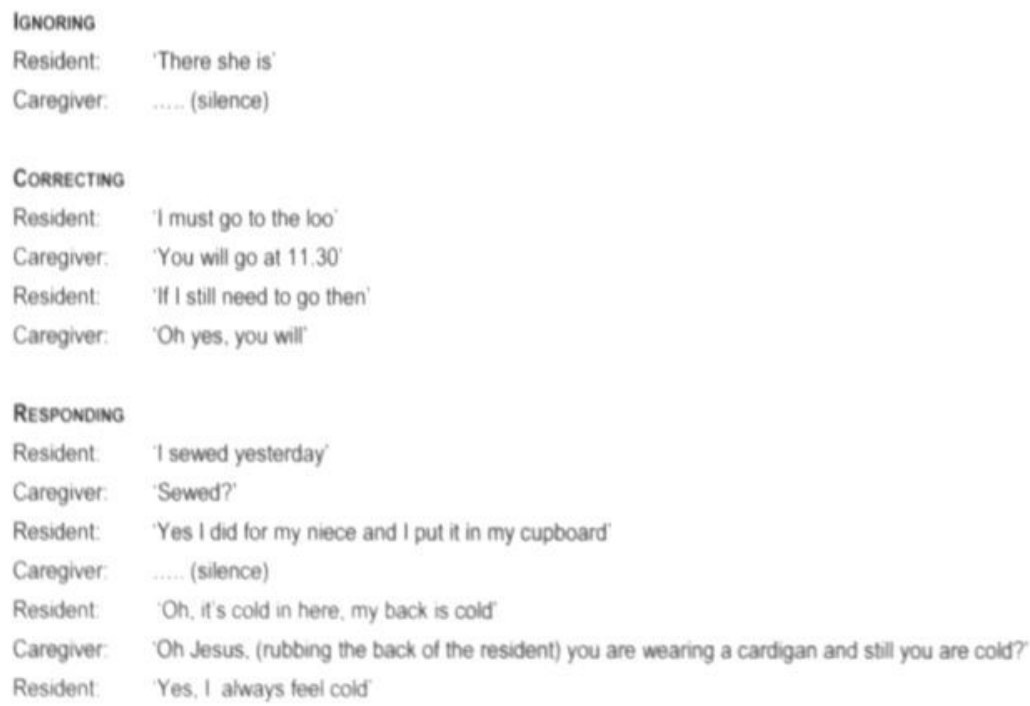

The complete material of (spontaneous) interactions between residents and caregivers showed no clear differences between intervention and control homes regarding the type of reactions (ignoring, correcting, responding or mix), nor regarding the frequency of the various reactions. 


\section{Care-plans}

The EOC training briefly addressed the system of reporting, the style of writing, and the content of a resident-oriented care plan. In analyzing the reports at the day-care units, it became obvious that the reporting systems differed within as well as between the intervention and control homes. In seven homes there was a separate system for practical issues and care or resident-related issues. Two homes (one intervention and one control) had an integrated resident-oriented care plan for both the ward and the day-care unit. In the other six homes separate reporting systems were used for the ward and the day-care units. Below some examples from the reports are presented. The first example originates from a diary of a day-care unit in an intervention home and the second from a resident specific careplan of a day-care unit in another intervention home.

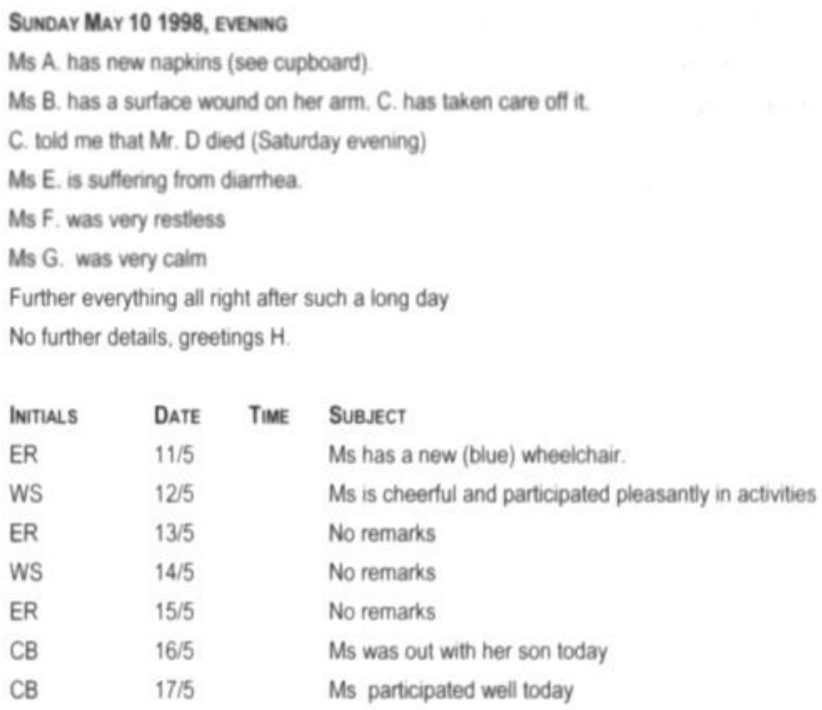

The next example comes from the day-care unit in a control home.

\begin{tabular}{|c|c|c|c|}
\hline INITLaLS & DATE & TIME & SUBJECT \\
\hline MR & $10 / 5$ & & Ms was out with her family \\
\hline AT & $11 / 5$ & & $\begin{array}{l}\text { Ms walked around and sat at the reception desk in the } \\
\text { afternoon. }\end{array}$ \\
\hline VB & $12 / 5$ & & $\begin{array}{l}\text { I have noticed that Ms has continuously much phlegm in her } \\
\text { mouth. Reason? Will be passed on to the ward. }\end{array}$ \\
\hline GP & $12 / 5$ & & Ms was very negative during dinner. She came around later. \\
\hline NU & $13 / 5$ & & Ms was very withdrawn and quiet. At lunchtime she slept. \\
\hline
\end{tabular}

The content of the reports showed no clear differences between the intervention and control homes. The style of reporting showed that all reports were brief and information about the behavior of residents relevant to EOC was often lacking. 


\section{Interviews}

Eight managers and eight caregivers from the intervention homes were interviewed. The interviewees consisted of eight staff members (four care managers and four heads of wards or day-care units) and eight professional caregivers (three working at a ward and five at a day-care unit). Two staff members and seven caregivers attended the EOC training.

The interview schedule contained three main topics: 1 . expectations with regard to the EOC training, 2. changes introduced by the training at the individual-, team-, and home-level, and 3. experiences with the implementation of the training.

\section{Expectations of the EOC training}

The interviews showed that staff members (especially the care managers) had high expectations of the EOC training. They viewed the training as a policy instrument to change the care approach in their homes. Many homes were trying to develop a new care vision in the direction of a resident-oriented care approach that matches good with the EOC training. Participation in the training program was of high importance to them.

We are working on a new vision on the care process in our home. In this care vision the residents themselves decide what they want and we support him or her if necessary. This new care-vision seems to be a good fit for elderly people who are able to make their own choices. For demented residents, however, this vision introduces a obstacle. Possibly the EOC training supplies information to offer good care to these residents.

The caregivers themselves had lower expectations. Boring experiences with a previous training and lack of information before the start of the EOC training resulted in low expectations in two caregivers.

We went full of apprehension to the EOC training. A few years ago we attended a different training which was very boring. When we got this invitation we all thought oh boy and this training takes six whole days. So our expectations were low.' (day-care unit)

Caregivers also expected the training to be a confirmation of the validity of their present careapproach.

We already work emotion-onented and I hoped to get better understanding in our daily activities. Are we doing well or not?' (day-care unit)

Some caregivers (mainly of the wards) hoped to learn something to improve their work.

Thoped to learn something from the EOC training. It looked interesting and that's why I enrolled.' (ward)

Overall it seemed that the caregivers had varying expectations about the training.

\section{Changes introduced by the EOC training}

Staff members mentioned some changes at the level of the day-care units, and almost no changes for the wards. The observed changes related to the attitude towards residents, reporting and to the co-operation between the wards and the day-care unit. 
They also mentioned that the EOC training was not the only factor that may have caused these changes. Other factors that were identified were, for example, the start of a careinnovation project.

The introduction of emotion-oriented care was simultaneous with the introduction of a new care-vision. Consequently it is difficult to tell what caused the observed changes."

Caregivers emphasized that the training was in many ways a confirmation of the previous care practice.

We already worked emotion-oriented. Before the training you did it automatically and now you do it more consciously resulting in better contacts with residents

(day-care unit)

:.... I try to imagine myself more in the place of the resident by observing and talking The training provided some enrichment. Fortunately if's not a world of difference

(day-care unit)

They experienced some changes at the individual level. They noticed that they felt more alert, conscious, confident, calm and patient. They also mentioned that their attitude towards the residents changed.

1 have become calmer and take more fime for the residents. .....' (ward)

I have more patience and I am less rushed. I take more time for residents as a result of which rest is passed on to residents. At the ward I see no changes or only small ones..... ' (ward)

Some caregivers reported that the co-operation between the day-care unit and the ward had become better and that the position of the day-care unit had improved. At the home-level, however, almost no changes in attitude were experienced.

\section{Implementation of the EOC training}

All interviewees indicated that the implementation of EOC was difficult and laborious and that there were (mainly organizational) obstacles that seem to hinder the implementation of the care model.

Two staff members (care managers) explained that the lack of central management and cooperation were the most important difficulties for a successful implementation of the training.

As long as there is no clear management and no integrated policy, the EOC will not spread unchecked.

In addition, some staff members thought that more caregivers of the ward should have attended the training.

The caregivers (from the wards as well as the day-care units) stated that too many changes and innovations were implemented simultaneously.

'At the time of the implementation there was some chaos in our home Too many plans and innovations had to be implemented at the same time. ..... There was simply not enough time ' (day-care unit)

'The implementation was difficult because approximately at the same time a new care innovation started ....' (day-care unit) 
They also noticed that too few caregivers of the wards attended the EOC training to realize the implementation successfully. Some caregivers of the ward also mentioned the lack of personnel and time.

'....Besides it would have been better if more caregivers of the wards attended the EOC training.' (day-care unit)

\begin{abstract}
The implementation is restricted to the caregivers who attended the EOC training. Apart from that, not very much happened. ..... At the moment we have only a few professional caregivers and not enough time for all the extra activities.' (ward)
\end{abstract}

'The home-wide implementation is difficult. ..... To increase the support, if's important that more caregivers of the ward attend the EOC training.' (ward)

\title{
Discussion
}

The aim of this study was to gain some insight into the compliance with the introduction of a new care model (emotion-oriented care (EOC)) as part of an intervention study in psychogeriatric care. By means of observations, analyzing reports and interviews, information about compliant behavior and experiences with the implementation of the intervention was gathered.

\section{Methodological considerations}

Given the limited time, the compliance study had to be restricted to half of the homes that participated in the intervention study. Although we are not sure that our findings represent all sixteen homes involved, no indications were found for important differences between the homes that were included and those that were not in this qualitative study.

We were unable to perform a baseline measurement. Consequently, we are uncertain about the possible changes over time due to the intervention (the EOC training). However, given the stratified randomization procedure, we believe that the intervention and control homes were quite comparable at the start of the study.

The observations were confined to one day at the day-care unit. One day is too short to draw firm conclusions. Another limitation is that no observations were conducted at the wards. It is possible that potential changes introduced by the intervention show up better at the ward. These caregivers have in general less experience with the care for cognitively impaired residents and possibly more profit can be reached in these caregivers. The interviews were restricted to a limited number of employees. Considering the rather consistent picture raised from the interviews, we assume that the differences between the various disciplines are valid.

\section{Results}

The observations showed that there were no clear differences between intervention and control homes with regard to the type of reactions (ignoring, correcting, responding or mix) of the caregivers to spontaneous initiatives of the residents at the day-care units observed. The analyses of the care-plans also showed no clear differences in content and style between intervention and control homes.

The interviews with staff and caregivers in the intervention homes concerning expectations, changes and implementations showed some clear differences between disciplines. Staff 
members considered the EOC training as a management tool, whereas the caregivers had varying expectations. With regard to the changes that occurred in daily practice, staff members mentioned mainly changes at the level of the day-care units, and almost no changes for the wards. They also mentioned that the EOC training was not the only factor that may have caused these changes. The caregivers merely experienced changes at the individual level, although some of them reported that the co-operation between the day-care unit and the wards had become better. No changes in attitude were reported at the home level. Every interviewee indicated that the implementation of EOC was difficult and laborious, and that several organizational obstacles hindered the implementation of the EOC approach.

\section{Implications}

Despite its methodological limitations, this compliance study offers important information for the interpretation of the EOC trial, as well as for future care intervention studies.

For our RCT we can conclude that there seems to be no clear difference between intervention and control homes as to the actual implementation of the intervention. Moreover, the organization of the activities at the day-care units was hardly in conformity with the principles of emotion-oriented care, either in the intervention homes or in the control homes. Therefore, it may be concluded that compliance with the intervention was not optimal

The interviews gave some insight into factors that may have caused the compliance problems. Representatives from various disciplines had different expectations of the intervention. For staff members, the training was a management tool supposed to make a significant contribution to changes in care which were deemed necessary. Caregivers on the other hand had varying expectations and saw the training, for example, as a confirmation of their present caring practice. The study shows that the introduction of and the compliance to a new nursing model is not easily realized. Apart from organizational obstacles that may have hindered an optimal implementation, an important issue is that emotion-oriented care fits best in a resident-oriented or demand-oriented environment. The observations showed, however, that the organization of activities at the day-care units remained mainly supplyoriented. Future studies should pay extra attention to the integration of supply-oriented and demand-oriented care.

Future care intervention studies should realize that the implementation of a new care model is not easily effected. Before starting new care interventions studies, one should very carefully contemplate the feasibility of the intervention and implementation strategy.

The stepwise implementation cycles developed by Grol could be used in developing new implementation strategies (Grol, 1997; Grol et al., 2000). They distinguished the following steps: determine goals, identify possible obstacles, develop strategy, implement and evaluate. An important step in their cycle is the attention for possible obstacles before developing and implementing a strategy.

Often fundamental organizational changes are needed. Besides the competence, motivation and commitment of all employees involved, the stimulating and facilitating role of management, is an important condition for success.

One specifically should take into account that different disciplines may have different views and expectations about interventions (Greene, 2000; Guba and Lincoln, 1989). Therefore, it is important to study the process of implementation, focusing upon participants' expectations and experiences. This requires a dialogic approach, discussing the implementation process with all the parties involved. Such a dialogue not only enables the researchers to monitor the process, but also to change it according to the needs of the people addressed (Abma, 1996; Widdershoven, 2001). 
If new RCTs in this field are conducted, we want to stress the use of additional qualitative research to describe the compliance and contrast in randomized trials. Qualitative research offers the opportunity for collecting 'in-depth' backstage information necessary to interpret both the limitations and the results of quantitative studies.

\section{ACKNOWLEDGEMENTS}

The authors are grateful to the residents as well as to the caregivers and their staff for their commitment to our study. We also would like to thank Hellen Heutz (department of Healthcare Ethics and Philosophy. Maastricht University) for her help in typing out the interviews and Hilde Ham (teacher CEREIN) for organizing and performing the intervention in our study.

This study was financially supported by grants from the Netherlands organization for health, research and development.

\section{REFERENCES}

Abma, TA. (1996). Responsief evalueren. Discoursen, controversen en allianties in het postmoderne. Rotterdam: Erasmus universiteit.

Feil, N. (1984). Communicating with the confused elderly patient. Geriatrics, 39(3), 131-132.

Feil, N. (1985). Resolution: The final life task. Journal of Humanistic Psychology. 25(2), 91-105.

Feil, N. (1989). Validation: An empathic approach to the care of dementia. Clinical Gerontologist, $8(3)$, 89-94

Feil, N. (1990). Validation therapy helps staff reach confused residents. Provider, (December), 33-34.

Feil, N. (1992). Validation therapy. Geriatric Nursing. 13(3), 129-133.

Feil, N, \& Wetzler, M. (1979). An innovative method of working with the severely disoriented aged. American Health Care Association Journal, (March), 41-44.

Finnema, EJ. (2000). Emotion-oriented care in dementia. A psychosocial approach. Groningen: Stichting Drukkerij C. Regenboog.

Greene, J. (2000). Understanding social programs through evaluation. In NK Denzin \& YS Lincoln (Eds.). Handbook of qualitative research (pp. 981-1000). Thousand Oaks, CA: Sage.

Grol, R. (1997). Personal Paper: Beliefs and evidence in changing clinical practice. Br. Med. J., 315(7105), 418-421.

Grol, RTPM, van Everdingen, JJE, \& Casparie, AF. (2000). Invoering van richtlijnen en veranderingen. Een handleiding voor de medische, paramedische en verpleegkundige praktijk. Maarsen: Elsevier/De Tijdstroom.

Guba, EG, \& Lincoln, YS. (1989). Fourth generation evaluation. Beverly Hills: Sage Publications.

Schrijnemaekers, VJJ, van Rossum, E. Candel, MJJM, Frederiks, CMA, Derix, MMA, Sielhorst, H, \& van den Brandt, PA. (2002a). Effects of emotion-oriented care on elderly people with cognitve impairment and behavioral problems. Int. J. Geriatr. Psychiatry, accepted.

Schrijnemaekers, VJJ, van Rossum, E, Candel, MJJM, Frederiks, CMA, Derix, MMA, Sielhorst, H, \& van den Brandt. PA. (2002b). Effects of emotion-oriented care on work-related outcomes in professional caregivers in homes for the elderly. The Journals of Gerontology: Social Sciences. accepted.

Strauss, A, \& Corbin, J. (1990). Basics of qualitative research: grounded theory procedures and techniques. Newbury Park, California: Sage Publications.

Widdershoven, GAM. (2001). Dialogue in Evaluation: A Hermeneutic Perspective. Evaluation, 7(2), 253-263 
Discussion 
Chapter 7 
This chapter reflects on the design, results and implications of our study. Firstly, a summary of our main findings is given. Secondly, some methodological reflections are presented. Next, our results will be compared to available evidence in this field, and finally recommendations for future research and practice will be presented.

\section{MAIN FINDINGS}

\section{Residents}

An important goal of emotion-oriented care is to reduce problem behavior in elderly people with cognitive impairment and behavioral problems. We were unable to confirm this presumed beneficial effect. The various primary as well as secondary outcome measures showed neither statistically significant nor clinically relevant results in favor of the intervention group. The primary outcome measure referred to seven behavior disturbances, namely nonsocial, apathetic, rebellious, restless, dependent and anxious behavior, and loss of decorum. The secondary outcomes included some other problem behaviors like agitation, and other measures such as functional status, psychotropic drug use, nursing home admission and mortality.

The results were consistent for all analyses conducted: analyses for the total study groups. for subgroups, for the various follow-up time points (three, six and twelve months after the start of the intervention) and per protocol analyses. Data for the different sources (caregivers of the day-care unit, caregivers of the ward and representatives of the resident) also showed consistently no positive effects or no convincing ones on the behavior of the residents in the intervention homes. The statistically significant effects after six months of follow-up on four outcome measures (only partly in favor of the intervention homes) were probably due to chance (multiple testing).

\section{Caregivers}

Another important goal of emotion-oriented care is to improve job satisfaction and other work-related aspects of professional caregivers, such as reduced burnout and sick-leave. With regard to the caregivers, the overall analyses showed some modest positive effects in favor of the intervention homes on job satisfaction and burnout subscales. For example, assuming a linear trend over time it appeared that the caregivers in the intervention group had a statistically significant better score on the job satisfaction scale 'opportunities for selfactualization', the short version of the job satisfaction scale, the study specific satisfaction item 'contact with residents', and the subscale 'personal accomplishment' of the burnout questionnaire.

Although all statistically significant differences were in favor of the intervention homes, one has to notice that they all were only significant at a 5\% significance level and that they have limited clinical meaning. For instance, the statistically significant difference of 0.05 point per month on "opportunities for self-actualization" implies (assuming a linear trend) a difference between the two groups of 0.6 points after twelve months on a scale ranging from 0 to 12 points.

In conclusion, our study did not confirm the presumed beneficial effects of emotion-oriented care on problem behavior in elderly people with cognitive impairment and showed only modest positive effects on job-related outcomes for the professional caregivers. 


\section{METHODOLOGICAL REFLECTIONS}

Our study was performed among residents and caregivers in sixteen homes for the elderly in the Netherlands. After pre-stratification the homes were randomly allocated to an intervention or control group and subsequently a selection of residents with cognitive impairment and behavioral problems as well as professional caregivers was made. The eight intervention homes received an emotion-oriented care training, while the eight control homes continued their usual care. Measurements were performed at baseline and after three, six and twelve months of follow-up. The main outcome measures were the behavior of the resident and jobrelated outcomes for the caregivers.

The randomized controlled trial is the most powerful design in intervention research. However, given the nature of our study population and intervention, compromises had to be made in the design and conduct of the study. In view of the cognitive impairments of the residents only indirect information on changes in their behavior could be obtained. The intervention, a home-wide implementation of a care model, made randomization at the individual level impossible and blinded measurements and a suitable placebo intervention difficult to conduct.

Consequently, the results of our study may have been subject to various sources of bias. Therefore we will reflect on methodological aspects of three major elements in experimental studies, namely the study population, the outcome measurements and the interventions compared. Given the relatively new technique used for analyzing our data, we will also comment briefly on multilevel analyses.

\section{Study populations}

To enhance the comparability of our intervention and control group, the homes were prestratified and randomized at the level of the homes. The homes were stratified before randomization on two characteristics, namely the capacity of the day-care unit and the degree of care innovation. A comparison of various baseline characteristics showed hardly any differences between the two study groups regarding both the residents and professional caregivers. Nevertheless, adjusted analyses were performed to control for small baseline differences.

The response rate was equally distributed over the control and intervention group of residents after one year of follow-up $(61 \%$ versus $62 \%)$. In both groups the cumulative mortality rate was $27 \%$ after twelve months. The response rate for the caregivers was also equally distributed over the two study groups after one year of follow-up ( $81 \%$ versus $80 \%$ ). The loss to follow-up due to discharge or transfer was somewhat higher in the intervention homes whereas the number of incidental non-responders was higher in the control homes. We have no indications that the (partly incidental) loss to follow-up was associated with the intervention in our study.

The sample size calculation for the residents indicated that, taking into account a loss to follow-up of $25 \%$ after one year, two groups of 80 residents were needed in our study. The number of residents included $(n=151)$ approximates closely the required number, but the loss to follow-up was higher in our study $(38 \%)$ compared to the expected rate $(25 \%)$. This relatively high loss to follow-up has an adverse impact on the precision of the effect estimations. However, given the absence of an intervention effect, it is not obvious that clinically meaningful effects would have emerged if the sample size had been larger. 
The required and included numbers of caregivers correspond. The loss to follow-up was somewhat lower $(19 \%)$ than expected $(25 \%)$, resulting in a higher number of caregivers at follow-up than strictly needed.

To clarify the power of our study, given the data collected, post hoc power analyses were conducted on the primary multilevel analyses (linear trend, alpha $=0.01$ ). The post hoc power analyses indicated that the study had sufficient power (ranging from 0.69 to 1.0 for the caregivers and 0.96 for the residents) to detect meaningful differences between the two groups.

In our study two study populations can be distinguished, namely residents and professional caregivers in homes for the elderly. We think that both populations represent the target populations for respectively receiving and providing emotion-oriented care

An important selection criterion for the residents was the presence of behavioral problems. It appeared that our population showed approximately the same or slightly more behavioral problems compared to residents of day-care units in other homes for the elderly in the Netherlands (Boom Poels, 1994; de Jonghe, personal communication). Compared to psycho-geriatric nursing home residents in the Netherlands, our population showed slightly fewer social behavioral problems such as nonsocial, apathetic and rebellious behavior and similar or somewhat more emotional behavior disturbances like anxious and dependent behavior (Finnema, 2000; Verstraten and van Eekelen, 1987). In sum, we think that the selected resident population is fairly comparable to residents in homes for the elderly who use additional day-care facilities and nursing home residents concerning behavioral disturbances.

The baseline job satisfaction scores of the professional caregivers in our study were quite well comparable to those of other caregivers in various healthcare settings in the Netherlands, such as hospitals, nursing homes and homes for the elderly (Landeweerd et al., 1996).

\section{Outcome measurements}

Non-blinded outcome measurements may introduce information bias, usually leading to an overestimation of effects. To compensate partly for the non-blinded observations, it was decided to use various assessors (caregivers of the day-care unit, caregivers of the ward and representatives of the residents) to measure the behavior of the residents. They were, from different perspectives, capable of assessing the behavior of the residents and revealed almost the same results.

We have no indications to believe that the assessments (about behavior of residents and work-related factors of the caregivers) in the intervention group were systematically different from those in the control group. Given the fact that only small effects were found, it does not seem likely that information bias masked real existing effects. On the other hand, it cannot be excluded that even the modest effects found were caused by non-blinding.

The instruments used were the most sensitive, reliable and valid scales available in Dutch versions. Although these instruments (mainly concerning the behavior of the residents) may arguably not be sensitive enough to measure relevant changes, we believe that a possible lack of sensitivity can not entirely explain the absence of convincing positive effects regarding the residents. 
The outcome measures used, assess the most important characteristics of interest. For the residents various measures for behavior were assessed, and for the caregivers the outcomes cover work-related domains on which effects for the caregivers were claimed (job satisfaction, burnout and sick-leave).

The timing of the follow-up measurements after three, six and twelve months seems adequate given the content and duration of the intervention. One could argue, however, that the implementation of a new care model takes longer to become visible and measurable. In psycho-geriatric practice, nevertheless, one year is about the maximum for follow-up measurements. Studies with a longer follow-up period will encounter (too) high loss to follow-up rates, mainly due to mortality.

\section{Interventions}

Because it was difficult to choose a suitable 'placebo' or control intervention, the experimental intervention was compared to usual care. This implies that the outcomes measured probably contain both specific and nonspecific elements.

If so, one would expect differences in effects in the subgroup analyses for the variable workplace. This variable distinguishes caregivers who work at the day-care unit (many participants of the emotion-oriented care training) and at the ward (few participants of the training). Contrary to our expectations, it appeared that caregivers of the day-care unit had no better outcomes compared to the caregivers of the ward. However, it remains possible that the modest effects found for the caregivers originate from nonspecific elements of the intervention.

The intervention in our trial was far more intensive than the usual training programs caregivers receive in homes for the elderly. Nevertheless, it is still possible that the intervention did not result in enough contrast between the study groups. On the one hand, the control homes may possibly have already been using the emotion-oriented care approach 'spontaneously' (contamination), while the implementation may not have been optimal in the intervention homes on the other.

To obtain some insight into the contrast between the study groups and the implementation process, a qualitative study was additionally performed (van Heusden et al., 1999). About eleven months after the baseline measurement, observations (one day per home) were conducted at the day-care units in four intervention homes and four control homes. The interaction between caregivers and residents was the major point of interest during these observations. The observations showed no clear differences in approach (e.g. communication and interaction) between observed day-care units of the intervention homes and control homes. In general, it seemed that the care at the day-care units was mainly offered according to a fixed program ('supply-oriented care') and that there was relatively little space for 'demand-oriented care' in both groups.

Analysis of the reporting systems at the day-care units showed differences within as well as between the intervention and control homes. The content of the reports showed no differences between the intervention and control homes.

Approximately one year after the start of the study, sixteen interviews were held in four intervention homes. The interviewees included care managers, heads of ward/unit and caregivers. Nine interviewees attended the training (students). The interviews were semistructured and the three most important topics were: expectations regarding the training. changes in approach in daily practice and the implementation of emotion-oriented care. The 
interviewees had different expectations of the EOC training. depending on their disciplinary background. The interviews also indicated that changes were experienced mainly in students of the training and that a home-wide implementation was difficult because of problems (mainly organizational) like lack of support and time.

Although the (small) qualitative study does not permit firm conclusions regarding the contrast between the two study groups, it gives us indications that the implementation of emotionoriented care was not optimal and that it is difficult to implement such a care model in daily practice. Consequently, the contrast may not have been optimal.

In many reports on care intervention studies, information about the degree of compliance and the obtained contrast is lacking. Although our qualitative study was subject to various methodological and practical limitations, it offered valuable information for the interpretation of our study results as well as for future studies in this field.

In addition to the qualitative study, per protocol analyses were conducted with the intention to optimize the contrast between the study groups in our study. Contrary to our expectations, these analyses showed no differences between the (three) intervention homes with a good implementation and the control homes, but some positive effects were found for the intervention homes with a moderate to poor implementation. Further it appeared that the average job satisfaction scores at baseline were lower (worse) for the intervention homes with a moderate to poor implementation compared to the intervention homes with a good implementation. Therefore, the training appears to be most profitable for the caregivers with a relatively low job satisfaction at the start of the study.

The intervention per home consisted of two clinical lessons, a six-day training for eight caregivers and three supervision meetings, and was organized and given by a qualified and motivated teacher. The teacher was experienced in the subject (emotion-oriented care) and the target population (professional caregivers in homes for the elderly). An evaluation at the end of the six-day training showed that the participants were (very) positive about the training and the teacher. The absence-rate at the training was (only) $9 \%$, of which almost half (4\%) was caused by illness. With respect to the foregoing, the intervention passed off well.

\section{Data analyses}

The data can be characterized as having a hierarchical structure: repeated measurements were nested within residents and caregivers, and residents and caregivers were nested within homes for the elderly. Resulting dependencies between measurements at the level of measurement occasions (due to being nested within residents/caregivers and homes) and at the level of residents (due to being nested within homes), made multilevel analyses an appropriate technique for analyzing the data (Bryk and Raudenbush, 1992; Snijders and Bosker, 1999). Multilevel analysis not only accommodates for such dependencies, but also handles missing data in an adequate way. All available data are included in the analysis. which implies more power for the analysis than the "complete cases only" approach employed by other techniques. A third advantage of multi-level analyses is that the length of follow-up time intervals may vary.

Using multilevel analysis, however, also has some disadvantages. Multilevel modeling is for example not (yet) available in user-friendly statistical software and is difficult to apply and interpret. One has to realize that researchers are more than usual dependent on the availability and willingness of specifically trained statisticians. 


\section{RESULTS OF PREVIOUS RANDOMIZED STUDIES IN THIS FIELD}

Over the last few decades several approaches or therapies have been developed in the care for psycho-geriatric patients. In 1997 the American Psychiatric Association (APA) developed practice guidelines for the treatment of patients with dementia (American Psychiatric Association, 1997). Besides psychiatric management and pharmacological options, the APA distinguishes four types of psychosocial treatments: behavior-oriented ${ }^{1}$, stimulation-oriented ${ }^{2}$, emotion-oriented ${ }^{3}$ and cognition-oriented treatments ${ }^{4}$.

The Dutch term 'Belevingsgerichte zorg' was translated by Finnema into 'emotion-oriented care' (Finnema, 2000). In the Netherlands the term emotion-oriented approaches is often understood in a broader sense than the APA definition, since other psychosocial interventions (e.g. music and art therapy) can also be included in an emotion-oriented approach (Finnema et al., 2000).

Over the last 5 years various reviews have been published on the effectiveness of emotionoriented treatments for patients with dementia (American Psychiatric Association, 1997; Day, 1997; Finnema et al., 2000; Koger and Brotons, 2000; Midence and Cunliffe, 1996; Neal and Briggs, 2000; Schrijnemaekers et al., 1995; Spector et al., 2000a; Spector et al., 2000b).

Schrijnemaekers (Schrijnemaekers et al., 1995) and Day (Day, 1997) reviewed the effectiveness of validation. Four (recently updated) Cochrane reviews were conducted for Reality Orientation Training (Spector et al., 2000a), reminiscence (Spector et al., 2000b), validation (Neal and Briggs, 2000) and music therapy (Koger and Brotons, 2000). Midence (Midence and Cunlifffe, 1996), the APA (American Psychiatric Association, 1997) as well as Finnema (Finnema et al., 2000) conducted reviews on various emotion-oriented interventions in dementia. The overall conclusion of these reviews is that there is insufficient (scientific and reliable) evidence yet for the effectiveness of the treatments studied and that there is a clear need for well-designed RCTs.

Below we summarize the results of previous randomized studies on the effectiveness of validation (the basis of the intervention in the underlying study) and other integrated emotionoriented care approaches. We will first discuss the results on the behavior of residents and then address work-related factors in caregivers.

\section{Effects on residents}

Among the many studies conducted on the effectiveness of validation (Day, 1997; Neal and Briggs, 2000; Schrijnemaekers et al., 1995), there are only three randomized controlled studies (Peoples, 1982; Robb et al., 1986; Toseland et al., 1997), of which two had serious methodological flaws. Peoples mentioned that the randomization was manipulated and in Robb et al.'s study the non-compliers were a separate group in the analyses. Both facts introduce serious internal validity problems. Peoples found significant changes in both the validation and control group. Robb et al. reported no positive effects in the (motivated) validation group compared to the control group. For more details about these studies, see chapter two.

The methodologically best performed study with larger study groups was that of Toseland et al. (Toseland et al., 1997). They compared nursing home residents who were assigned to a

\footnotetext{
'behavior therapy

${ }^{2}$ recreabional therapy (crat. games, pets), art therapy (music, dance, art)

'supportive psychotherapy, reminiscence, validation, sensory integraton. simulated presence therapy

“ reality onentation, skills training
} 
validation group $(n=31)$, a social contact group $(n=29)$ and a control group $(n=28)$ in the USA. The duration of the group sessions in both the validation and the social contact group was thirty minutes, four times a week for one year. The follow-up measurements (regarding psycho-social functioning, agitated and positive behavior, medication and use of physical restraints) took place after three and twelve months. The results of this study provided limited support for the effectiveness of group validation for nursing home residents with dementia. Although the nursing staff reported some reduction on agitated behavior, the non-participant observers did not confirm these reductions. There were no significant effects on all other outcome measures like psychological functioning. positive behavior, medication and use of physical restraints.

Other non-experimental evaluation studies nearly all suffered from serious methodological shortcomings and showed conflicting results (see chapter 2). Overall it appeared that the better the study, the less favorable the outcomes were.

Approximately simultaneously with our study, another randomized study started on the effectiveness of emotion-oriented care in nursing homes (Finnema, 2000; Finnema et al., 1998). Finnema's study was conducted on sixteen psycho-geriatric wards in fourteen nursing homes in the Netherlands. She evaluated the effects (cognitive, emotional and social adaptation) of emotion-oriented care on 146 demented residents. All caregivers of the sixteen wards first received a basic training to meet the conditions for quality of care of the Dutch Association for Nursing Home Care. Next, employees of eight intervention wards received an extensive training: all caregivers (230 nurses and many paramedical disciplines) received a basic training of two days, 75 caregivers received additionally an advanced course 'emotion-oriented care worker' of seven days, and fourteen participants also received a 10-day 'adviser emotion-oriented care' training. Besides, there was training on the job for the wards and consultants. At the eight control wards usual care was continued. The followup measurement took place after seven months. The results of this study provide also limited support for the effectiveness of emotion-oriented care. Only for two (small) subgroups were statistically significant results found on one of the nine outcome measures. A statistically significant effect in favor of the intervention group was found in the group of residents less in need of assistance on the emotional adaptive tasks 'maintaining emotional balance' and 'preserving a positive self-image'. So, even in case of a more intensive intervention, no substantial reduction in problem behavior could be identified in a well-performed RCT.

Additionally, these colleagues investigated at the end of their study the execution of the intervention by means of measuring 'coping behavior' and 'nursing skills in handling demented elderly' in the nursing assistants. Whereas the coping behavior showed no differences, some nursing skills seem to have improved in the experimental group.

\section{Effects on caregivers}

Only few studies have addressed the effect of validation or emotion-oriented care on caregivers. Four small-scale studies without a control group on the effects of validation do not allow firm conclusions (Alprin, 1980; Blanchard et al., 1991: Nooren-Staal et al., 1995; Ronaldson and Savy, 1991).

Finnema (2000) (see previous subsection) also studied the effects on the general health of nursing assistants $(n=99)$ in nursing homes. General health was measured by feelings of stress, stress reactions, feelings of competence and illness. For the total population no statistically significant effects were found. Fewer stress reactions were found for one 
subgroup, namely those trained in integrated emotion-oriented care and who perceived improvement in their emotion-oriented care skills.

Because the outcome measures differ considerably, the findings of Finnema (2000) are only to a small extent comparable to our results. Both studies show no differences in sick-leave.

Although the interventions and outcome measures in the few previous randomized trials on validation or emotion-oriented differed, our results are to a large extent comparable, indicating no convincing positive effects of emotion-oriented care.

\section{RECOMMENDATIONS FOR FUTURE RESEARCH}

Two Dutch large-scale randomized studies on the effectiveness of emotion-oriented care showed no or only modest positive effects for cognitively impaired residents and their professional caregivers. Where does this leave us? Should we look for alternative care approaches?

For the moment, we tend to give emotion-oriented care the benefit of the doubt. Firstly, results of only two trials are available and both trials were performed in the Netherlands. The Netherlands has a relatively good basic healthcare, which possibly makes it more difficult to obtain contrast between the study groups. Subsequently, trials in this field are complex and have partly inevitable methodological limitations, which implies that one has to be reluctant in drawing (too) firm conclusions. In this context, we especially mention the potential lack of contrast between the study populations. Finally, many caregivers are very enthusiastic about this intuitively attractive approach and evidence-based alternatives are not (yet) available.

Given the foregoing, we think that additional studies are needed to settle the discussion. Given the limited cogency of the two Dutch trials with relatively intensive interventions, we think that before more large-scaled randomized intervention studies are planned, more insight is needed into the optimization of training and implementation strategies regarding emotion-oriented care in long-term-care facilities. Based on the experiences in our study and the literature we will subsequently briefly address some preconditions and alternative training and implementation strategies.

\section{Preconditions}

Because a home-wide implementation of emotion-oriented care makes great demands on the management and the professional caregivers, it is important that the approach is supported by all those involved and that all parties are fully informed upon the goal(s) and the training and implementation strategy.

Besides the competence, motivation and commitment of all employees involved, the stimulating and facilitating role of management seems an important condition for success. In addition to workers' participation. Karasek for example stresses the importance of broad institutional support, expressed in sufficient economic and technical resources (Karasek, 1992). Berkhout mentioned a variety of reasons for the failure of interventions in nursing care, like top-down solutions, lack of long-term support of management, inability to delegate authority, passive instead of active involvement of employees and lack of supervisor support (Berkhout, 2000). These reasons particularly relate to management and organizational issues. To overcome organizational resistance to staff management interventions in geriatric long-term-care facilities, Burgio and Burgio suggested obtaining the support of hierarchies, elaborating on effective staff management components already in place within the setting. 
using participative management, keeping the program simple and proceeding slowly, being flexible and sharing the results of the program with the various hierarchies (Burgio and Burgio, 1990).

Finally, the management should also refrain from introducing too many other changes at the same time as the implementation of a new care approach. Multiple introductions distract from the primary goals and makes too much appeal on the resilience of the professional caregivers.

\section{Training strategy}

In our study we chose to offer the training in emotion-oriented care to a limited number of key-figures in the care for psycho-geriatric residents in the homes for the elderly (about five caregivers of the day-care units and three of the wards). It was the intention that they. supported by management and under the supervision of a trainer, would be able to disseminate and implement the emotion-oriented care approach in their homes.

Other training strategies may lead to different results. These strategies could, for example, focus on another target population or a modification of the content of the training program.

A possible alternative target population is offering the training in particular to caregivers of the wards in homes for the elderly. These caregivers have in general less experience and affinity with the care for residents with cognitive impairment and behavioral problems and therefore possibly more profit can be achieved in these caregivers. Another alternative is to train especially or at least all nursing management staff. These staff members are probably more capable of integrating the emotion-oriented care approach in the overall care policy and may have (better) capacities to pass on knowledge to others and to supervise the implementation of a new care approach.

With regard to the content of the training we may ask whether an integrated emotion-oriented care approach could be too 'broad' to implement and evaluate. Clear guidelines about which approach should be applied to whom and when are lacking and often a trial-and-error procedure has to be used. Possibly a restricted training program (e.g. focused on specific behaviors or care situations) is more suitable in practice and research.

\section{Implementation strategy}

In our study, three supervision-meetings (half-a-day each) were offered in the intervention homes to support the implementation of the new care model. The meetings were 'tailormade' and the content depended on the specific bottlenecks in each intervention home.

One can also consider alternative implementation strategies. Possibilities to consider are a more intensive hands-on training with a performance feedback system (Burgio and Burgio, 1990; Stevens et al., 1998) or contract out the total implementation to an external professional organization. Both alternative implementation strategies are labor-intensive and consequently expensive.

Burgio et al. (2001) recently discussed the importance of inducing and assessing treatment implementation strategies in care giving trials. They propose Lichstein's implementation model (Lichstein et al., 1994) as an potential guide. This model distinguishes three fundamental components of implementation: delivery, receipt and enactment. Burgio and colleagues also discuss various strategies for assessing treatment delivery, receipt and enactment, varying from treatment manuals (delivery), assessing knowledge (receipt) to observations (enactment) (Burgio et al., 2001). 
If more insight becomes available on optimal training and implementation strategies of emotion-oriented care, an additional efficacy study could be conducted. Such a study should also include a cost-effectiveness analysis and should preferably be conducted in a country with, compared to the Netherlands, less good basic healthcare or a greater variety in quality of care. Possibly, the contrast between study groups can be realized more easily elsewhere. In case new RCTs are conducted in this field, we want to stress the use of additional qualitative methods to monitor the compliance and contrast. At the moment information about compliance and obtained contrast is often lacking in care intervention studies. These qualitative studies should consider the use of baseline measurements to be certain about changes over time due to the intervention and observations for several days (possibly at various wards) to be able to draw convincing conclusions. New trials should also contemplate the use of video recordings to blindly assess the compliance and outcomes (e.g. behavior of residents). Additional qualitative research and blind assessments are both laborintensive and therefore costly, but can provide very valuable information.

\section{RECOMMENDATIONS FOR PRACTICE}

We think that there is insufficient scientific evidence yet to implement emotion-oriented care on a large scale. Given the fact that rather intensive training and implementation strategies as in our study and others showed no or only modest effects, offering ad hoc training to professional caregivers (at the moment often the daily routine) is not advisable.

Obviously, the conclusions mentioned above are rather frustrating for caregivers involved in the daily care for psycho-geriatric patients. Frustrating, because on the one hand many caregivers are very enthusiastic about emotion-oriented care approaches of which the effectiveness is as yet not clearly demonstrated, and on the other hand no other evidencebased alternatives are (yet) available.

In expectation of additional evidence, we want to mention that also no negative effects or side effects were found and that there are consequently no reasons to stop immediately the use of emotion-oriented care approaches.

Yet, if psycho-geriatric long-term care facilities nevertheless intend to start up an (intensive) training and implementation of emotion-oriented care, the previously mentioned preconditions and considerations regarding the training and implementation strategies may be helpful. However, one should take into account the attending high costs of training and implementation programs and the mostly lacking evidence for the time being.

Finally, we want to stress the following.

Cognitive impairment and especially the accompanying behavior problems often have an (extremely) effect on the quality of life of patients and their caregivers. Postponing or slowing down cognitive decline may represent an important benefit and even modest improvements in behavioral disturbances can markedly improve their quality of life. These patients, and their caregivers, deserve and need special attention in geriatric research, policy and practice. 


\section{REFERENCES}

Alprin, SI. (1980). Staff attitudes after validation. Cleveland, Ohio: Cleveland State University. American Psychiatric Association. (1997). Practice guideline for the treatment of patients with Alzheimer's disease and other dementias of late life. Am. J. Psychiatry, 154(5 Suppl), 1-39.

Berkhout, A. (2000). Resident-oriented care in nursing homes. An evaluation study of the model of resident-oriented care, the implementation and the effects. Maastricht: Datawyse.

Blanchard, F, Prentczynski, J, Wong, C, Lamaze, B, Bocquet, P, Jolly, D, \& Lorton, O. (1991). An application of the validation method at the geriatrics care unit of the University Hospital in Reims. France. Reims: Hôspital Sebastopol, Service de Médicine Interne et Geriatrie.

Boom Poels, PG. (1994). Het gedragsprofiel van psychogeriatrische patienten in substitutieprojecten: verpleeghuiszorg in het verzorgingstehuis. Tijdschr. Gerontol. Geriatr., 25(1), 17-21.

Bryk, AS, \& Raudenbush, SW. (1992). Hierarchical Linear Models, Applications and Data Analysis Methods. Newbury Park, CA: Sage

Burgio, L, Lichstein, KL, Nichols, L, Czaja, S, Gallagher Thompson, D, Bourgeois, M, Stevens, A, Ory, M, \& Schulz, R. (2001). Judging outcomes in psychosocial interventions for dementia caregivers: the problem of treatment implementation. Gerontologist, The, 41(4), 481-489.

Burgio, LD, \& Burgio, KL. (1990). Institutional staff training and management: a review of the literature and a model for geriatric, long-term-care facilities. Int. J. Aging Hum. Dev., 30(4), 287-302

Day. CR. (1997). Validation therapy. A review of the literature. J. Gerontol. Nurs ., 23(4), 29-34

Finnema, E, Dröes, RM, Ribbe, M, \& Tilburg, WV. (2000). The effects of emotion-oriented approaches in the care for persons suffering from dementia: A review of the literature. Int. J. Geriatr. Psychiatry, 15(2), 141-161.

Finnema, EJ. (2000). Emotion-oriented care in dementia. A psychosocial approach. Groningen: Stichting Drukkerij C. Regenboog.

Finnema, EJ, Drōes, RM, van der Kooij, CH, de Lange, J, Rigter, H, van Montfort, APWP, \& van Tilburg. W. (1998). The design of a large-scale experimental study into the effect of emotionoriented care on demented elderly and professional carers in nursing homes. Archives of Gerontology and Geriatrics, suppl 6, 193-200.

Karasek, R. (1992). Stess prevention through work reorganization: A summary of 19 international case studies. Conditions of Work Digest, 11, 23-41.

Koger, SM, \& Brotons, M. (2000). Music therapy in dementia symptoms, The Cochrane Libary (Vol. Issue 4). Oxford: Update Software.

Landeweerd, JA, Boumans, NPG, \& Nissen, JMF. (1996). Arbeidsvoldoening bij verplegenden en verzorgenden. De Maastrichtse arbeidssatisfactieschaal voor de gezondheidszorg. In CC van Beek \& TC van Dorsten \& GJ Stam (Eds.), Handboek Verpleegkundige innovatie. Loghem/Houten: Bohn Stafleu.

Lichstein, KL, Riedel, BW, \& Grieve, R. (1994). Fair tests of clinical trials: A treatment implementation model. Adv. Behav. Res. Ther., Vol 16(1), 1-29.

Midence, K, \& Cunlifffe, L. (1996). The impact of dementia on the suffer and available treatment interventions: an overview. The J. of Psychol., 130(6), 589-602.

Neal, M. \& Briggs, M. (2000). Validation therapy for dementia, The Cochrane libary (Vol. Issue 4). Oxford: Update Software.

Nooren-Staal, WHC, Frederiks, CMA, \& te Wierik, MJM. (1995). Validation; effecten bij bewoners en personeel in een verzorgingshuis. Tijdschr. Gerontol. Geriatr., 26(3), 117-121

Peoples, MM (1982). Validation therapy versus reality orientation as treatment for the institutionalized disoriented elderly (thesis). Akron: University of Akron.

Robb, SS, Stegman, CE, \& Wolanin, MO (1986). No research versus research with compromised results: a study of validation therapy. Nurs. Res., 35(2), 113-118.

Ronaldson, S, \& Savy, P. (1991). Validation therapy: a viable option for gerontic nursing practice. Geriaction, (Autumn), 7-10

Schrijnemaekers, VJ, Duijnhouwer, E, te Wierik, MJ. \& Frederiks, CM. (1995). De effectivitert van validation. Een literatuuronderzoek. Tijdschr. Gerontol. Geriatr., 26(5), 205-213.

Snijders, TAB, \& Bosker, RJ. (1999). Multilevel Analysis: An introduction to basic and advanced multilevel modeling. London: Sage.

Spector, A, Orrell, M. Davies, S. \& Woods, B. (2000a). Reality orientation for dementia, The Cochrane Library (Vol. Issue 4). Oxford: Update Software. 
Spector, A, Orrell, M, Davies, S, \& Woods, R. (2000b). Reminisence therapy for dementia, The Cochrane Library (Vol. Issue 4). Oxford: Update Software.

Stevens, AB, Burgio, LD, Bailey, E, Burgio, KL, Paul, P, Capilouto, E, Nicovich, P, \& Hale, G. (1998). Teaching and maintaining behavior management skills with nursing assistants in a nursing home. Gerontologist, The, 38(3), 379-384.

Toseland, RW, Diehl, M, Freeman, K, Manzanares, T, Naleppa, M, \& McCallion, P. (1997). The impact of validation group therapy on nursing home residents with dementia. Journal of Applied Gerontology, Vol 16(1), 31-50.

van Heusden, M, Widdershoven, G, Schrijnemaekers, V, \& van Rossum, E. (1999). Een kwalitatief onderzoek naar compliance en ervaringen met belevingsgerichte zorg in verzorgingshuizen. Maastricht: Universiteit Maastricht.

Verstraten, PFJ, \& van Eekelen, CWJM. (1987). Handleiding voor GIP. Gedragsobservatieschaal voor de intramurale psychogeriatrie. Nijmegen: Van Loghum Slaterus. 


\section{Summary}

The introduction of this thesis (chapter 1) describes the background and relevance of the study. It is stated that dementia and the often accompanying behavioral disturbances occur frequently in elderly people. These problems critically impact on the patient and their caregivers.

As little is known about the etiology of dementia, no effective treatments are yet available. Consequently, treatment often addresses symptom management. There are no real effective pharmaceutical treatments available for the behavioral disturbances in dementia patients and they induce many side-effects. Over the last decades several care approaches and therapies have been developed in the care for psycho-geriatric patients. In general four types of psychosocial treatments are distinguished : behavior-oriented, stimulation-oriented, emotionoriented and cognition-oriented.

'Validation' is a frequently used and popular psychosocial approach in dementia care. This approach has been developed in the 1960 s by Feil. She describes it as a process of communicating with disoriented elderly people by validating and respecting their feelings. Validation does not force disoriented elderly people into 'our reality'; instead the elderly person's perception of the environment is validated. In the Netherlands there is a tendency to apply validation in combination with other approaches, such as sensory-stimulation and reminiscence. This combined approach, mainly based on the validation approach, is called emotion-oriented care. Because there is insufficient scientific evidence for the effectiveness of the various approaches, additional research is needed.

We investigated the effects of emotion-oriented care on elderly people with moderate to severe cognitive impairment and behavioral problems and their professional caregivers in homes for the elderly.

Chapter 2 describes a literature review on the effectiveness of the validation approach in the care for disoriented elderly people. Various computerized data-sets (such as MEDLINE and PSYCHLIT) and other sources were used to search for relevant studies. By contacting Feil, also unpublished articles and reports became available.

The search resulted in sixteen studies. These studies were conducted in different parts of the world, relate to (relatively small) populations in various settings, use different outcome measures and have follow-up measurements varying from ten days to twelve months. The interventions related to group sessions of validation (with a large variety in frequency and duration), training of caregivers in validation, and/or the implementation of validation. The study designs also show major differences: three randomized controlled trials, three quasi experiments with a control group and ten studies without a control group and/or without pretest measurements. Nearly all studies suffered from serious methodological shortcomings and the results were conflicting. It appeared that the better the study, the less favorable the effects of validation were. It is concluded that there is insufficient evidence yet for the effectiveness of validation and that additional research is needed.

Chapter 3 presents the design of the study to test the effects of emotion-oriented care on residents and their professional caregivers in homes for the elderly. A randomized controlled trial (RCT) has been conducted in sixteen homes for the elderly. After pre-stratification the homes were randomly allocated to an intervention or control group. 151 Residents with moderate to severe cognitive impairment and behavioral problems have been included in the study. All included residents participated in a structured day-care program in the home for the elderly. Furthermore, 300 professional caregivers in the homes were selected for the study. 
In the eight intervention homes the caregivers at the day-care unit and some caregivers of the wards, received a training program in emotion-oriented care. In the eight control homes usual care was continued.

To study the effects of the new care approach, measurements were performed at baseline and after three, six and twelve, months of follow-up. The primary outcome measure for the resident was behavioral problems and for the caregivers job satisfaction. Secondary outcomes for the residents were some other behavior-related outcomes and for the caregivers burnout and sick-leave. Various multilevel analyses were conducted to study the differences between the two study groups.

The chapters 4 and 5 present the results for the residents and the professional caregivers in the homes for the elderly.

An important goal of emotion-oriented care is to reduce problem behavior in elderly people with cognitive impairment and behavioral problems. These behavioral problems relate to among others: loss of decorum and nonsocial, apathetic, rebellious, restless, dependent and anxious behavior. We were unable to confirm the presumed beneficial effects. Although relatively more estimated differences were in favor of the intervention group, the differences were neither statistically significant nor clinically relevant. Data from various sources (caregivers of the day-care unit, caregivers of the ward, and representatives of the resident) showed consistently no positive effects. Some statistically significant effects after six months of follow-up, only partly in favor of the intervention homes, were probably due to chance (multiple testing).

A second goal of emotion-oriented care is to improve job satisfaction and other work-related aspects of professional caregivers. With regard to the caregivers, some modest positive effects in favor of the intervention homes on subscales of job satisfaction and burnout were found. The caregivers in the intervention group had, for instance, a statistically significant better score on the job satisfaction subscale 'opportunities for self-actualization' and on the burnout subscale 'personal accomplishment'. Although all statistically significant differences were in favor of the intervention homes, one has to notice that they have limited clinical meaning.

Chapter 6 presents the results of an additional qualitative study. This investigation studied two questions: (1) to what extent did the intervention sites comply to the 'rules' of the new care model, and (2) what were experiences of employees in the intervention homes concerning the training in and the implementation of the new care model?

The qualitative study was performed in eight of the sixteen homes for the elderly (four intervention and four control homes). In both the intervention and control homes, observations on the day-care units were conducted and care plans were studied to answer the first question. To study the experiences of the caregivers with the training and implementation of emotion-oriented care, semi-structured interviews were conducted with four persons in each of the four intervention sites (a total of sixteen interviews).

The observations showed no clear differences between intervention and control homes with regard to the communication and interactions between residents and professional caregivers. Analysis of the reporting systems revealed differences within as well as between the intervention and control homes. The content of the reports showed no differences between the intervention and control homes. The interviewees had different expectations of the EOC training, depending on their disciplinary background. The caregivers regarded the training as a confirmation of their current practice. They experienced some changes at the individual level and some of them reported that the co-operation between units had become better. At 
the home-level no changes were reported. Often interviewees indicated that the implementation of EOC was difficult and laborious.

Chapter 7 presents a summary of the main findings and a methodological reflection on the study. Methodological points of interest are the non-blinded outcome measurements, the absence of a control or placebo intervention and the contrast between the intervention and control group.

Subsequently, our findings are embedded in the available evidence regarding emotionoriented care approaches. Up to now, only two large randomized studies of good methodological quality were conducted. Although the interventions and outcome measures in these two trials differed, our results are to a large extent comparable, indicating no convincing positive effects.

We conclude that there is insufficient evidence yet to implement emotion-oriented care on a large scale and that offering ad hoc training to professional caregivers is not advisable.

Given the modest effects, combined with the enthusiasm in the field and the lack of alternative care approaches, additional research is recommended. Before new large-scaled randomized studies are conducted, more insight is needed into the optimization of training and implementation strategies for emotion-oriented care. 


\section{Samenvatting ${ }^{1}$}

In de inleiding (hoofstuk 1) van dit proefschrift wordt de relevantie en aanleiding van het onderzoek beschreven. Aangegeven wordt dat dementie en de hiermee vaak gepaard gaande gedragsstoornissen veel voorkomen bij oudere mensen en dat dit veel leed, zorgen en frustratie met zich mee kan brengen voor patiênten en hun zorgverleners.

Omdat er nog maar weinig bekend is over de etiologie van dementie, is er op dit moment nog geen effectieve preventie en genezing mogelijk. Dientengevolge richt de behandeling zich vaak op symptoombestrijding. Er zijn nog nauwelijks effectieve farmacologische behandelingen voor gedragsstoornissen bij demente ouderen en deze behandelingen gaan vaak gepaard met veel bijwerkingen. De ontwikkeling van niet farmacologische behandelingen en benaderingen heeft de afgelopen jaren veel aandacht gekregen. Zo worden bijvoorbeeld door de American Psychiatric Association (APA) vier soorten benaderingen onderscheiden: gedrags-, stimulatie-, emotie- en cognitie-georiënteerd. 'Validation' is een veel gebruikte en populaire emotie-georiènteerde benadering in de psycho-geriatrie. Deze benadering is in de jaren zestig ontwikkeld door Feil met als uitgangspunten het herkennen en bevestigen van gevoelens vanuit een empathische houding. In plaats van de demente ouderen voortdurend bij onze werkelijkheid te betrekken. wordt de oudere in zijn belevingswereld 'erkend' of 'gevalideerd'. Sinds enige jaren is er een voorkeur ontstaan om de benaderingswijze validation te combineren met (elementen uit) andere methodieken, zoals reminiscentie en zintuigactivering. Dit gecombineerde aanbod, met validation als basis, wordt belevingsgerichte zorg genoemd. Voor de effectiviteit van verschillende benaderingen is nog onvoldoende wetenschappelijk bewijs. $\mathrm{Er}$ is derhalve behoefte aan nieuw onderzoek.

Het voorgaande was voor ons de aanleiding om onderzoek te verrichten naar de effectiviteit van belevingsgerichte zorg. Het onderzoek richt zich op de effecten op het gedrag van verzorgingshuisbewoners met cognitieve stoornissen en gedragsproblemen enerzijds en anderzijds op de arbeidstevredenheid van het verzorgend personeel in verzorgingshuizen.

Hoofdstuk 2 beschrijft de bevindingen van een literatuuronderzoek naar de effectiviteit van validation als benadering in de zorg voor dementerende ouderen. Om relevante effectiviteitstudies op te sporen zijn verschillende databases zoals MEDLINE en PSYCHLIT gebruikt, is de Science Citation Index geraadpleegd en zijn alle in literatuurlijsten gevonden studies gecheckt. Door contact op te nemen met Feil zijn ook ongepubliceerde artikelen en rapporten beschikbaar gekomen.

Uiteindelijk zijn zestien rapportages van effectstudies opgespoord. Deze studies zijn afkomstig uit drie verschillende werelddelen, hebben betrekking op (relatief kleine) populaties in verschillende settingen en hanteren diverse uitkomstmaten met follow-up metingen variërend van tien dagen tot twaalf maanden. De beschreven interventies betreffen groepssessies validation (van sterk uiteenlopende intensiteit en duur) en trainingen validation voor personeel en/of de implementatie van validation. Ook de methoden van onderzoek verschillen sterk: drie gerandomiseerde gecontroleerde onderzoeken, drie quasiexperimenten met controle groep en tien ongecontroleerde onderzoeken. De gevonden effectstudies naar validation hebben veel methodologische beperkingen en de resultaten zijn tegenstrijdig. Het blijkt dat hoe beter de methodologische kwaliteit van het onderzoek is, hoe minder gunstig de resultaten voor validation zijn. Concluderend wordt gesteld dat er (nog)

\footnotetext{
1. Een uitgebreide Nederlandstalige rapportage over het onderzoek is opgenomen in

Schninemaekers, VJJ, Rossum, van E. Candel, MJJM, Frederiks, CMA. Derix, MMA. Brandt, van den PA. (2000) Eflecten van belevingsgenchte zorg in verzorgingshuizen Maastncht Universitest Maastncht. Capactentsgroep Epidemiologie
} 
onvoldoende bewijs is voor de effectiviteit van validation en dat aanvullend onderzoek nodig is.

In hoofdstuk 3 wordt de opzet van het onderzoek naar de effectiviteit van belevingsgerichte zorg op verzorgingshuisbewoners en hun professionele zorgverleners beschreven. Het onderzoek is in zestien verzorgingshuizen uitgevoerd in de vorm van een gecontroleerd experiment (RCT). Na pre-stratificatie zijn de huizen random toegewezen aan de interventieof controlegroep. Er hebben 151 verzorgingshuisbewoners met matig tot ernstige cognitieve stoornissen en gedragsproblemen deelgenomen aan het onderzoek. Deze bewoners maakten allemaal gebruik van een project voor gestructureerde opvang (b.v. groepsverzorging of substitutieproject) in het verzorgingshuis. Daarnaast hebben er 300 zorgverleners uit de verzorgingshuizen deelgenomen aan het onderzoek.

In de acht interventiehuizen ontving het personeel van de groepsverzorging (activiteitenbegeleiders en verzorgenden), alsmede enkele medewerkers van de afdeling, een cursus belevingsgerichte zorg. Vervolgens werd deze zorg geïmplementeerd in de betreffende huizen. In de acht controlehuizen werd de standaardzorg gecontinueerd. Na drie, zes en twaalf maanden vonden metingen plaats bij het verzorgend personeel en familieleden van de ouderen om de effecten van de nieuwe zorgbenadering op bewoners en personeel vast te stellen. De primaire effectmaat voor de bewoners was het gedrag en voor het verzorgend personeel de arbeidstevredenheid. Daarnaast zijn vele andere aan gedrag gerelateerde effectmaten geëvalueerd bij de bewoners en is bij het verzorgend personeel ook gekeken naar 'burnout' en ziekteverzuim. Verschillende multilevel analyses zijn uitgevoerd.

In de hoofdstukken 4 en 5 worden achtereenvolgens de resultaten voor de verzorgingshuisbewoners en het verzorgend personeel gepresenteerd.

Een belangrijk doel van belevingsgerichte zorg is het verminderen van gedragsproblemen bij ouderen met matige tot ernstige cognitieve en gedragsstoornissen. De belangrijkste gedragsproblemen waren: decorum verlies en niet sociaal, apathisch, opstandig, onrustig. afhankelijk en angstig gedrag. Het veronderstelde gunstige effect, hebben wij in ons onderzoek niet kunnen bevestigen. Verschilscores op de verschillende effectmaten met betrekking tot het gedrag van de bewoners waren iets vaker licht in het voordeel van de interventiegroep. De gevonden verschillen tussen de twee groepen waren echter over het geheel genomen statistisch niet significant en klinisch niet relevant. Dit laatste bleek consistent voor de verschillende uitgevoerde analyses. Bovendien verschilden de uitkomsten niet tussen de drie groepen beoordelaars: medewerkers groepsverzorging, afdelingsverzorgenden en contactpersonen van de bewoners. Enkele statistisch significante resultaten na zes maanden -die overigens slechts ten dele in het voordeel van de interventie groep waren- zijn waarschijnlijk toevalsbevindingen (kanskapitalisatie).

Een tweede doel van belevingsgerichte zorg is het verbeteren van de arbeidstevredenheid en andere arbeidsgerelateerde aspecten bij het verzorgend personeel. Voor het verzorgend personeel zijn bescheiden positieve effecten gevonden op subschalen van arbeidstevredenheid en 'burnout'. De verzorgenden in de interventiegroep hadden bijvoorbeeld een statisch significant betere score op de arbeidstevredenheid subschaal 'groeimogelijkheden' en op de 'burnout' subschaal 'persoonlijke bekwaamheid'. Hierbij moet aangetekend worden dat de gevonden verschillen in de regel niet groot waren. Statistisch significante verschillen waren in de regel 'borderline'. Door de redelijke omvang van de onderzoeksgroepen (circa 150 personen per groep), zijn enkele net statistisch significante verschillen tussen de groepen uit klinisch oogpunt bescheiden. 
Hoofdstuk 6 presenteert de bevindingen van een aanvullende kwalitatieve studie, waarin twee vragen centraal stonden: (1) zijn er verschillen tussen de interventie- en controlehuizen waarneembaar in de communicatie en interactie met bewoners en (2) hoe ervaart het personeel in de interventiehuizen het belevingsgericht werken en de implementatie daarvan? Het kwalitatieve onderzoek is bijna een jaar na de start van de interventieperiode uitgevoerd bij acht van de zestien deelnemende verzorgingshuizen (vier interventie- en vier controlehuizen). Om de eerste vraag te beantwoorden zijn op beperkte schaal observaties verricht en zorgdossiers van deelnemende bewoners bestudeerd. Voor de tweede vraag zijn zestien semi-gestructureerde interviews met verschillende disciplines in de vier interventiehuizen uitgevoerd.

Uit de observaties kwamen geen duidelijke verschillen in communicatie en interactie op de groepsverzorging tussen de interventie- en controlehuizen naar voren. De analyses van de rapportages laten zowel verschillen binnen als tussen de interventie- en controlehuizen zien. Er werden geen verschillen gevonden in de inhoud van de rapportages tussen interventie- en controlehuizen.

Uit de interviews kwam naar voren dat men, afhankelijk van de hiërarchische positie, verschillende verwachtingen had van de cursus belevingsgerichte zorg. Veel zorgverleners beschouwden de training als een bevestiging van hun dagelijks handelen en ervaarden veranderingen in de omgang met bewoners op individueel niveau. Op afdelings- en huisniveau werden vrijwel geen veranderingen geconstateerd. Geïnterviewden gaven meermaals aan dat de implementatie van belevingsgerichte zorg moeilijk en arbeidsintensief is.

In hoofdstuk 7 wordt een samenvatting van de belangrijkste resultaten gevolgd door een reflectie op de gehanteerde methoden van onderzoek. De belangrijkste aandachtspunten hierbij zijn de niet-geblindeerde effectmetingen, het ontbreken van een controle of placebo interventie en het contrast tussen de interventie- en controlegroep.

Vervolgens worden onze resultaten vergeleken met die van ander onderzoek naar de effectiviteit van validation of belevingsgerichte zorg. Tot nu toe zijn er slechts twee grote, methodologisch goed uitgevoerde gerandomiseerde studies uitgevoerd. Alhoewel de interventies en effectmaten van deze twee onderzoeken deels anders zijn dan die in ons onderzoek, zijn de resultaten over het algemeen vergelijkbaar: er worden geen overtuigend positieve effecten aangetoond.

Tot slot wordt geconcludeerd dat er momenteel nog onvoldoende wetenschappelijk bewijs is om belevingsgerichte zorg op grote schaal te implementeren en dat ad hoc training van personeel niet zinvol lijkt.

Gelet op de bescheiden resultaten, in combinatie met het enthousiasme in de praktijk en het ontbreken van alternatieven, wordt aanvullend onderzoek aanbevolen. Hierbij moet eerst aandacht besteed worden aan het optimaliseren van trainings- en implementatiestrategieên alvorens een nieuwe effectiviteitstudie wordt uitgevoerd. 
Appendix 1 Vragenlijst bewoner 
Appendix 1 


\title{
Belevingsgerichte zorg in verzorgingshuizen
}

\author{
Vragenlijst bewoner (meting na 3 maanden) \\ - verzorgende(n) van de afdeling -
}

w Wilt u de volgende gegevens a.u.b. controleren en de invuldatum invullen ?

Naam verzorgingshuis:

Naam bewoner:

Naam eerste verzorgende:

Naam tweede verzorgende:

(alleen voor het invullen van de GIP: pagina 3, 4 en 5)

Invuldatum:

19 
De vragen op de eerste 3 pagina's met betrekking tot gedrag zijn afkomstig van de Gedragsobservatieschaal voor de Intramurale Psychogeriatrie (GIP) (Verstraten \& van Eekelen, 1987).

De gehanteerde ADL-schaal is een aangepaste versie (Schrijnemaekers \& Haveman, 1993) van de ADL-schaal van Katz (1976).

De gebruikte items omtrent 'communicatie' zijn afkomstig van de Geriatric Residents Goal Scale (GRGS) (Cornbleth, 1978; Nederlandse vertaling: Dröes, 1986).

De 29 items over 'agitatie' zijn afkomstig van de Nederlandse versie (de Jonghe, 1996) van de Cohen Mansfield Agitation Inventory (CMAI) (Cohen Mansfield \& Billig. 1986).

De 19 items over 'depressie' zijn afkomstig van de Nederlandse versie (Dröes, 1993) van de Cornell Depression Scale (Alexopoulos, 1988). 


\section{GEDRAG (GIP)}

Bij het beantwoorden van de vragen van de GIP (pagina 3, 4 en 5) is het noodzakelijk dat dit door twee personen tezamen gedaan wordt. Bij voorkeur dienen deze vragen ingevuld te worden door de twee verzorgenden die op de kaft van deze vragenlijst vermeld staan.

Verdere aanwijzingen voor het invullen van de vragen:

* Geef voor iedere uitspraak aan in welke mate jullie de genoemde gedragingen de laatste twee weken bij de bewoner hebben waargenomen.

w. Beantwoord iedere uitspraak door éen van de vier antwoordmogelijkheden te onderstrepen.

w Wanneer jullie twijfelen, bijvoorbeeld tussen 'soms' en 'vaak', onderstreep ze dan niet beide, maar probeer toch tot ' $n$ keuze te komen en onderstreep maar één antwoord.

w Sla geen uitspraken over. Beantwoord ze allemaal.

* Beantwoord de vragen op basis van wat jullie zelf zien en meemaken met de bewoner.

w Voorbeeld

Indien jullie van mening zijn dat de bewoner vaak zit te suffen, dan geven jullie dat als volgt aan:

$0 \quad$ Zit te suffen

nooit - soms - vaak - altijd

$1 \quad$ Lijkt blij met bezoek van familieleden

nooit - soms - vaak - altijd

$2 \quad$ Neemt deel aan gezamenlijke activiteiten buiten de afdeling

nooit - soms - vaak - altijd

3 Is bereid om desgevraagd iemand te helpen

nooit - soms - vaak - altijd

4 Begint uit zichzelf een gesprek met anderen

nooit - bijna nooit - soms - vaak

$5 \quad$ Heeft contact met de verpleging/verzorging (met of zonder woorden)

nooit - soms - regelmatig - vaak

$6 \quad$ Lijkt te luisteren naar wat anderen vertellen

nooit - soms - vaak - altijd

$7 \quad$ Kan met medebewoners heel goed opschieten

niemand - enkele - meerdere - de meeste

8 Toont interesse voor personeelsleden

nooit - soms - vaak - altijd

$9 \quad$ Reageert wanneer hij/zij aangesproken wordt

meestal niet - soms - regelmatig - vaak

10 Leest krant en/of tijdschrift

nooit - soms - vaak - altijd

11 Toont emoties bij niet-alledaagse of ingrijpende gebeurtenissen

nooit - soms - vaak - altijd

12 Reageert zichtbaar op muziek

nooit - soms - vaak - meestal

13 Kijkt op als er iemand binnenkomt of als er iets gebeurt

nooit - soms - vaak - altijd

14 Luistert naar de radio en/of kijkt televisie

nooit - bijna nooit - soms - vaak 
15 Schrikt op uit een soort droomtoestand als hij/zij wordt aangesproken nooit - bijna nooit - soms - vaak

16 Suft weg tijdens gesprekken of bezigheden nooit - zelden - regelmatig - meestal

17 Zit onderuit gezakt zonder moeite te doen rechtop te zitten nooit - zelden - regelmatig - meestal

18 Besteedt zorg aan het uiterlijk

nooit - soms - vaak - altijd

19 Laat ongegeneerd boeren of winden

nooit - zelden - soms - vaak

20 Houdt zich aan de gewone omgangsvormen (groeten, danken, verontschuldigen)

nooit - soms - vaak - altijd

21 Laat vocht uit mond of neus gewoon lopen (zonder het af te vegen)

nooit - zelden - regelmatig - voortdurend

22 Probeert uit het huis te ontsnappen, uit verzet tegen het verblijf hier nooit - bijna nooit - soms - regelmatig

23 Sputtert tegen als er wat gevraagd wordt nooit - bijna nooit - soms - vaak

24 Houdt zich aan regels en gebruiken van de afdeling

zelden - vaak niet - meestal wel - altijd

25 Wijst hulp van personeel van de hand nooit - bijna nooit - soms - vaak

26 Werkt mee wanneer dat gevraagd wordt nooit - soms - vaak - altijd

27 Trekt op de verkeerde plaats kleren uit (zonder seksuele bedoelingen) nooit - bijna nooit - soms - vaak

28 Kan de dingen zodanig duidelijk maken dat men begrijpt wat bedoeld wordt nooit - soms - vaak - altijd

29 Kent naaste familieleden bij naam nooit - soms - vaak - altijd

30 Onthoudt wat gevraagd of opgedragen wordt nooit - soms - vaak - altijd

$31 \quad$ Lijkt te beseffen welk tijdstip van de dag het is nooit - soms - vaak - altijd

32 Uit het gedrag is af te leiden dat hij/zij het heden met het verleden verwisselt nooit - zelden - regelmatig - voortdurend

33 Schuift met de voeten heen en weer nooit - bijna nooit - soms - vaak

34 Praat of mompelt langdurig, tegen niemand in het bijzonder nooit - bijna nooit - soms - vaak

35 Loopt rusteloos rond in huis

nooit - soms - vaak - voortdurend 
36 Praat veel en snel

nooit - soms - vaak - meestal

37 Kan rustig stil blijven zitten/liggen

nooit - zelden - vaak - altijd

38 Gedraagt zich zenuwachtig

nooit - soms - regelmatig - meestal

39 Is te ongedurig om langere tijd met iets bezig te blijven

nooit - soms - vaak - altijd

40 Beweert dat anderen hem/haar niet mogen

nooit - bijna nooit - soms - vaak

41 Gedraagt zich wantrouwend tegenover personeelsleden

nooit - bijna nooit - soms - vaak

42 Zegt zich neerslachtig te voelen

nooit - soms - regelmatig - vaak

43 Lijkt zich ongelukkig te voelen

nooit - soms - vaak - voortdurend

44 Gedraagt zich afhankelijk ten opzichte van het personeel

nooit - soms - vaak - altijd

45 Vraagt om geholpen te worden bij dingen die hij/zij zelf blijkt te kunnen nooit - bijna nooit - soms - vaak

46 Vraagt personeelsleden om raad of advies

nooit - bijna nooit - soms - vaak

47 Probeert op alle mogelijke manieren de aandacht op zich te vestigen nooit - bijna nooit - soms - vaak

48 Lijkt aarzelend of onzeker in het nemen van kleine beslissingen nooit - soms - vaak - altijd

49 Raakt in paniek bij het verlaten van de afdeling

nooit - bijna nooit - soms - vaak

50 Laat merken bang te zijn voor bepaalde personen of dingen nooit - bijna nooit - soms - vaak

51 Is plotseling angstig. zonder duidelijke reden nooit - bijna nooit - soms - vaak

52 Is angstig in aanwezigheid van bepaalde andere bewoners nooit - bijna nooit - soms - vaak

53 Toont angst wanneer hij/zij door het personeel geholpen wordt nooit - bijna nooit - soms - vaak

54 Is angstig in aanwezigheid van 'onbekenden' nooit - bijna nooit - soms - vaak 


\section{HINDERLIJKE GEDRAGINGEN}

Drie maanden geleden hebben wij u gevraagd om maximaal 3 gedragingen van de bewoner aan te geven, waarvan u het meest hinder ondervond. Bovendien heeft u daarbij aangegeven hoe vaak deze gedragingen toen voorkwamen.

$\mathrm{Nu}$ (inmiddels drie maanden later) willen wij u opnieuw vragen om aan te geven hoe vaak diezelfde gedragingen op dit moment voorkomen.

\section{Aanwijzingen voor het beantwoorden van deze vraag:}

*a In het overzicht hieronder staan de gedragingen van de bewoner vermeld, waarvan u drie maanden geleden heeft aangegeven het meest hinder te ondervinden.

w Geeft u a.u.b. aan, hoe vaak deze gedragingen op dit moment bij de bewoner voorkomen, door één van de antwoordmogelijkheden aan te kruisen.

\begin{tabular}{|ccccccc|}
\hline $\begin{array}{c}\text { De door u drie maanden geleden } \\
\text { aangegeven (meest) hinderlijke } \\
\text { gedragingen van de bewoner } \\
\mathbf{v}\end{array}$ & $\begin{array}{c}\text { Minder dan } \\
\text { eens } \\
\text { per week }\end{array}$ & $\begin{array}{c}1 \text { á } 2 \text { keer } \\
\text { per week }\end{array}$ & $\begin{array}{c}\text { Meerdere } \\
\text { keren } \\
\text { per week }\end{array}$ & $\begin{array}{c}1 \text { à } 2 \text { keer } \\
\text { per dag }\end{array}$ & $\begin{array}{c}\text { Meerdere } \\
\text { keren } \\
\text { per dag }\end{array}$ & $\begin{array}{c}\text { Meerdere } \\
\text { keren } \\
\text { per uur }\end{array}$ \\
\hline & $\square$ & $\square$ & $\square$ & $\square$ & $\square$ & $\square$ \\
$\square$ & $\square$ & $\square$ & $\square$ & $\square$ & $\square$ \\
\hline
\end{tabular}

Vindt $u$ dat deze (meest) hinderlijke gedragingen van de bewoner zijn verbeterd of verslechterd in de afgelopen 3 maanden ?

Aanwijzingen voor het beantwoorden van deze vraag:

* In het overzicht hieronder staan opnieuw de gedragingen van de bewoner vermeld, waarvan u drie maanden geleden heeft aangegeven het meest hinder te ondervinden.

w Geeft u a.u.b. aan of deze gedragingen van de bewoner zijn verbeterd of verslechterd in de afgelopen drie maanden door één van de antwoordmogelijkheden te aan te kruisen.

\begin{tabular}{|c|c|c|c|c|c|}
\hline $\begin{array}{l}\text { De door u drie maanden geleden } \\
\text { aangegeven (meest) hinderlijke } \\
\text { gedragingen van de bewoner } \\
\nabla\end{array}$ & $\begin{array}{l}\text { Verbeterd } \\
\text { in afgelopen } \\
3 \text { maanden }\end{array}$ & $\begin{array}{c}\text { Beetje } \\
\text { verslechterd } \\
\text { in afgelopen } \\
3 \text { maanden }\end{array}$ & $\begin{array}{l}\text { Zelfde gebleven } \\
\text { in afgelopen } \\
3 \text { maanden }\end{array}$ & $\begin{array}{c}\text { Beetje } \\
\text { verslechterd } \\
\text { in afgelopen } \\
3 \text { maanden }\end{array}$ & $\begin{array}{l}\text { Verslechterd } \\
\text { in afgelopen } \\
3 \text { maanden }\end{array}$ \\
\hline & a & a & a & a & a \\
\hline & $\square$ & $\square$ & a & $\square$ & a \\
\hline & a & a & a & a & a \\
\hline
\end{tabular}




\section{ZELFREDZAAMHEID (ADL)}

Hierna volgen een aantal zogenaamde Algemene Dagelijkse Levensverrichtingen ( $A D L$ ).

\section{Aanwijzingen:}

w. Wilt u per verrichting aangeven of de bewoner dit nog (al dan niet met moeite) zelfstandig kan uitvoeren, deels zelfstandig kan uitvoeren of dit alleen met hulp kan uitvoeren, door het juiste antwoord aan te kruisen.

w Het gaat er nadrukkelijk om, of de bewoner de verrichting nog kan verrichten en niet of hij/zij het ook nog doet.

" Alleen indien u nooit aanwezig bent bij bepaalde verrichtingen, kunt u 'niet te beoordelen' aankruisen.

\begin{tabular}{|c|c|c|c|c|c|}
\hline & & $\begin{array}{l}\text { Zelfstandig } \\
\text { (al dan niet met } \\
\text { moeite) }\end{array}$ & $\begin{array}{c}\text { Deels } \\
\text { zelfstandig }\end{array}$ & $\begin{array}{c}\text { Alleen } \\
\text { met hulp }\end{array}$ & $\begin{array}{c}\text { Niet te } \\
\text { beoordelen }\end{array}$ \\
\hline 1 & Uit bed komen & a & ב & a & a \\
\hline 2 & Gezicht en handen wassen & a & a & a & a \\
\hline 3 & Aankleden & a & ב & a & a \\
\hline 4 & Kousen en schoenen aantrekken & a & ב & a & a \\
\hline 5 & Boterham smeren en snipden & a & ב & 口 & ב \\
\hline 6 & Binnenshuis verplaatsen & a & a & 口 & a \\
\hline 7 & Zichzelf helemaal wassen & a & ב & 口 & a \\
\hline 8 & Elen en drinken & a & a & a & a \\
\hline 9 & In en uit stoel & a & ב & a & a \\
\hline 10 & In bed komen & a & ב & a & a \\
\hline 11 & Naar het toilet gaan overdag & a & ב & a & ] \\
\hline 12 & Naar het toilet gaan 's nachts & a & ב & a & a \\
\hline
\end{tabular}

\section{COMMUNICATIE}

De volgende 7 items hebben betrekking op de communicatie en interactie van de bewoner.

\section{Aanwijzing:}

Er Kruis a.u.b. het juiste antwoord aan.

1 Antwoordt verzorging indien toegesproken

2 Spreekt tegen andere bewoners als ze iets vragen

3 Spreekt uit zichzelf tegen stafleden

4 Spreekt uit zichzelf tegen bewoners

5 Voert regeimatig gesprekken met bewoners

6 Noemt bekende objecten by naam

7 Spreekt in zinnen

\begin{tabular}{|c|c|}
\hline Ja & Nee \\
\hline$a$ & $a$ \\
\hline$a$ & $a$ \\
\hline$a$ & $a$ \\
\hline$a$ & $a$ \\
\hline$a$ & $a$ \\
\hline$a$ & $a$ \\
\hline$a$ & $a$ \\
\hline
\end{tabular}




\section{AGITATIE}

De volgende 29 vragen hebben betrekking op verbaal en non-verbaal agressief gedrag oftewel geagiteerd gedrag van de bewoner.

\section{Aanwijzing:}

* Geef aan hoe vaak het gedrag bij de bewoner voorkwam de laatste twee weken door één van de hokjes achter elke uitspraak aan te kruisen.

\begin{tabular}{|c|c|c|c|c|c|c|c|c|}
\hline & & Nooit & $\begin{array}{l}\text { Minder } \\
\text { dan eens } \\
\text { per week }\end{array}$ & $\begin{array}{c}1 \text { á } 2 \\
\text { keer } \\
\text { per week }\end{array}$ & $\begin{array}{l}\text { Meerdere } \\
\text { keren } \\
\text { per week }\end{array}$ & $\begin{array}{c}1 \text { á } 2 \\
\text { keer } \\
\text { per dag }\end{array}$ & $\begin{array}{l}\text { Meerdere } \\
\text { keren } \\
\text { per dag }\end{array}$ & $\begin{array}{c}\text { Meerdere } \\
\text { keren } \\
\text { per uur }\end{array}$ \\
\hline 1 & IJsberen, doelloos rondlopen (eVt. in rolstoel) & a & a & 口 & ב & 口 & 口 & a \\
\hline 2 & Verkeerd kleden of uitkleden & a & a & a & 口 & $\square$ & a & $\square$ \\
\hline 3 & Spugen (ook tijdens maaltijen) & a & a & a & ב & a & ב & a \\
\hline 4 & Vloeken of agressief woordgebruik & a & a & 口 & a & a & a & $\square$ \\
\hline 5 & Voortdurend, buitensporig vragen om aandacht of hulp & a & ב & 口 & ב & 口 & ב & 口 \\
\hline 6 & Telkens herhaalde zinnen of vragen & a & a & a & a & ם & ב & 口 \\
\hline 7 & Slaan (anderen, zichzelf of voorwerpen) & a & 口 & $\square$ & ב & ב & ב & 口 \\
\hline 8 & Schoppen (anderen of voorwerpen) & a & ב & a & $\square$ & 口 & ב & a \\
\hline 9 & Anderen aanklampen & a & a & a & $\square$ & $\square$ & ב & ם \\
\hline 10 & Duwen (anderen) & a & a & a & $\square$ & 口 & $\square$ & 口 \\
\hline 11 & Gooien met voorwerpen (b.v. eten) & a & a & a & ב & a & ב & ם \\
\hline 12 & Vreemde geluiden (b.v. vreemd lachen huilen, kreunen) & a & a & ם & 口 & a & 口 & 口 \\
\hline 13 & Gillen, knisen, schreeuwen & a & ב & a & a & a & a & a \\
\hline 14 & Bitten (anderen, zichzelf, voorwerpen) & 口 & ב & 口 & a & ם & ב & a \\
\hline 15 & Krabben (anderen, zichzelf, voorwerpen) & a & 口 & 口 & a & 口 & a & $\square$ \\
\hline 16 & Weglopen (b.v. een andere kamer, gebouw) & a & ב & a & a & 口 & ב & ב \\
\hline 17 & Opzettelijk vallen & a & a & a & ב & a & a & 口 \\
\hline 18 & Klagen, jammeren & a & $\square$ & a & a & a & a & a \\
\hline 19 & $\begin{array}{l}\text { Negativisme } \\
\text { (b.v. negatieve houding, werkt niet mee, niets is goed) }\end{array}$ & a & ב & a & ב & a & ב & a \\
\hline 20 & Ongeschikte stoffen eten of drinken & ב & ב & a & a & a & a & a \\
\hline 21 & Zichzelf of anderen bezeren (b.v. sigaret, heet water) & a & a & a & a & a & a & a \\
\hline 22 & $\begin{array}{l}\text { Verkeerd gebruik van voorwerpen } \\
\text { (verplaatsen meubels, spelen met eten) }\end{array}$ & a & a & a & ב & a & a & a \\
\hline 23 & Voorwerpen verstoppen & ם & a & ם & a & a & ב & ב \\
\hline 24 & Voorwerpen verzamelen & 口 & ב & a & a & a & a & a \\
\hline 25 & Voorwerpen verscheuren of eigendommen kapot maken & a & a & a & ב & a & a & a \\
\hline 26 & $\begin{array}{l}\text { Telkens herhalende gedragingen } \\
\text { (b.v. schuiven met voeten, plukken, wriven.) }\end{array}$ & a & a & a & ב & a & ב & ב \\
\hline 27 & Verbale seksuele toenadering zoeken & a & a & a & a & a & ב & a \\
\hline 28 & Lichamelijke seksuele toenadering zoeken & a & ב & a & ב & a & ב & a \\
\hline 29 & Algemene rusteloosheid & a & a & a & ב & a & ב & a \\
\hline
\end{tabular}




\section{DEPRESSIE}

Hierna volgen een aantal symptomen en kenmerken van depressie

\section{Aanwijzingen:}

w. Uw beoordeling dient gebaseerd te zijn op symptomen en kenmerken zoals waargenomen in de voorafgaande week.

w Er dient 'afwezig' gescoord te worden wanneer de symptomen of kenmerken afwezig zijn of wanneer deze het resultaat zijn van lichamelijke beperkingen of ziekte.

- Alleen indien u nooit aanwezig bent bij bepaalde gebeurtenissen (b.v. inslapen) kunt u 'niet te beoordelen' aan kruisen.

\begin{tabular}{|c|c|c|c|c|c|}
\hline & & Afwezig & $\begin{array}{l}\text { Licht of } \\
\text { wisselend } \\
\text { aanwezig }\end{array}$ & Ernstig & $\begin{array}{c}\text { Niet te } \\
\text { beoordelen }\end{array}$ \\
\hline 1 & $\begin{array}{l}\text { Angst } \\
\text { (angstige gezichtsuitdrukking, peinzend, zorgelip) }\end{array}$ & a & a & a & a \\
\hline 2 & $\begin{array}{l}\text { Verdrietig } \\
\text { (verdnetige gezichtsuldrukking/stem, hulerig) }\end{array}$ & a & a & a & a \\
\hline 3 & Reageert niet of plezienge gebeurtenissen & a & a & a & a \\
\hline 4 & $\begin{array}{l}\text { Prikkelbaarheid } \\
\text { (gauw kwaad, slecht gehumeurd) }\end{array}$ & a & ב & a & a \\
\hline 5 & $\begin{array}{l}\text { Agitate } \\
\text { (nusteloos, handenwringen, haarplukken) }\end{array}$ & a & a & a & a \\
\hline 6 & $\begin{array}{l}\text { Vertraging } \\
\text { (trage bewegingen/reacties, langzame spraak) }\end{array}$ & a & a & a & a \\
\hline 7 & $\begin{array}{l}\text { Meervoudige lichamelike klachten } \\
\text { (scoor 'afwezig' indien alleen maag-/darmklachten) }\end{array}$ & a & a & a & a \\
\hline 8 & $\begin{array}{l}\text { Interesseverlies in gebruikelike activiteiten } \\
\text { (scoor alleen indien er een plotselinge verandering is opgetreden } \\
\text { i.e. binnen een periode van } 1 \text { maand) }\end{array}$ & a & ב & a & a \\
\hline 9 & $\begin{array}{l}\text { Vermindering van eetlust } \\
\text { (eet minder dan gewoonlijk) }\end{array}$ & a & ב & a & a \\
\hline 10 & $\begin{array}{l}\text { Gewichtsverlies } \\
\text { (scoor 'ernstig' indien meer dan } 2 \text { kilo in } 1 \text { maand) }\end{array}$ & ב & a & ב & a \\
\hline 11 & $\begin{array}{l}\text { Gebrek aan energie } \\
\text { (gauw moe, niet in staat activiteiten vol te houden) } \\
\text { (scoor alleen indien er een plotselinge verandering is opgetreden } \\
\text { i.e. binnen een periode van } 1 \text { maand) }\end{array}$ & a & ב & a & 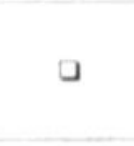 \\
\hline 12 & $\begin{array}{l}\text { Dagelijkse stemmingsschommelingen } \\
\text { ('s morgens meer symptomen) }\end{array}$ & a & a & a & a \\
\hline 13 & $\begin{array}{l}\text { Moeite met inslapen } \\
\text { (later dan gewoonlijk voor deze persoon) }\end{array}$ & a & ב & ב & ב \\
\hline 14 & Wordt 's nachts meerdere maien wakker & a & a & a & a \\
\hline 15 & $\begin{array}{l}\text { Wordt's morgens vroeg wakker } \\
\text { (vroeger dan gewoonlijk voor deze persoon) }\end{array}$ & ב & ב & ב & ב \\
\hline 16 & $\begin{array}{l}\text { Suicide gedachten } \\
\text { (vindt het leven niet de moente waard, heeft doodswensen of doet een poging } \\
\text { tot zelfmoord) }\end{array}$ & a & ב & a & a \\
\hline 17 & $\begin{array}{l}\text { Lage zelfwaardering } \\
\text { (zelfverwiten, minacht zichzelf) }\end{array}$ & a & ב & a & a \\
\hline 18 & $\begin{array}{l}\text { Pessimisme } \\
\text { (verwacht het ergste) }\end{array}$ & ב & ב & ב & ב \\
\hline 19 & $\begin{array}{l}\text { Wanen die overeenstemmen met de stemming } \\
\text { (wanen } \mathrm{m} . \mathrm{bt} \text { armoe. ziekte. verlies) }\end{array}$ & ב & ב & ב & ב \\
\hline
\end{tabular}




\section{BIJZONDERE GEBEURTENISSEN}

Zijn er de afgelopen maand gebeurtenissen voorgevallen, die het functioneren van de bewoner momenteel negatief beïnvloeden ?

\section{Aanwijzingen voor het beantwoorden van deze vraag:}

"Fruis a.u.b. één van de antwoordmogelijkheden aan

w. Indien er bijzondere gebeurtenissen zijn voorgevallen die niet vermeld worden, kunt u deze onderaan noteren en het antwoord aankruisen.

\begin{tabular}{|c|c|c|c|c|}
\hline & & \multirow[t]{2}{*}{$\stackrel{\text { Niet }}{\text { meegemaakt }}$} & \multicolumn{2}{|c|}{$\begin{array}{l}\text { Meegemaakt, en } \\
\text { het beînvloedt de bewoner in zijn/haar } \\
\text { functioneren: }\end{array}$} \\
\hline & & & niet/ soms & $\begin{array}{l}\text { regelmatig / } \\
\text { voortdurend }\end{array}$ \\
\hline 1 & Dood van een familielid & 口 & a & ב \\
\hline 2 & Dood van een vriend / kennis & ב & a & a \\
\hline 3 & Overplaatsing naar een andere woning & a & ב & ב \\
\hline 4 & Scheiding van een belangrijk persoon & ב & ב & ב \\
\hline 5 & Ziekte & a & ב & a \\
\hline 6 & Conflict met medebewoner & a & ב & 曰 \\
\hline 7 & Conflict met familie & 口 & a & a \\
\hline 8 & Sterke afname bezoekfrequentie familie / vrienden & 口 & ב & a \\
\hline 9 & Dagbehandeling verpleeghuis & ב & a & a \\
\hline 10 & Ziekenhuisopname & a & a & 口 \\
\hline 11 & 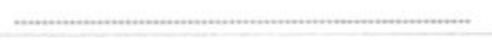 & a & 曰 & $\square$ \\
\hline 12 & 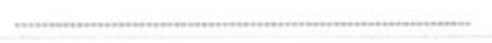 & a & 口 & ב \\
\hline
\end{tabular}

\section{ALGEMEEN OORDEEL OVER HET FUNCTIONEREN}

Wat is uw indruk over het algemene functioneren van de bewoner op dit moment in vergelijking met 3 maanden geleden ?

Aanwijzing voor het beantwoorden van deze vraag:

* Kruis a.u.b. het juiste antwoord aan.

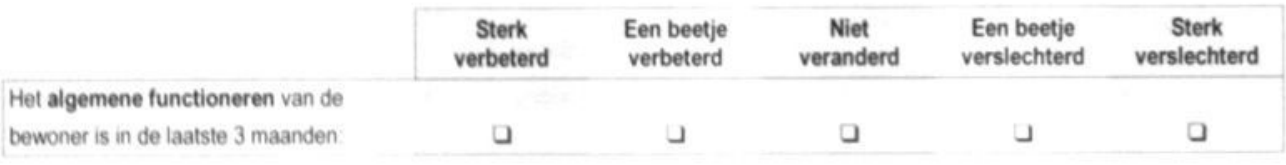




\section{MEDICATIEGEBRUIK}

Welke medicatie (inclusief dosering) gebruikt deze bewoner momenteel ?

\section{Aanwijzingen voor het beantwoorden van deze vraag: \\ w Voor het beantwoorden van deze vraag willen wij u vragen een kopie te maken van de meest recente medicijnkaart van deze bewoner en deze (liefst geniet) toe te voegen aan deze vragenlijst. \\ w Controleert u a.u.b. of naast de medicatie met dosering ook de naam van de bewoner goed leesbaar is op de kopie van de medicijnkaart.}

\section{Tot slot}

* Wilt u a.u.b. controleren of alle vragen zijn beantwoord ?

wr Hartelijk bedankt voor het invullen van deze vragenlijst.

Eventuele vragen of opmerkingen:

Voor vragen of opmerkingen kunt $u$ ook altijd contact opnemen met:

Universiteit Maastricht

Vakgroep Epidemiologie

Veron Schrijnemaekers

(D) 043-3882392

Hilde Sielhorst

(c) $043-3882380$

Bij afwezigheid kunt u ook terecht bij het secretariaat van de vakgroep 043-3882374 
Appendix 2

Vragenlijst verzorgende 
Appendix 2 


\section{Belevingsgerichte zorg in verzorgingshuizen}

\section{Vragenlijst verzorgende (meting na 3 maanden) \\ - verzorgende -}

w Wilt u de volgende gegevens a.u.b. controleren en de invuldatum invullen ?

Naam verzorgingshuis:

Naam invuller:

Invuldatum vragenlijst: . . . $19 \ldots$ 
Een groot aantal vragen over uw werksituatie zijn afkomstig van de Maastrichtse arbeidssatisfactie schaal voor de gezondheidszorg (MAS-GZ) (Landeweerd, Boumans \& Nissen, 1996).

De 22 vragen over de beleving van uw werk zijn afkomstig van de Nederlandse versie (Schaufeli, 1994) van de Maslach Burnout Inventory (MBI) (Maslach \& Jackson, 1986). 
De volgende vragen hebben betrekking op bepaalde aspecten van uw werksituatie.

\section{Aanwijzing:}

w. Geef a.u.b. per vraag aan hoe tevreden u momenteel bent met het betreffende aspect, door één van de hokjes achter elke uitspraak aan te kruisen.

\begin{tabular}{|c|c|c|c|c|c|c|}
\hline & & $\begin{array}{c}\text { Zeer } \\
\text { ontevreden }\end{array}$ & Ontevreden & Neutraal & Tevreden & $\begin{array}{c}\text { Zeer } \\
\text { tevreden }\end{array}$ \\
\hline 1 & $\begin{array}{l}\text { De mate waarin u over het algemeen bid hebt uw } \\
\text { bewoners goed te verzorgen }\end{array}$ & a & a & a & ב & a \\
\hline 2 & $\begin{array}{l}\text { De mate waarin u als verzorgende goede } \\
\text { promobernogelipheden heeft in dit verzorgingshuis }\end{array}$ & a & a & a & a & a \\
\hline 3 & $\begin{array}{l}\text { De mate waarin het werk u het gevoel geeft dat u } \\
\text { werkelipk rets kunt }\end{array}$ & a & a & a & a & a \\
\hline 4 & De mate waarin u uw collega's graag mag & a & a & a & a & a \\
\hline 5 & $\begin{array}{l}\text { De mate waarin u individuele zorgverlening aan uw } \\
\text { bewoners kunt geven }\end{array}$ & a & a & a & a & a \\
\hline 6 & De mate waann u uw bewoners graag mag & a & a & a & a & a \\
\hline 7 & $\begin{array}{l}\text { De mate waarin u uw kundigheden en mogelipheden kunt } \\
\text { gebrukken }\end{array}$ & a & a & a & a & a \\
\hline 8 & $\begin{array}{l}\text { De mate waarin u in uw werk kunt laten merken dat u uw } \\
\text { collega's sympathiek vindt }\end{array}$ & a & a & a & a & a \\
\hline 9 & $\begin{array}{l}\text { De mate waarn het afdelingshoold op de hoogte is van de } \\
\text { gang van zaken van de aldeling }\end{array}$ & a & a & a & a & a \\
\hline 10 & $\begin{array}{l}\text { De mate waarin u het gevoel hebt dat de leiding van de } \\
\text { afdeling goed verloopt }\end{array}$ & ב & a & a & ב & a \\
\hline 11 & $\begin{array}{l}\text { De mate waarin het werk het beste uit u haalt waartoe } u \text { in } \\
\text { staat bent }\end{array}$ & ב & a & 曰 & 曰 & a \\
\hline 12 & $\begin{array}{l}\text { De mate waarin u verteld wordt wat er van u verwacht } \\
\text { wordt }\end{array}$ & ב & a & a & 山 & a \\
\hline 13 & $\begin{array}{l}\text { De mate waarin u het gevoel hebt dat bewoners u een } \\
\text { geschikte 'meid' of 'kerel' vinden }\end{array}$ & ב & ב & a & a & a \\
\hline 14 & $\begin{array}{l}\text { De mate waarin u te maken hebt met collega's die u graag } \\
\text { mogen }\end{array}$ & a & a & 口 & 山 & a \\
\hline 15 & De mate waanin het afdelingshoofd zijn vak goed verstaat & a & a & a & a & a \\
\hline 16 & $\begin{array}{l}\text { De mate waarin u het gevoel hebt psycho-sociale } \\
\text { begeleiding aan uw bewoners te geven }\end{array}$ & a & ב & a & ] & ב \\
\hline 17 & $\begin{array}{l}\text { De mate waarin u te maken hebt met bewoners die u } \\
\text { graag mogen }\end{array}$ & ב & ב & a & a & ב \\
\hline 18 & $\begin{array}{l}\text { De mate waarin u daadwerkelijk contact heeft met } \\
\text { bewoners met cognifieve stoornissen envol } \\
\text { gedragsproblemen }\end{array}$ & ב & ב & a & ב & 口 \\
\hline 19 & $\begin{array}{l}\text { De mate waarin u goede zorg kunt bieden aan bewoners } \\
\text { met cogniteve stoornissen envof gedragsproblemen }\end{array}$ & ב & ב & ב & 山 & 口 \\
\hline 20 & De mate waarin u al met al plezer heeft in uw werk & ב & a & ב & ב & a \\
\hline
\end{tabular}


Hieronder staan 22 uitspraken die betrekking hebben op hoe $u$ uw werk beleeft en hoe u zich daarbij voelt.

\section{Aanwijzing:}

v. Geef aan hoe vaak iedere uitspraak op u van toepassing is. Kruist u hiervoor a.u.b. één van de hokjes aan achter elke uitspraak.

\begin{tabular}{|c|c|c|c|c|c|c|c|c|}
\hline & & Nooit & $\begin{array}{c}\text { Een } \\
\text { paar } \\
\text { keer per } \\
\text { jaar of } \\
\text { minder }\end{array}$ & $\begin{array}{c}\text { Eens } \\
\text { per } \\
\text { maand } \\
\text { of } \\
\text { minder }\end{array}$ & $\begin{array}{c}\text { Een } \\
\text { paar } \\
\text { keer per } \\
\text { maand }\end{array}$ & $\begin{array}{c}\text { Eens } \\
\text { per } \\
\text { week }\end{array}$ & $\begin{array}{c}\text { Een } \\
\text { paar } \\
\text { keer per } \\
\text { week }\end{array}$ & Dagelijks \\
\hline 1 & Ik voel me mentaal uitgeput door mijn werk & 口 & 口 & 口 & 口 & 曰 & 口 & 口 \\
\hline 2 & Aan het einde van een werkdag voel ik me leeg & $\square$ & $\square$ & $\square$ & $\square$ & $\square$ & $\square$ & $\square$ \\
\hline 3 & $\begin{array}{l}\text { Ik voel me vermoeid als ik's morgens opsta en er } \\
\text { weer een werkdag voor me ligt }\end{array}$ & $\square$ & $\square$ & $\square$ & $\square$ & $\square$ & $\square$ & $\square$ \\
\hline 4 & $\begin{array}{l}\text { Ik kan me gemakkelijk inleven in de gevoelens van } \\
\text { de bewoners }\end{array}$ & $\square$ & $\square$ & $\square$ & $\square$ & $\square$ & $\square$ & $\square$ \\
\hline 5 & $\begin{array}{l}\text { Ik heb het gevoel dat ik sommige bewoners te } \\
\text { onpersoonlijk behandel }\end{array}$ & $\square$ & $\square$ & $\square$ & $\square$ & $\square$ & $\square$ & $\square$ \\
\hline 6 & $\begin{array}{l}\text { De hele dag met mensen werken vormt een zware } \\
\text { belasting voor mij }\end{array}$ & $\square$ & $\square$ & $\square$ & $\square$ & $\square$ & $\square$ & $\square$ \\
\hline 7 & $\begin{array}{l}\text { Ik weet de problemen van de bewoners adequaat op } \\
\text { te lossen }\end{array}$ & $\square$ & $\square$ & $\square$ & $\square$ & $\square$ & 口 & $\square$ \\
\hline 8 & Ik voel me "opgebrand" door mijn werk & $\square$ & $\square$ & $\square$ & $\square$ & $\square$ & $\square$ & $\square$ \\
\hline 9 & $\begin{array}{l}\text { Ik heb het gevoel dat ik het leven van andere } \\
\text { mensen op een positieve manier beinvloed door } \\
\text { mijn werk }\end{array}$ & $\square$ & 曰 & $\square$ & $\square$ & 口 & $\square$ & 口 \\
\hline 10 & $\begin{array}{l}\text { Ik heb het idee dat ik onverschilliger ben geworden } \\
\text { tegenover andere mensen sinds ik deze baan heb }\end{array}$ & $\square$ & $\square$ & $\square$ & $\square$ & $\square$ & $\square$ & $\square$ \\
\hline 11 & $\begin{array}{l}\text { Ik maak me zorgen dat mijn werk mij gevoelsmatig } \\
\text { atstompt }\end{array}$ & a & a & $\square$ & $\square$ & $\square$ & a & a \\
\hline 12 & Ik voel me vol energie & $\square$ & 口 & 曰 & a & ב & 曰 & ב \\
\hline 13 & Ik voel me getrustreerd door mijn baan & 曰 & 曰 & 曰 & $\square$ & 曰 & $\square$ & a \\
\hline 14 & Ik denk dat ik me teveel inzet voor mijn werk & $\square$ & 曰 & $\square$ & $\square$ & $\square$ & 曰 & $\square$ \\
\hline 15 & $\begin{array}{l}\text { Het kan me niet echt schelen wat er met sommige } \\
\text { bewoners gebeurt }\end{array}$ & $\square$ & $\square$ & $\square$ & $\square$ & $\square$ & $\square$ & $\square$ \\
\hline 16 & $\begin{array}{l}\text { Het direct werken met mensen roept spanningen bij } \\
\text { me op }\end{array}$ & $\square$ & $\square$ & $\square$ & $\square$ & $\square$ & $\square$ & $\square$ \\
\hline 17 & $\begin{array}{l}\text { Met mijn bewoners kan ik gemakkelijk een } \\
\text { ontspannen steer scheppen }\end{array}$ & 曰 & 曰 & $\square$ & 口 & a & $\square$ & $\square$ \\
\hline 18 & Het werken met bewoners vrolijkt mij op & 曰 & a & 曰 & 曰 & 曰 & 曰 & 曰 \\
\hline 19 & Ik heb in deze baan veel waardevolle dingen bereikt & $\square$ & $\square$ & $\square$ & 曰 & 口 & $\square$ & 口 \\
\hline 20 & Ik voel me aan het eind van mijn latijn & 曰 & $\square$ & $\square$ & $\square$ & a & 曰 & 口 \\
\hline 21 & $\begin{array}{l}\text { In mijn werk ga ik heel rustig om met emotionele } \\
\text { problemen }\end{array}$ & $\square$ & 曰 & $\square$ & a & $\square$ & $\square$ & $\square$ \\
\hline 22 & $\begin{array}{l}\text { Ik heb het gevoel dat bewoners mij hun problemen } \\
\text { verwiten }\end{array}$ & $\square$ & $\square$ & $\square$ & a & 曰 & 曰 & $\square$ \\
\hline
\end{tabular}


Hierna volgen enkele algemene vragen over uw werk(situatie) en eventueel ziekteverzuim.

\section{Aanwijzing:}

s. Kruis bij vraag $1 \mathrm{t} / \mathrm{m} 3$ a.u.b. het juiste hokje aan en vermeld bij vraag 4 en 5 uw antwoord a.u.b. zo duidelijk mogelijk.

\section{Algemeen}

1 Heeft u op dit moment een andere functie in vergelijking met 3 maanden geleden ?

(b. v. activiteitenbegeleider, verpleegkundige, ziekenverzorgende, bejaardenverzorgende, helpende)

a nee a ja, nl.

2 Bent $u$ in de afgelopen 3 maanden op een andere afdeling / unit gaan werken ?

a nee ja, nl.

3 Is er de afgelopen 3 maanden iet veranderd in het aantal uren dat u gemiddeld per week werkt ?

nee a ja, nl.

\section{Ziekteverzuim}

4 Hoe vaak heeft u zich de afgelopen 3 maanden ziek gemeld ?

keer

5 Hoeveel dagen (kalenderdagen van ziekmelding tot herstelmelding)

bent $u$ in de afgelopen 3 maanden in totaal ziek geweest ?

(Indien $u$ dit niet meer precies weet. geeft u dan a u b een zo goed mogelyke schatting)

Verder willen wij u vragen:

Wat is uw algemene indruk over uw werksituatie op dit moment in vergelijking met 3 maanden geleden ?

\section{Aanwijzing:}

- Kruis a u.b. het juiste antwoord aan

\begin{tabular}{|c|c|c|c|c|c|c|c|}
\hline & $\begin{array}{c}\text { Zeér } \\
\text { sterk } \\
\text { verbeterd }\end{array}$ & $\begin{array}{c}\text { Sterk } \\
\text { verbeterd }\end{array}$ & $\begin{array}{c}\text { Een } \\
\text { beetje } \\
\text { verbeterd }\end{array}$ & $\begin{array}{c}\text { Niet } \\
\text { veranderd }\end{array}$ & $\begin{array}{c}\text { Een } \\
\text { beetje } \\
\text { versiechterd }\end{array}$ & $\begin{array}{l}\text { Sterk } \\
\text { orslechterd }\end{array}$ & $\begin{array}{c}\text { Zeer } \\
\text { sterk } \\
\text { gerslechterd }\end{array}$ \\
\hline $\begin{array}{l}\text { Mijn werksituate is in de laatste } 3 \\
\text { maanden: }\end{array}$ & ב & ם & ב & ב & ם & ] & a \\
\hline
\end{tabular}

Indien u vindt dat uw werksituatie veranderd is in de laatste 3 maanden, kunt $u$ dan aangeven waardoor deze verandering volgens u veroorzaakt is ?

\section{Aanwijzing:}

E. Formuleer uw antwoord hieronder zo bondig mogelijk. 
Hierna volgen twee vragen over ingrijpende gebeurtenissen.

Aanwijzing:

« Kruis a.u.b. één van de antwoordmogelijkheden aan en geef indien 'ja' een korte toelichting.

1 Is er de afgelopen 3 maanden iets vervelends gebeurt, dat u heel erg heeft bezig gehouden ? (b.v. overlijden, ziekte, financiele tegenslag, enz.)

๖ee a ja, nl.

2 Heeft u de afgelopen 3 maanden iet leuks meegemaakt, dat $u$ heel erg heeft bezig gehouden ? (b.v. trouwen, geboorte, financiele meevaller, enz.)

๖ee a ja, nl.

Tot slot

w Wilt u a.u.b. controleren of alle vragen zijn beantwoord ?

w Hartelijk bedankt voor het invullen van deze vragenlijst.

Eventuele vragen of opmerkingen:

Voor vragen of opmerkingen kunt $u$ ook altijd contact opnemen met:

Universiteit Maastricht

Vakgroep Epidemiologie

Veron Schrijnemaekers

Hilde Sielhorst

(D) $\quad 043-3882392$

(b) $\quad 043-3882380$

Bij afwezigheid kunt u ook terecht bij het secretariaat van de vakgroep $\varnothing$ 043-3882374 


\section{DANKWOORD}

Veel mensen hebben op verschillende wijze een bijdrage geleverd aan dit proefschrift.

Samen met Carla Frederiks en Margreet te Wierik zijn de eerste plannen geschreven voor een studie naar de effectiviteit van validation. In 1996 is de financiering rond gekomen, waarbij inmiddels belevingsgerichte zorg centraal stond. Het Landelijk Centrum voor Verpleging en Verzorging (LCWV) was bereid het vooronderzoek en het leeuwendeel van het hoofdonderzoek te financieren. Aanvullende financiering hebben we ontvangen van de Provincie Limburg, het VSB-fonds en het toenmalige Praeventie Fonds.

Door het vertrek van Margreet naar Kenya heeft Erik van Rossum al spoedig het roer als projectleider overgenomen.

Al snel werd er een projectgroep samengesteld. Alle mensen in deze projectgroep hebben bijzondere deskundigheden, waar ik dankbaar gebruik van heb kunnen maken.

Eenieder die Erik kent, weet dat je je als onderzoeker bijna geen betere projectleider c.q copromotor kunt wensen. Erik heeft mij met een enorme dosis deskundigheid, enthousiasme, stimulans, inzet, geduld, loyaliteit, relativeringsvermogen, betrokkenheid, tact, humor, vriendelijkheid, ...... (en zo kan ik nog wel even doorgaan) begeleid. Erik, ik heb heel veel van je geleerd. Onze samenwerking zal ik missen. Heel veel dank voor alles.

Carla, tevens promotor, heeft grote kennis van en ervaring met onderzoek op het terrein van de verpleging en verzorging. Haar bijdragen zijn altijd zeer constructief. Carla, ik ben heel blij dat je deze klus in je vrije tijd hebt willen afmaken.

Piet van den Brandt, eveneens promotor, heeft op een deskundige en betrokken wijze een vinger aan de pols gehouden. Ik vond het opvallend hoe snel hij zich als relatieve 'outsider' kon verplaatsen in het onderwerp. Piet, ik heb je waardevolle commentaar bij de concept teksten erg op prijsgesteld.

Hilde Sielhorst heeft als ervaren onderzoeksassistent een grote bijdrage geleverd aan dit onderzoek. Met name ten tijde van het veldonderzoek fungeerde zij als rots in de branding en heeft zij veel werk voor haar rekening genomen.

Hoewel Fons Kessels de projectgroep helaas voortijdig heeft moeten verlaten, heb ik in de opstartfase van het onderzoek dankbaar gebruik gemaakt van zijn scherp inzicht en advies.

Mayke Derix heeft haar specifieke ervaring en deskundigheid met onderzoek en zorgverlening in de psycho-geriatrie ingebracht in het project.

Math Candel, heeft mij bijgestaan bij de uitvoering en interpretatie van de multilevel analyses. Zonder zijn hulp was mij dit nooit gelukt.

Ook was er een begeleidingscommissie. Deze commissie had, onder voorzitterschap van Ada Kerkstra, als belangrijkste taak de kwaliteit van de uitvoering van het project te bewaken. Alle leden van de commissie hebben dit vanuit verschillende invalshoeken met deskundigheid en enthousiasme gedaan.

In de zomer van 1997 is gestart met de werving van verzorgingshuizen. Zij vormden de spil van het onderzoek. Ik wil dan ook heel graag de bewoners, hun contactpersonen alsmede de personeelsleden van de zestien deelnemende verzorgingshuizen' bedanken voor hun

\footnotetext{
1. Bocholtz. De Baenje. De Bron, Douvenrade. Dr Ackenshuis. Hoog Anstel, Lenculenhot. Malberg. Oosterbeemd. Providenta. RCG
} Roncall. St Joseph. Ter Eyck. Van Berlo Heem, Vroenhof 
deelname. Zonder hun medewerking ben je als onderzoeker nergens. Met name het invullen van de vele vragenlijsten heeft een schat aan informatie opgeleverd.

Hilde Ham van CEREIN heeft op professionele wijze de organisatie en uitvoering van de interventie voor haar rekening genomen.

Het onderzoek is uitgevoerd vanuit de capaciteitsgroep Epidemiologie. De vele (ex-)collega's van 'Epi' dank ik voor de prettige samenwerking en goede werksfeer. In het bijzonder noem ik mijn ex-kamergenoten, Marian Maaskant, Ingeborg Poorterman, Patty Nelemans en Mariëlle Kroese. Samen hebben we veel lief en leed gedeeld in de afgelopen jaren. Een aantal collega's zijn actief betrokken geweest bij het onderzoek en het daarop gebaseerde proefschrift. Jos Slangen heeft ons vaak op efficiënte wijze bijgestaan bij de dataverwerking en computerperikelen. Marijke Moll heeft geholpen bij het screenen van bewoners. Cobie Martens heeft de lay-out van dit proefschrift professioneel verzorgd.

Guus van Rooy heeft op de valreep het ontwerp van de kaft vormgegeven. Bob Wilkinson van Worldneth Talencentum heeft de hoofdstukken van dit proefschrift nauwkeurig en snel gecorrigeerd.

Voor de uitvoering van het kwalitatieve onderzoek is nauw samengewerkt met Guy Widdershoven en Michèle van Heusden van de capaciteitsgroep Zorgwetenschappen, sectie Gezondheidsethiek en Wijsbegeerte. Michèle heeft alle gegevens verzameld en verwerkt.

Tijdens de afronding van dit proefschrift was ik inmiddels werkzaam bij het Centrum Ontwikkeling Palliatieve Zorg Maastricht (COPZ-M) van het azM. Ook mijn collega's aldaar dank ik voor hun belangstelling.

Erg blij ben ik met mijn paranimfen, Annemie Courtens en Patty Nelemans. Ik vind het fijn dat ik van jullie steun en ervaring gebruik mag maken en dat jullie me op de $31^{\circ}$ mei terzijde willen staan.

Familie en vrienden hebben mij met warme belangstelling gesteund. Vooral Peer, Meer en Carol wil ik met name noemen. Zonder jullie vertrouwen en aanhoudende aandacht was het er wellicht nooit van gekomen. 'Meer en Peer, geer staot altied veur us klaor. Daoveur hiel văöl daank'.

Tot slot, het allerbelangrijkste: het thuisfront. Huub, je bent voor mij een nimmer aflatende steun. Donna en Rick zijn onze liefste 'sjatte' en 'boeve' die gelukkig veel van onze tijd vragen. Huub, Donna en Rick, ik ben ontzettend blij met jullie. 


\section{CURRICULUM VITAE}

Veron Schrijnemaekers was born in 1964 in Maastricht. After completing secondary school (VWO) in 1982, she studied Health Sciences at Maastricht University with a specialization in Nursing Science.

From September 1986 to November 1988 she worked as an assistant researcher at the Netherlands Institute of Primary Health Care (NIVEL) in Utrecht. From August 1988 till March 2001 she was a researcher at Maastricht University (departments of Epidemiology, General Practice, and Nursing Science). In these twelve years she mainly worked on various studies in geriatric care. She conducted, among others, a RCT on the effectiveness of an outpatient geriatric assessment unit with three years follow-up, performed analyses for various studies at the department of General Practitioners, carried out a study for a National Health Service Insurer (LIASS) and developed and tested a standardized instrument to assess the quality of care given by (practical) nurses in homes for the elderly. From 1996 she worked on the study into the effects of emotion-oriented care, as reported in this thesis. Since January 2000 she works at the University Hospital Maastricht as a researcher for the Center for the Development of Palliative Care. 


\section{Effects of Emotion-oriented}

\section{Care in Homes for the Elderly}

Many elderly persons with dementia display behavioral disturbances which critically impact the patient and caregiver. As little is known about the etiology and treatment of dementia, treatment often addresses symptom management. 'Validation' is a popular but not yet evidence based psycho-social approach in dementia care. In the Netherlands, validation is more and more used in combination with other approaches such as sensory stimulation and reminiscence. This combined approach is called emotion-oriented care (EOC). This thesis reports on a study (randomized controlled trial) on the effects of EOC on elderly people with cognitive impairment and behavioral problems, and their professional caregivers, in sixteen homes for the elderly. Eight intervention homes received a training program in EOC, eight control homes continued usual care. The change in behavior of the residents and job satisfaction of the caregivers were the primary endpoints of the study. Effects were measured after three, six and twelve months of follow-up. This thesis describes the results for the elderly residents and their professional caregivers. Also, the results of an additional qualitative study on the compliance with the introduction of the new care model are described.

At the end, some methodological reflections are presented and recommendations for future research and practice are given.

Veron J.J. Schrijnemaekers 